Supporting Information

\title{
Indoline Catalyzed Acylhydrazone/Oxime Condensation Under Neutral Aqueous Conditions
}

Yuntao Zhou, ${ }^{\mathrm{a}}$ Irene Piergentili, ${ }^{\mathrm{b}}$ Jennifer Hong, ${ }^{\mathrm{b}}$ Michelle P. van der Helm, ${ }^{\mathrm{b}}$ Mariano

Macchione, ${ }^{\mathrm{b}}$ Yao Li, ${ }^{\text {a }}$ Rienk Eelkema, ${ }^{*}$ b Sanzhong Luo,a

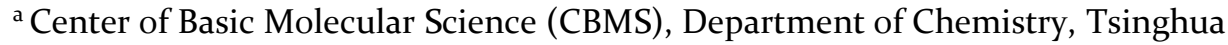

University, Beijing 100084, China

b Department of Chemical Engineering, Delft University of Technology, van der Maasweg 9, 2629HZ Delft, the Netherlands
\end{abstract}

\section{Table of Contents}

1. General information ...........................................................................2

2. Kinetic Experiments ...........................................................................2

3. Data analysis..................................................................................................2

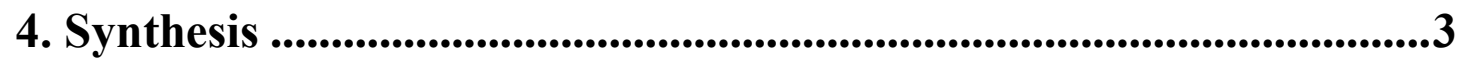

5. Absorbance spectra for determination of reaction rates ....................8

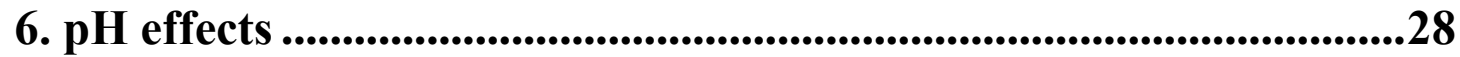

7. Turbidity measurements of catalytic trishydrazone hydrogelator

formation and appearance. ......................................................................................28

8. Rheology of trishydrazone hydrogelator formation..........................29

9. Inverted tube tests of catalytic hydrogelator formation ...................30

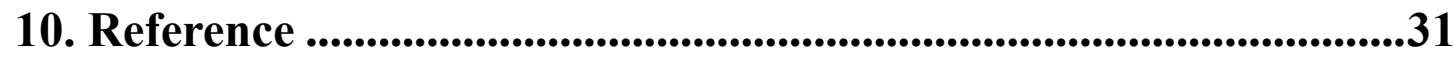

11. ${ }^{1} \mathrm{H}-\mathrm{NMR}$ and ${ }^{13} \mathrm{C}$-NMR spectra for synthesized compounds.........33 


\section{General information}

All Commercial reagents were used without further purification unless otherwise specified. ${ }^{1} \mathrm{H}$ NMR and ${ }^{13} \mathrm{C}$ NMR spectra were recorded on a Bruker NMR instrument or an Agilent-400 MR DD2 (400 MHz and $100.5 \mathrm{MHz}$ for ${ }^{1} \mathrm{H}$ and ${ }^{13} \mathrm{C}$, respectively) at $298 \mathrm{~K}$. Chemical shifts are reported in ppm relative to the residual solvent peaks, the multiplicity is reported as follows: $\mathrm{s}=$ singlet, $\mathrm{d}=$ doublet, $\mathrm{t}=$ triplet, $\mathrm{q}=$ quartet, $\mathrm{m}=$ multiplet, and $\mathrm{J}$-couplings $(J)$ are reported in Hertz (Hz). HPLC - MS analysis was performed on a Shimadzu Liquid Chromatography Mass Spectrometer LCMS-2010, LC-8A pump with a diode array detector SPD-M20. Reactions were monitored by analytical thin-layer chromatography (TLC) on silica gel plates (Merck 60F 254 ) using UV light $(254 \mathrm{~nm})$ as the visualizing agent. Flash chromatography was performed on 230-400 mesh silica gel (Sigma Aldrich). High-resolution mass spectral data was performed on the Thermo Scientific Q Exactive hybrid quadrupole-Orbitrap mass spectrometer.

All UV/Vis experiments were performed on PerkinElmer LAMBDA 950. Buffers were prepared with ultrapure water. For kinetic experiments, phosphate buffered saline (PBS) with DMF (DMF : $\mathrm{H}_{2} \mathrm{O}=1: 10$ ) contained $123 \mathrm{mM} \mathrm{NaCl}, 2.4 \mathrm{mM} \mathrm{KCl}$ and $10.7 \mathrm{mM}$ sodium and potassium phosphates ( $\mathrm{pH}$ from 7.40 to 4.50 ) was freshly prepared daily. For the turbidity experiment, 100 $\mathrm{mM}$ sodium phosphate buffer was prepared by mixing $61.0 \mathrm{~mL} 0.2 \mathrm{~mol} / \mathrm{L} \mathrm{Na}_{2} \mathrm{HPO}_{4}$ and $39.0 \mathrm{~mL}$ $0.3 \mathrm{~mol} / \mathrm{L} \mathrm{NaH}{ }_{2} \mathrm{PO}_{4}$, the solution was diluted to $200 \mathrm{~mL}$ after adjust $\mathrm{pH}=7.0$.

\section{Kinetic Experiments}

The kinetic experiments were performed according to reported literature. ${ }^{1}$

To a quartz cuvettes $(1 \mathrm{~cm}$ path length) containing $2970 \mu \mathrm{L}$ PBS solution $(\mathrm{pH}=7.4$, DMF : $\mathrm{H}_{2} \mathrm{O}=1: 10$ ) was added $15 \mu \mathrm{L}$ aldehyde solution ( $200 \mathrm{mM}$ in DMF) and $15 \mu \mathrm{L}$ catalyst ( $200 \mathrm{mM}$ in DMF), resulting in a 1:9 DMF: $\mathrm{H}_{2} \mathrm{O}$ solution. The solution was mixed by rapid pipetting up and down 10 times. A background spectrum was measured and subtracted. The reaction was then started by adding $7.5 \mu \mathrm{L}$ acylhydrazine stock solution ( $8.0 \mathrm{mM}$ in PBS solution) and mixed by rapid pipetting up and down 10 times. The cuvettes were capped and spectra were measured from $250 \mathrm{~nm}$ to $450 \mathrm{~nm}$ repeatedly at specific time intervals. For $\mathrm{pH}$ effect, similar procedures were performed except for solution $\mathrm{pH}$ values.

\section{Data analysis}

The kinetic data analysis were performed according to reported literature. ${ }^{2}$

The absorption data at maximum absorption wavelength were selected and analyzed by linear least-squares fits using the Guggenheim (time lag) method. In this method, the data obtained at regular intervals $\tau$ are divided into halves, and early absorbance data are subtracted from the second-half data as shown in the following equation:

$$
\ln \left(A_{t+\tau}-\mathrm{A}_{\mathrm{t}}\right)=\ln \left[\left(A_{\infty}-\mathrm{A}_{0}\right)\left(1-e^{-k \tau}\right)\right]-k \mathrm{t}
$$

A linear plot of $\ln \left(A_{t+\tau}-\mathrm{A}_{\mathrm{t}}\right)$ versus $t$ is made and the pseudo-first-order rate constant $k$ was obtained from the slope. 


\section{Synthesis}

4.1 General synthetic procedure for indoline derivatives. ${ }^{3}$

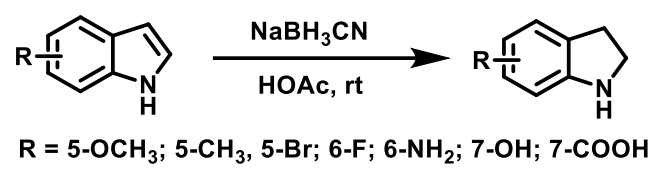

To a stirred solution of substituted indole $(1.0 \mathrm{mmol})$ in acetic acid $(20 \mathrm{~mL})$ was cooled to $0^{\circ} \mathrm{C}$, then $\mathrm{NaBH}_{3} \mathrm{CN}$ (126 mg-252 mg, 2.0-4.0 equiv.) was added in portions within 0.5 hours. After the mixture was stirred at room temperature about 4 hours, the solution was neutralized with saturated $\mathrm{NaHCO}_{3}$ solution and extracted with EtOAc $(3 \times 15 \mathrm{~mL})$. The organic layer was washed with brine $(3 \times 15 \mathrm{~mL})$ and dried over $\mathrm{Na}_{2} \mathrm{SO}_{4}$. The solvent was removed in vacuo and the crude was then purified by column chromatography in petroleum ether / ethyl acetate (PE/EA) to afford the pure product.

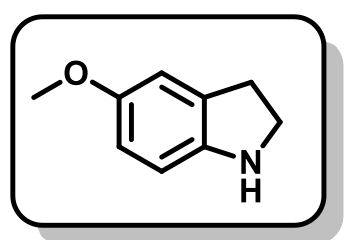

5-methoxylindoline, purification by column chromatography on silica gel (PE/EA = 4:1, $142.0 \mathrm{mg}, 95 \%$ yield), colourless oil. ${ }^{1} \mathbf{H}$ NMR (300 $\left.\mathrm{MHz}, \mathrm{CDCl}_{3}\right) \delta 6.76(\mathrm{~s}, 1 \mathrm{H}), 6.59(\mathrm{~s}, 2 \mathrm{H}), 3.75(\mathrm{~s}, 3 \mathrm{H}), 3.56-3.31(\mathrm{br}$, $1 \mathrm{H}), 3.54(\mathrm{t}, \mathrm{J}=8.2 \mathrm{~Hz}, 2 \mathrm{H}), 3.01(\mathrm{t}, \mathrm{J}=8.3 \mathrm{~Hz}, 2 \mathrm{H}) .{ }^{13} \mathbf{C}$ NMR $(101$ $\left.\mathrm{MHz}, \mathrm{CDCl}_{3}\right) \delta 153.7,145.3,131.3,112.2,111.7,110.3,56.1,47.9$, 30.6. HRMS (ESI) $\mathrm{m} / z$ : $[\mathrm{M}+\mathrm{H}]^{+}$Calcd. for $\mathrm{C}_{9} \mathrm{H}_{12} \mathrm{NO} 150.0913$; Found 150.0907 .

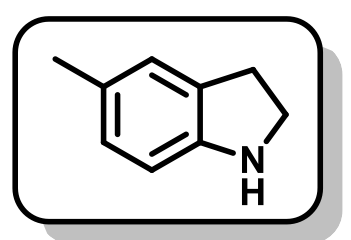

5-methylindoline, purification by column chromatography on silica gel $(\mathrm{PE} / \mathrm{EA}=4: 1,126.3 \mathrm{mg}, 95 \%$ yield $)$, colourless oil. ${ }^{\mathbf{1}} \mathbf{H}$ NMR $(300$ $\left.\mathrm{MHz}, \mathrm{CDCl}_{3}\right) \delta 6.96(\mathrm{~s}, 1 \mathrm{H}), 6.83(\mathrm{~d}, \mathrm{~J}=7.8 \mathrm{~Hz}, 1 \mathrm{H}), 6.57(\mathrm{~d}, \mathrm{~J}=7.8$ $\mathrm{Hz}, 1 \mathrm{H}), 3.89-3.40$ (br, 1H), 3.53 (t, J = $8.3 \mathrm{~Hz}, 2 \mathrm{H}), 3.00$ (t, J = $8.3 \mathrm{~Hz}$, 2H), $2.26(\mathrm{~s}, 3 \mathrm{H}) .{ }^{13} \mathrm{C}$ NMR $\left(101 \mathrm{MHz}, \mathrm{CDCl}_{3}\right) \delta 149.3,129.8,128.2$, 127.6, 125.5, 109.5, 47.7, 30.1, 20.9. HRMS (ESI) $m / z$ : $[\mathrm{M}+\mathrm{H}]^{+}$Calcd. for $\mathrm{C}_{9} \mathrm{H}_{12} \mathrm{~N}$ 134.0964; Found 134.0962 .

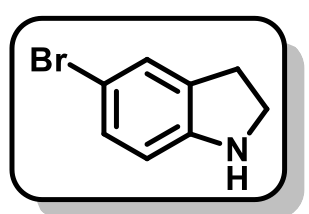

5-bromoindoline, purification by column chromatography on silica gel $(\mathrm{PE} / \mathrm{EA}=4: 1,177.2 \mathrm{mg}, 90 \%$ yield $)$, pale yellow oil. ${ }^{1} \mathbf{H} \mathbf{~ N M R}(500 \mathrm{MHz}$, $\left.\mathrm{CDCl}_{3}\right) \delta 7.20(\mathrm{~s}, 1 \mathrm{H}), 7.09(\mathrm{~d}, \mathrm{~J}=8.2 \mathrm{~Hz}, 1 \mathrm{H}), 6.50(\mathrm{~d}, \mathrm{~J}=10.0 \mathrm{~Hz}, 1 \mathrm{H})$, 3.76 (br, 1H), 3.56 (t, J = 7.5 Hz, 2H), 3.02 (t, J = 8.4 Hz, 2H). ${ }^{13} \mathbf{C}$ NMR $\left(126 \mathrm{MHz}, \mathrm{CDCl}_{3}\right) \delta 150.8,131.9,129.9,127.7,110.6,110.2,47.7,29.8$. HRMS (ESI) $m / z$ : $[\mathrm{M}+\mathrm{H}]^{+}$Calcd. for $\mathrm{C}_{8} \mathrm{H}_{9} \mathrm{BrN}$ 197.9913; Found 197.9909.

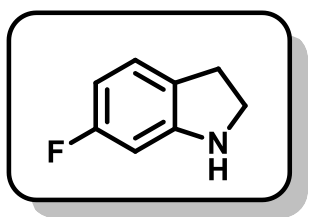

6-fluoroindoline, purification by column chromatography on silica gel (PE/EA = 4:1, $109.6 \mathrm{mg}, 80 \%$ yield), colourless oil. ${ }^{1} \mathbf{H}$ NMR $(400 \mathrm{MHz}$, $\left.\mathrm{CDCl}_{3}\right) \delta 7.01-6.95(\mathrm{~m}, 1 \mathrm{H}), 6.34(\mathrm{~m}, 2 \mathrm{H}), 3.93-3.50(\mathrm{br}, 1 \mathrm{H}), 3.59(\mathrm{t}, \mathrm{J}=$ $8.4 \mathrm{~Hz}, 2 \mathrm{H}), 2.97$ (t, J = 8.3 Hz, 2H). $\left.{ }^{13} \mathbf{C ~ N M R ~ ( 1 0 1 ~ M H z , ~} \mathrm{CDCl}_{3}\right) \delta$ $163.2(\mathrm{~d}, J=240.6 \mathrm{~Hz}), 153.2(\mathrm{~d}, J=11.8 \mathrm{~Hz}), 124.9$ (d, $J=10.4 \mathrm{~Hz})$, 124.6 (d, $J=2.2 \mathrm{~Hz}), 104.5$ (d, $J=22.6 \mathrm{~Hz}), 97.1$ (d, $J=26.2 \mathrm{~Hz}), 48.2,29.0$. HRMS (ESI) $\mathrm{m} / z$ : $[\mathrm{M}+\mathrm{H}]^{+}$Calcd. for $\mathrm{C}_{8} \mathrm{H}_{9} \mathrm{FN}$ 138.0714; Found 138.0710. 


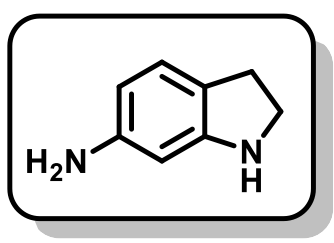

Indolin-6-amine, purification by column chromatography on silica gel ( $\mathrm{PE} / \mathrm{EA}=3: 1,53.6 \mathrm{mg}, 40 \%$ yield), red brown oil. ${ }^{1} \mathbf{H}$ NMR $(300 \mathrm{MHz}$, $\left.\mathrm{CDCl}_{3}\right) \delta 6.88(\mathrm{~d}, \mathrm{~J}=8.1 \mathrm{~Hz}, 1 \mathrm{H}), 6.08-6.05(\mathrm{~m}, 2 \mathrm{H}), 3.72-3.25(\mathrm{br}, 3 \mathrm{H})$, $3.52(\mathrm{t}, \mathrm{J}=8.2 \mathrm{~Hz}, 2 \mathrm{H}), 2.92(\mathrm{t}, \mathrm{J}=8.2 \mathrm{~Hz}, 2 \mathrm{H}) .{ }^{13} \mathbf{C} \mathbf{~ N M R}(101 \mathrm{MHz}$, $\left.\mathrm{CDCl}_{3}\right) \delta 152.9,146.3,125.1,119.8,105.7,97.5,47.9,29.2$. HRMS (ESI) $m / z:[\mathrm{M}+\mathrm{H}]^{+}$Calcd. for $\mathrm{C}_{8} \mathrm{H}_{11} \mathrm{~N}_{2}$ 135.0917; Found 135.0912.

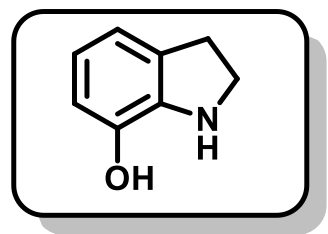

Indolin-7-ol, purification by column chromatography on silica gel ( $\mathrm{PE} / \mathrm{EA}=3: 1,41.8 \mathrm{mg}, 31 \%$ yield), brown solid. ${ }^{1} \mathrm{H}$ NMR $(400 \mathrm{MHz}$, DMSO- $\left.d_{6}\right) \delta 8.68(\mathrm{~s}, 1 \mathrm{H}), 6.55(\mathrm{~d}, J=7.1 \mathrm{~Hz}, 1 \mathrm{H}), 6.46(\mathrm{~d}, J=7.3 \mathrm{~Hz}$, $1 \mathrm{H}), 6.40$ (t, 1H), $4.72(\mathrm{~s}, 1 \mathrm{H}), 3.36$ (t, $J=8.5,2 \mathrm{H}), 2.87$ (t, $J=8.5 \mathrm{~Hz}$, $2 \mathrm{H}) .{ }^{13} \mathrm{C}$ NMR (101 MHz, DMSO- $\left.d_{6}\right) \delta 142.5,140.4,130.5,118.4,116.0$, 114.1, 47.3, 30.5. HRMS (ESI) $m / z$ : $[\mathrm{M}+\mathrm{H}]^{+}$Calcd. for $\mathrm{C}_{8} \mathrm{H}_{10} \mathrm{NO}$ 136.0757; Found 136.0754 .

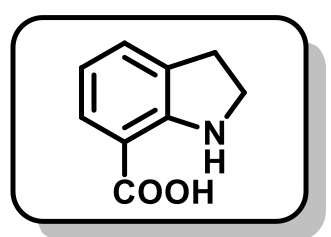

Indoline-7-carboxylic acid, purification by column chromatography on silica gel $(\mathrm{EA} / \mathrm{MeOH}=100: 1,32.6 \mathrm{mg}, 20 \%$ yield), yellow brown solid. ${ }^{1}$ H NMR (400 MHz, DMSO- $\left.d_{6}\right) \delta 7.39(\mathrm{~d}, J=7.9 \mathrm{~Hz}, 1 \mathrm{H}), 7.14(\mathrm{~d}, J=$ $6.9 \mathrm{~Hz}, 1 \mathrm{H}), 6.46(\mathrm{t}, 1 \mathrm{H}), 3.57$ (t, $J=8.6 \mathrm{~Hz}, 2 \mathrm{H}), 2.95$ (t, $J=8.6 \mathrm{~Hz}$, 2H). ${ }^{13} \mathbf{C}$ NMR (101 MHz, DMSO- $\left.d_{6}\right) \delta 168.9,154.6,131.4,128.5$, 128.3, 115.6, 108.2, 46.8, 28.3. HRMS (ESI) $\mathrm{m} / \mathrm{z}$ : $[\mathrm{M}+\mathrm{H}]^{+}$Calcd. for $\mathrm{C}_{9} \mathrm{H}_{10} \mathrm{NO}_{2}$ 164.0706, Found 164.0704 .

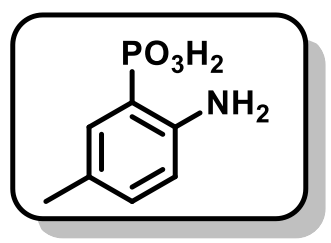

5-methyl-2-aminobenzene phosphonic acid was prepared according reported literature. ${ }^{4}$ Light yellow amorphous solid. ${ }^{1} \mathbf{H}$ NMR $(400 \mathrm{MHz}$, DMSO- $\left.d_{6}\right) \delta 7.14(\mathrm{~d}, J=14.5 \mathrm{~Hz}, 1 \mathrm{H}), 6.97(\mathrm{~d}, J=8.3 \mathrm{~Hz}, 1 \mathrm{H}), 6.56(\mathrm{t}$, 1H), 4.53 (br, 4H)2.13 (s, 3H). ${ }^{13} \mathrm{C}$ NMR (101 MHz, DMSO- $\left.d_{6}\right) \delta 148.5$ $(\mathrm{d}, J=7.9 \mathrm{~Hz}), 133.3(\mathrm{~d}, J=2.3 \mathrm{~Hz}), 132.8(\mathrm{~d}, J=7.7 \mathrm{~Hz}), 123.8$ (d, $J=$ $13.5 \mathrm{~Hz}), 116.1(\mathrm{~d}, J=12.6 \mathrm{~Hz}), 114.0(\mathrm{~d}, J=177.5 \mathrm{~Hz}), 20.4 .{ }^{31} \mathbf{P}$ NMR $\left(162 \mathrm{MHz}, \mathrm{DMSO}-d_{6}\right) \delta$ 15.30. HRMS (ESI) $m / z$ : $[\mathrm{M}+\mathrm{H}]^{+}$Calcd. for $\mathrm{C}_{7} \mathrm{H}_{11} \mathrm{NO}_{3} \mathrm{P}$ 188.0471; Found: 188.0472 .

\subsection{Synthesis of (4-nitrobenzylidene)benzohydrazide 1}

The acylhydrazone product (4-nitrobenzylidene)benzohydrazide $\mathbf{1}$ was prepared according to reported procedure. ${ }^{5}$<smiles>NNC(=O)c1cccc(Oc2ccc(NNC(=O)c3ccccc3)cc2)c1</smiles>

To a stirred solution of 4-nitrobenzaldehyde (151 mg, 1.0mmol) and benzoylhydrazine (137 mg, $1.0 \mathrm{mmol})$ in $10 \mathrm{~mL}$ EtOH was added $5 \% \mathrm{TFA}(4 \mu \mathrm{L})$. The mixture was heated to reflux overnight in oil bath. After cooling to room temperature, the resulting precipitate was filtered, washed with cooled ethanol $(3 \times 8 \mathrm{~mL})$ and dried to give light-yellow solid products $(223 \mathrm{mg}, 83 \%$ yield).

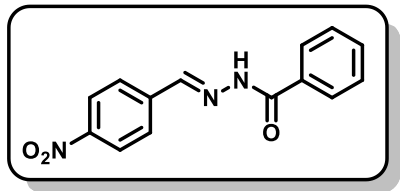

${ }^{1}$ H NMR (400 MHz, DMSO- $\left.d_{6}\right) \delta 12.16(\mathrm{~s}, 1 \mathrm{H}), 8.56(\mathrm{~s}, 1 \mathrm{H}), 8.31$ (d, $J=8.4 \mathrm{~Hz}, 2 \mathrm{H}), 8.00(\mathrm{~d}, J=8.2 \mathrm{~Hz}, 2 \mathrm{H}), 7.94(\mathrm{~d}, J=7.2 \mathrm{~Hz}$, 2H), $7.62(\mathrm{t}, J=7.1 \mathrm{~Hz}, 1 \mathrm{H}), 7.55(\mathrm{~m}, 2 \mathrm{H}) .{ }^{13} \mathbf{C}$ NMR $(101 \mathrm{MHz}$, 
DMSO- $\left.d_{6}\right) \delta 163.4,147.8,145.3,140.6,133.1,132.1,128.5,128.0,127.7,124.1$. HRMS (ESI) $m / z:[\mathrm{M}+\mathrm{H}]^{+}$Calcd. for $\mathrm{C}_{14} \mathrm{H}_{12} \mathrm{~N}_{3} \mathrm{O}_{3} 270.0873$; Found 270.0867 .

\subsection{Synthesis of trishydrazide $H$ and aldehyde $A$}

Trishydrazide $\mathbf{H}$ and aldehyde $\mathbf{A}$ were prepared according to reported literature. ${ }^{6}$
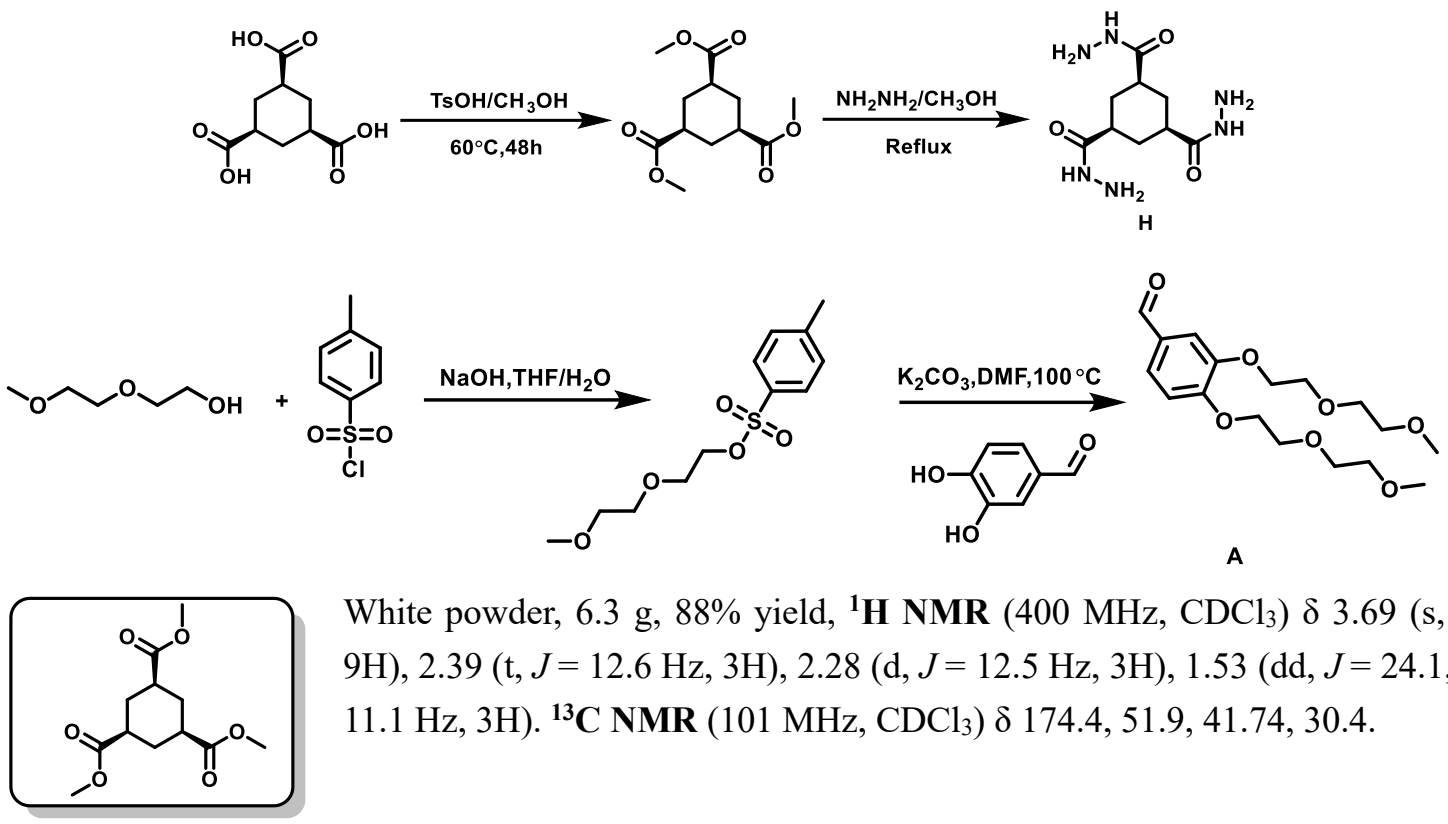

White powder, $6.3 \mathrm{~g}, 88 \%$ yield, ${ }^{1} \mathbf{H}$ NMR $\left(400 \mathrm{MHz}, \mathrm{CDCl}_{3}\right) \delta 3.69(\mathrm{~s}$, 9H), 2.39 (t, $J=12.6 \mathrm{~Hz}, 3 \mathrm{H}), 2.28$ (d, $J=12.5 \mathrm{~Hz}, 3 \mathrm{H}), 1.53$ (dd, $J=24.1$, $11.1 \mathrm{~Hz}, 3 \mathrm{H}) .{ }^{13} \mathbf{C}$ NMR $\left(101 \mathrm{MHz}, \mathrm{CDCl}_{3}\right) \delta 174.4,51.9,41.74,30.4$.

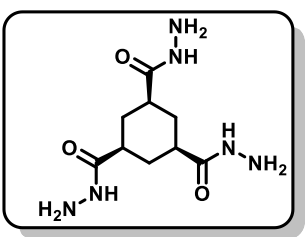

White powder, $6.3 \mathrm{~g}, 99 \%$ yield. ${ }^{1} \mathbf{H}$ NMR (400 MHz, DMSO- $\left.d_{6}\right) \delta 8.96(\mathrm{~s}$ $3 \mathrm{H}), 4.16(\mathrm{~s}, 6 \mathrm{H}), 2.15-2.09(\mathrm{~m}, 3 \mathrm{H}), 1.60-1.57(\mathrm{~m}, 3 \mathrm{H}), 1.52-1.43(\mathrm{~m}$, $3 \mathrm{H}) .{ }^{13} \mathrm{C}$ NMR (101 MHz, DMSO- $\left.d_{6}\right) \delta 173.5,40.7,31.3$. HRMS (ESI) $m / z$ : $[\mathrm{M}+\mathrm{Na}]^{+}$Calcd. for $\mathrm{C}_{9} \mathrm{H}_{18} \mathrm{~N}_{6} \mathrm{O}_{3} \mathrm{Na} 281.1338$; Found 281.1326.

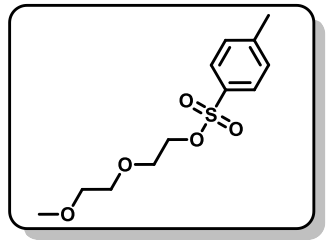

Colourless oil, $17.1 \mathrm{~g}, 88 \%$ yield. ${ }^{1} \mathbf{H}$ NMR $\left(400 \mathrm{MHz}, \mathrm{CDCl}_{3}\right) \delta 7.82(\mathrm{~d}$, $J=8.3 \mathrm{~Hz}, 2 \mathrm{H}), 7.36(\mathrm{~d}, J=8.0 \mathrm{~Hz}, 2 \mathrm{H}), 4.20-4.18(\mathrm{~m}, 2 \mathrm{H}), 3.72-3.70$ (m, 2H), 3.61- 3.59 (m, 2H), $3.51-3.49(\mathrm{~m}, 2 \mathrm{H}), 3.37$ (s, 3H), 2.47(s, 3H) ${ }^{13} \mathrm{C}$ NMR $\left(101 \mathrm{MHz}, \mathrm{CDCl}_{3}\right) \delta 144.8,133.0,129.8,128.0,71.8,70.7$, $69.2,68.7,59.1,21.6$.

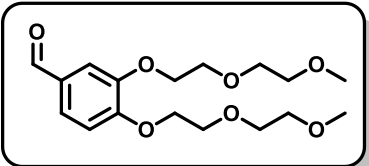

Colourless oil, $6.3 \mathrm{~g}, 97 \%$ yield. ${ }^{1} \mathbf{H}$ NMR $\left(400 \mathrm{MHz}, \mathrm{CDCl}_{3}\right) \delta 9.86$ (s, 1H), 7.47-7.45 (m, 2H), $7.01(\mathrm{~d}, J=7.9 \mathrm{~Hz}, 1 \mathrm{H}), 4.29-4.24(\mathrm{~m}$, 4H), 3.95-3.91 (m, 4H), 3.78-3.75 (m, 4H), 3.60-3.58 (m, 4H), 3.41 $(\mathrm{s}, 6 \mathrm{H}) .{ }^{13} \mathrm{C}$ NMR $\left(101 \mathrm{MHz}, \mathrm{CDCl}_{3}\right) \delta 190.8,154.3,149.2,130.4$, 126.7, 112.5, 112.0, 99.9, 72.01, 72.0, 70.9, 70.8, 69.6, 69.4, 68.8, 68.7, 59.1. HRMS (ESI) $\mathrm{m} / \mathrm{z}$ : $[\mathrm{M}+\mathrm{Na}]^{+}$Calcd. for $\mathrm{C}_{17} \mathrm{H}_{26} \mathrm{O}_{7} \mathrm{Na} 365.1576$; Found 365.1566.

\subsection{Synthesis of 4-(11-bromoundecyloxy)benzaldehyde}

4-hydroxybenzaldehyde $(2.00 \mathrm{~g}, 16.4 \mathrm{mmol})$ was dissolved in $9.0 \mathrm{~mL}$ of dry THF. The solution was cooled at $0^{\circ} \mathrm{C}$ under stirring and 11-bromoundecanol $(4.12 \mathrm{~g}, 16.4 \mathrm{mmol})$ was added. The system was placed under nitrogen atmosphere by applying vacuum and filling with nitrogen three 
times. Afterwards, triphenylphosphine $(4.73 \mathrm{~g}, 18.0 \mathrm{mmol})$ was added to the solution under nitrogen atmosphere, and DIAD (3.72 g, $18.4 \mathrm{mmol})$ was added dropwise. ${ }^{7}$ The reaction was then stirred at $0^{\circ} \mathrm{C}$ for the first hour and then slowly allowed to heat up to room temperature. The reaction was monitored by TLC and, after 4 hours, the mixture was concentrated under reduced pressure. The resulting residue was dissolved in ethyl acetate, washed first with a saturated solution of $\mathrm{NaHCO}_{3}$ and successively with brine. The combined organic layers were dried over $\mathrm{Na}_{2} \mathrm{SO}_{4}$ and the solvent was removed through rotatory evaporation. The crude product was further purified by flash chromatography over silica gel (petroleum ether/ethyl acetate 8:2) to yield $45.2 \%$ of the final product $(2.66 \mathrm{~g}, 7.49 \mathrm{mmol})$ as a yellow crystalline solid. ${ }^{1} \mathrm{H}-\mathrm{NMR},{ }^{13} \mathrm{C}-\mathrm{NMR}$ and MS data aligns with those reported in literature. ${ }^{7}$

\subsection{Synthesis of 11-(4-formylphenoxy)undecane-1-sulfonate (AS)}

To a three-neck $50 \mathrm{~mL}$ round-bottom flask 4-(11-bromoundecyloxy)benzaldehyde (500 mg, 1.41 mmol), sodium sulfite $(355 \mathrm{mg}, 2.82 \mathrm{mmol})$, benzyltriethyl-ammonium bromide $(19.3 \mathrm{mg}, 0.07$ mmol), methanol $(4.00 \mathrm{~mL})$ and water $(5.10 \mathrm{~mL})$ were added under stirring. ${ }^{8}$ The reaction was refluxed overnight with oil bath. The resulting mixture was extracted with $\mathrm{Et}_{2} \mathrm{O}$ and water (2 times) and, the aqueous layer was collected. Once the aqueous solution was cooled at $0^{\circ} \mathrm{C}$, white crystals were obtained. The remaining water was freeze dried. The product was recrystallized by re-dissolving the dry crystals in Milli-Q water under heating and sonication and letting the solution slowly cool down at room temperature, leading to crystallization. The mixture was centrifuged for $45 \mathrm{~min}$ and the supernatant was carefully removed. The obtained crystals were dried again with the freeze dryer to obtain $158 \mathrm{mg}(31.6 \%)$ of the pure white solid product. ${ }^{1} \mathbf{H}$ NMR (400 MHz, DMSO-d $d_{6} \delta 9.85(\mathrm{~s}, 1 \mathrm{H}), 7.85(\mathrm{~d}, J=8.22 \mathrm{~Hz}, 2 \mathrm{H}), 7.11(\mathrm{~d}, J=8.26 \mathrm{~Hz}, 2 \mathrm{H})$, $4.07(\mathrm{t}, J=6.54 \mathrm{~Hz}, 2 \mathrm{H}), 2.45-2.35(\mathrm{~m}, 2 \mathrm{H}), 1.72(\mathrm{~m}, 2 \mathrm{H}), 1.55(\mathrm{~m}, 2 \mathrm{H}), 1.44-1.19(\mathrm{~m}, 14 \mathrm{H})$. ${ }^{13}$ C NMR (101 MHz, DMSO- $\left.d_{6}\right) \delta 191.3,163.7,131.8,129.5,114.9,68.0,51.5,29.0,29.0,28.9$, 28.7, 28.5, 28.4, 25.5, 25.4, 25.1. LRMS (ESI) $m / z$ : [M-Na $]$ Calcd. for $\mathrm{C}_{18} \mathrm{H}_{27} \mathrm{O}_{5} \mathrm{~S}^{-}$355.1585; Found 355.1510 . 


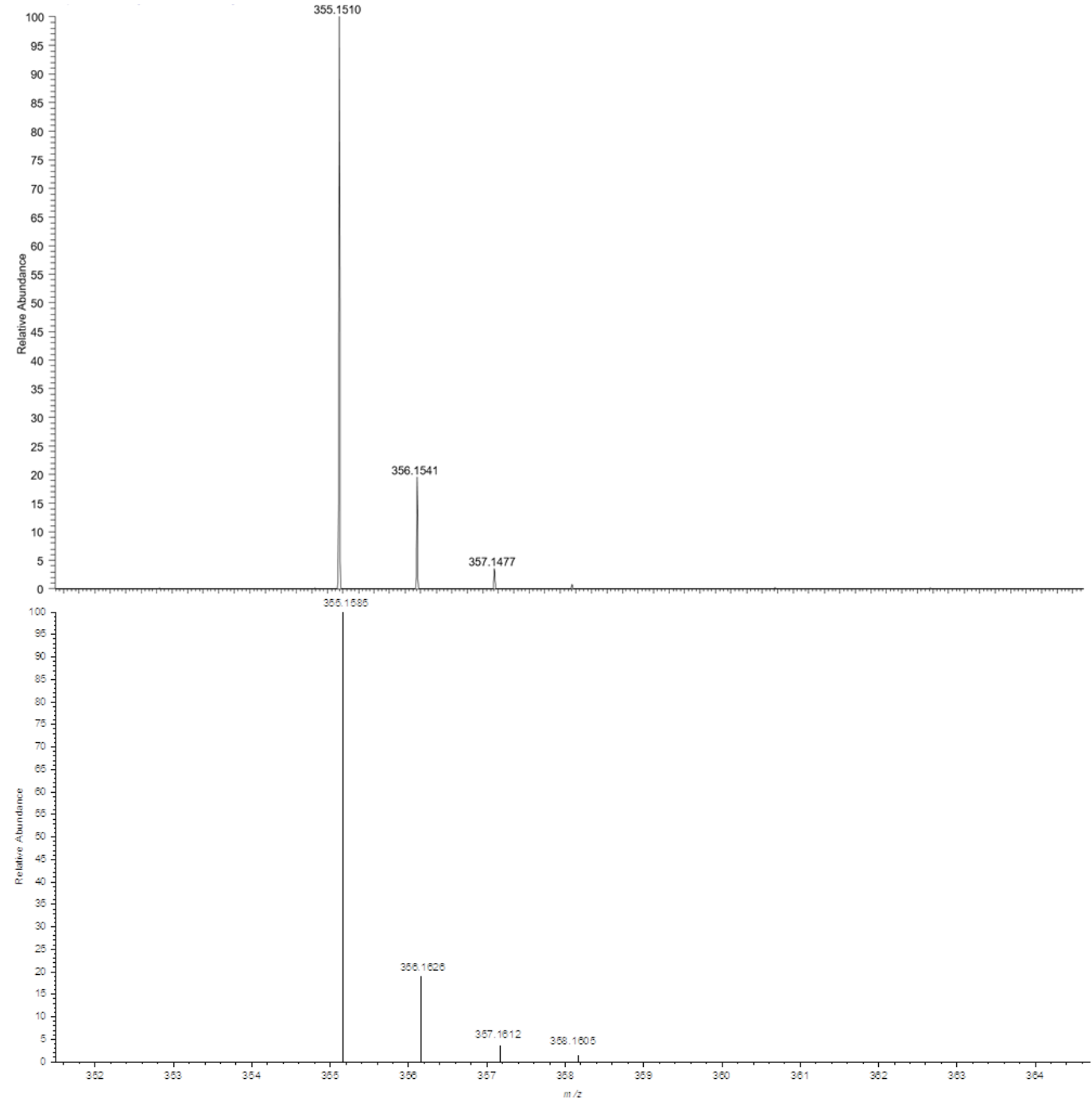

HRMS of compound alkylsulfonate benzaldehyde AS (top) and calculated isotopic pattern (bottom) 


\section{Absorbance spectra for determination of reaction rates}

Figure S1. (a) Uv-vis titration curve; (b) calibration curve of (4-nitrobenzylidene)benzohydrazide 1; (c) the absorption spectrum of starting material and product 1 in phosphate buffered saline (PBS) with DMF (DMF : $\mathrm{H}_{2} \mathrm{O}=1: 9$ ) at $\mathrm{pH}=7.4$; (d) Kinetic order experiment for 4-nitrobenzaldehyde and catalyst (5-methylindoline as representative, $0.02 \mathrm{mM}$ benzoylhydrazine was used under conditions of Table 1).

(a)

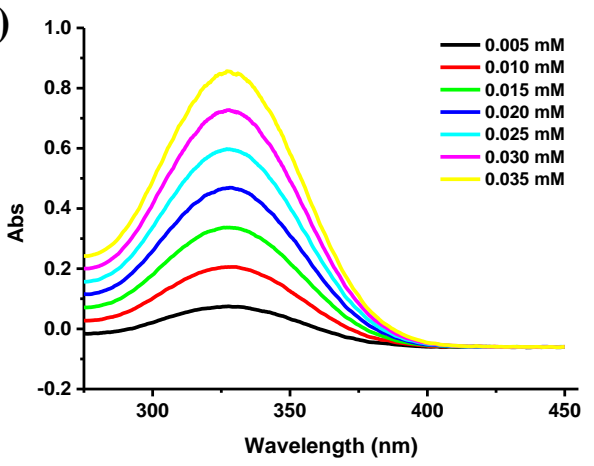

(c)

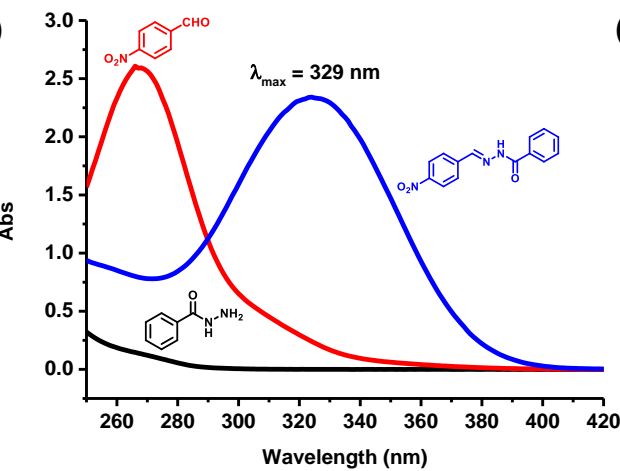

(b)

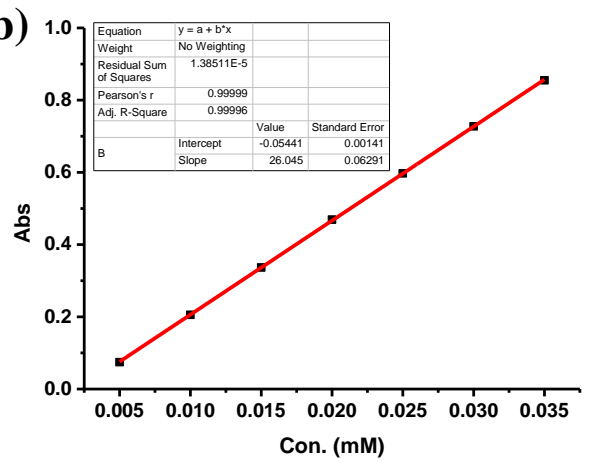

(d)

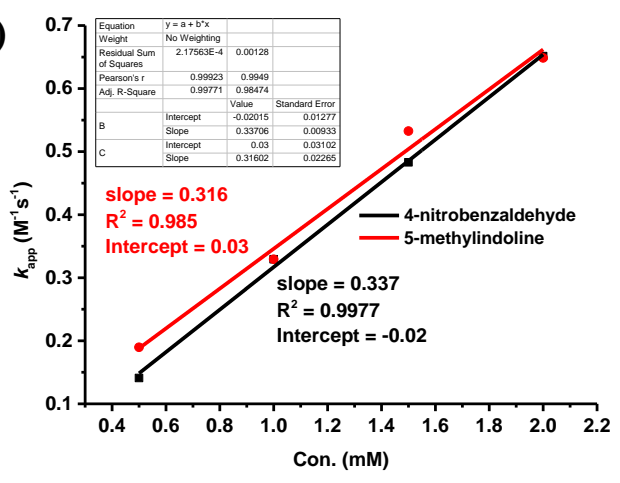


Figure S2. Representative kinetic UV-Vis Spectra for catalyst screening.
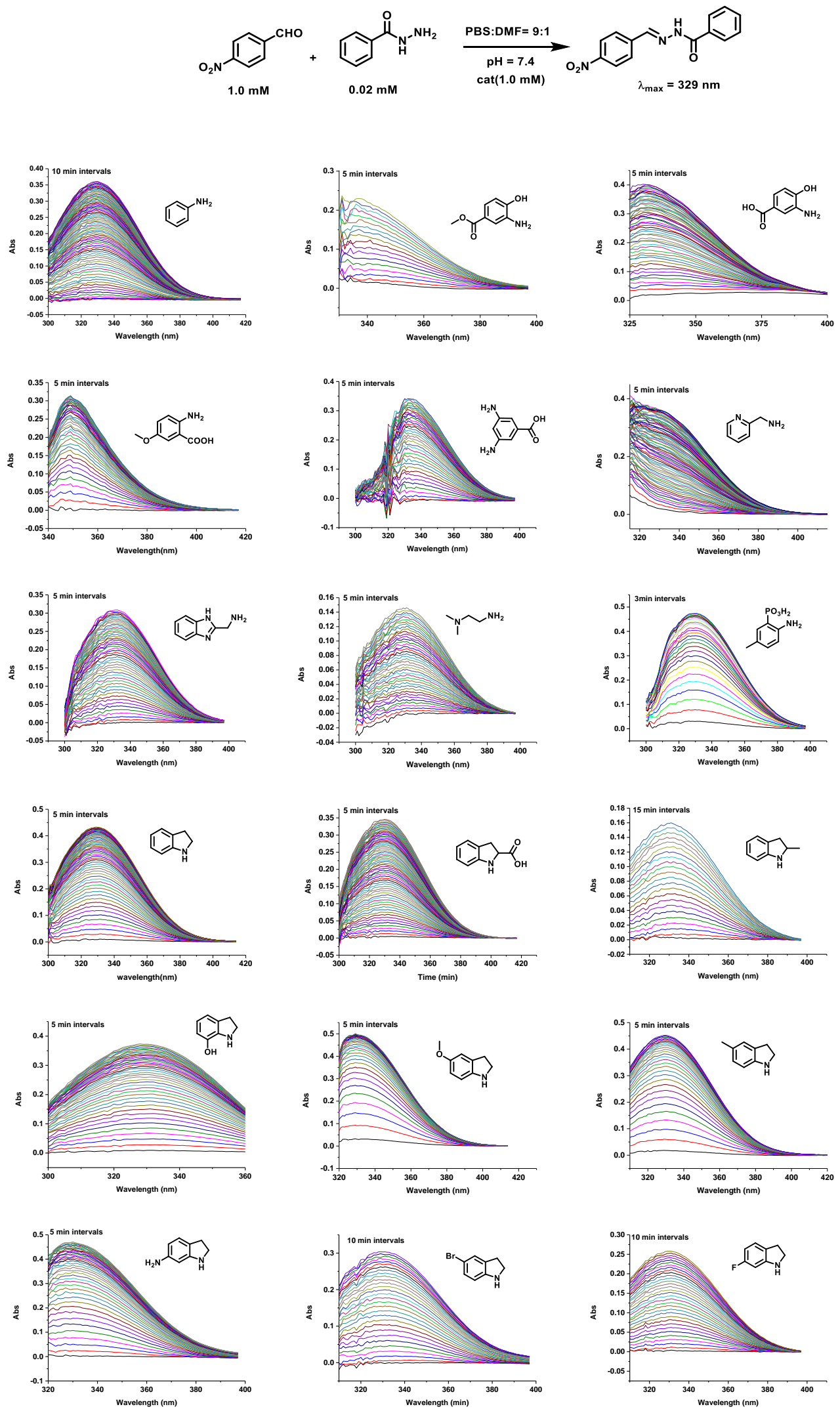
Figure S3. Absorption kinetics of the model reaction for the different catalysts measured at 329 $\mathrm{nm}$ as a function of time (left) accompanied by the linear least-squares fits (right).
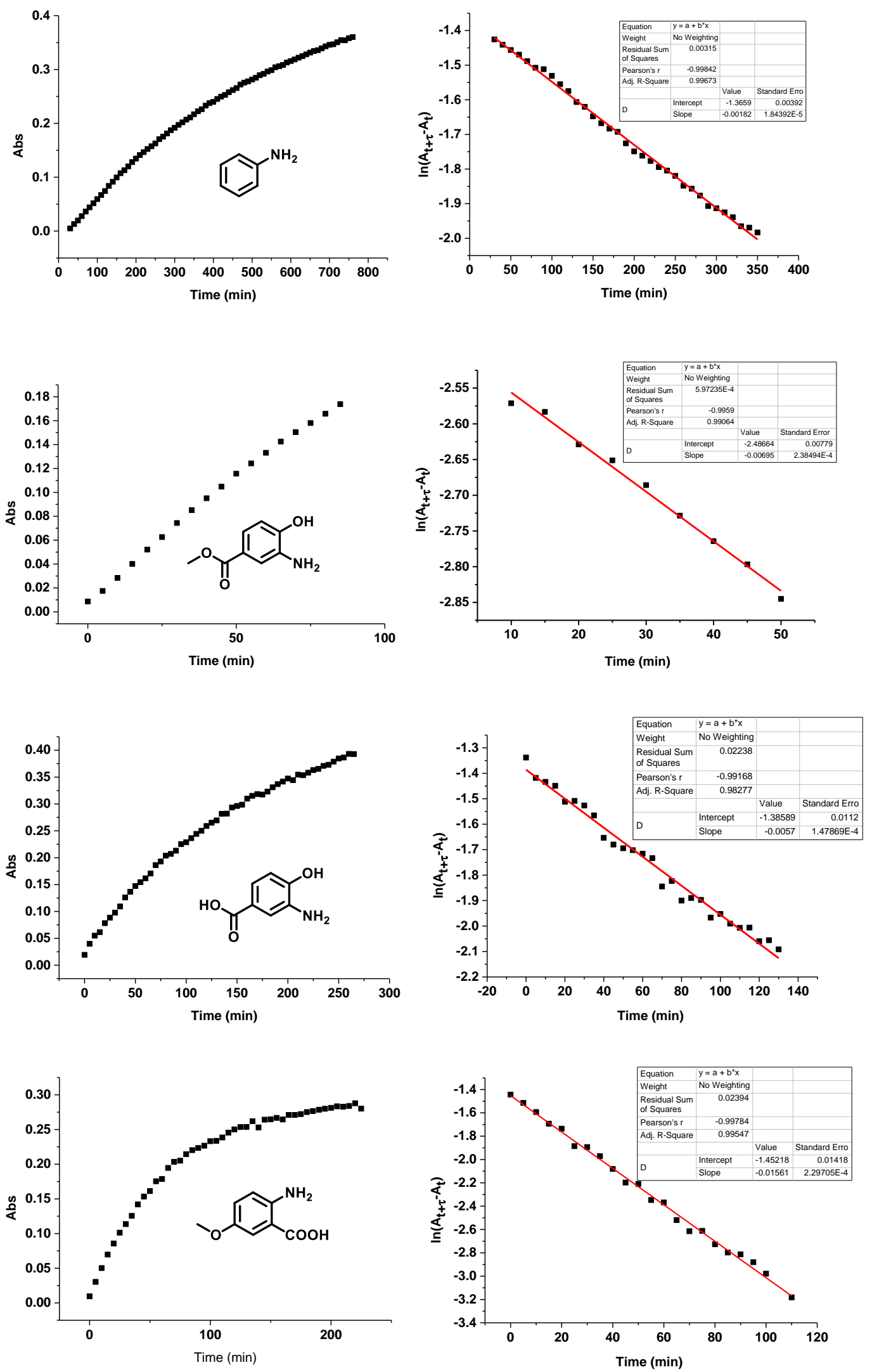

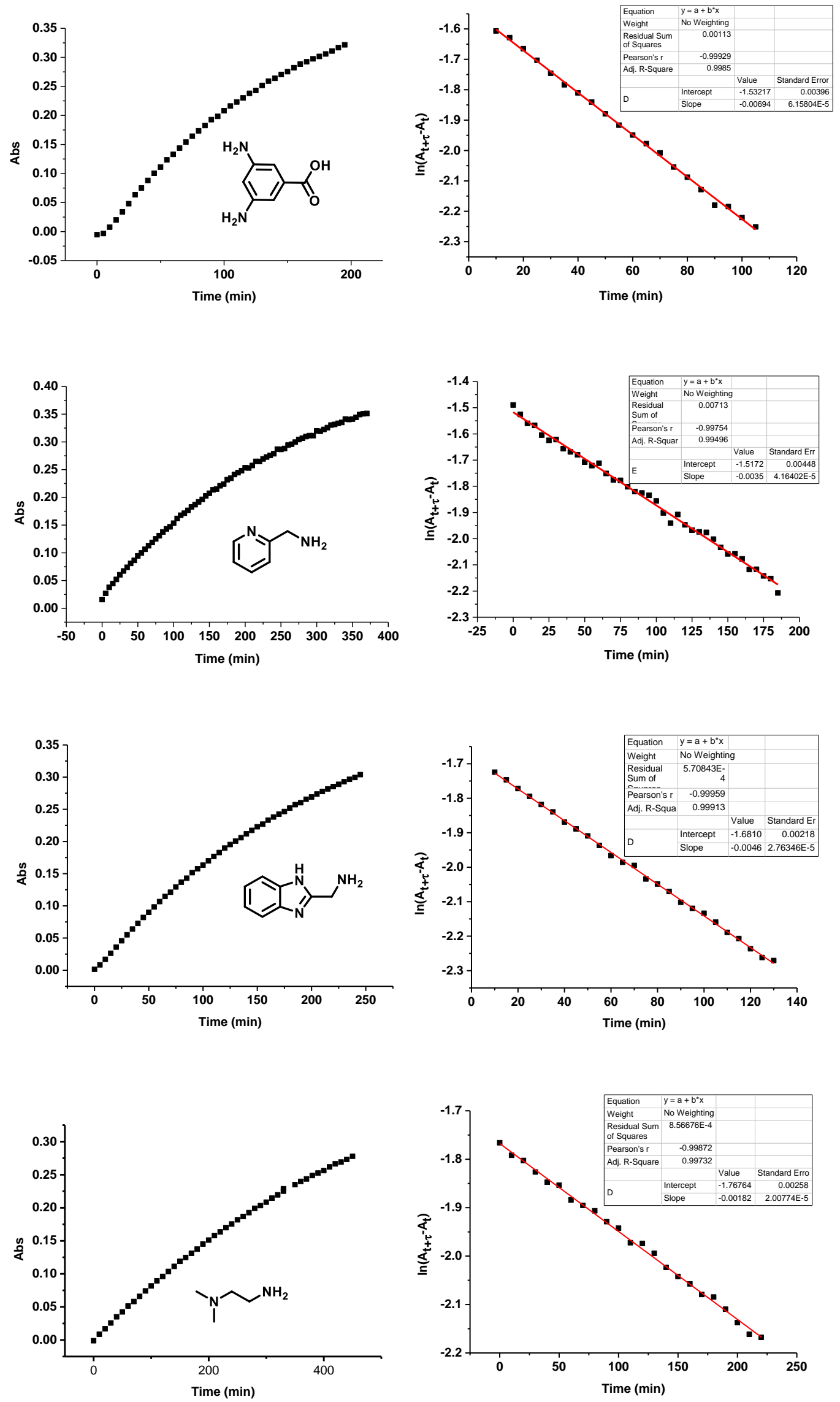

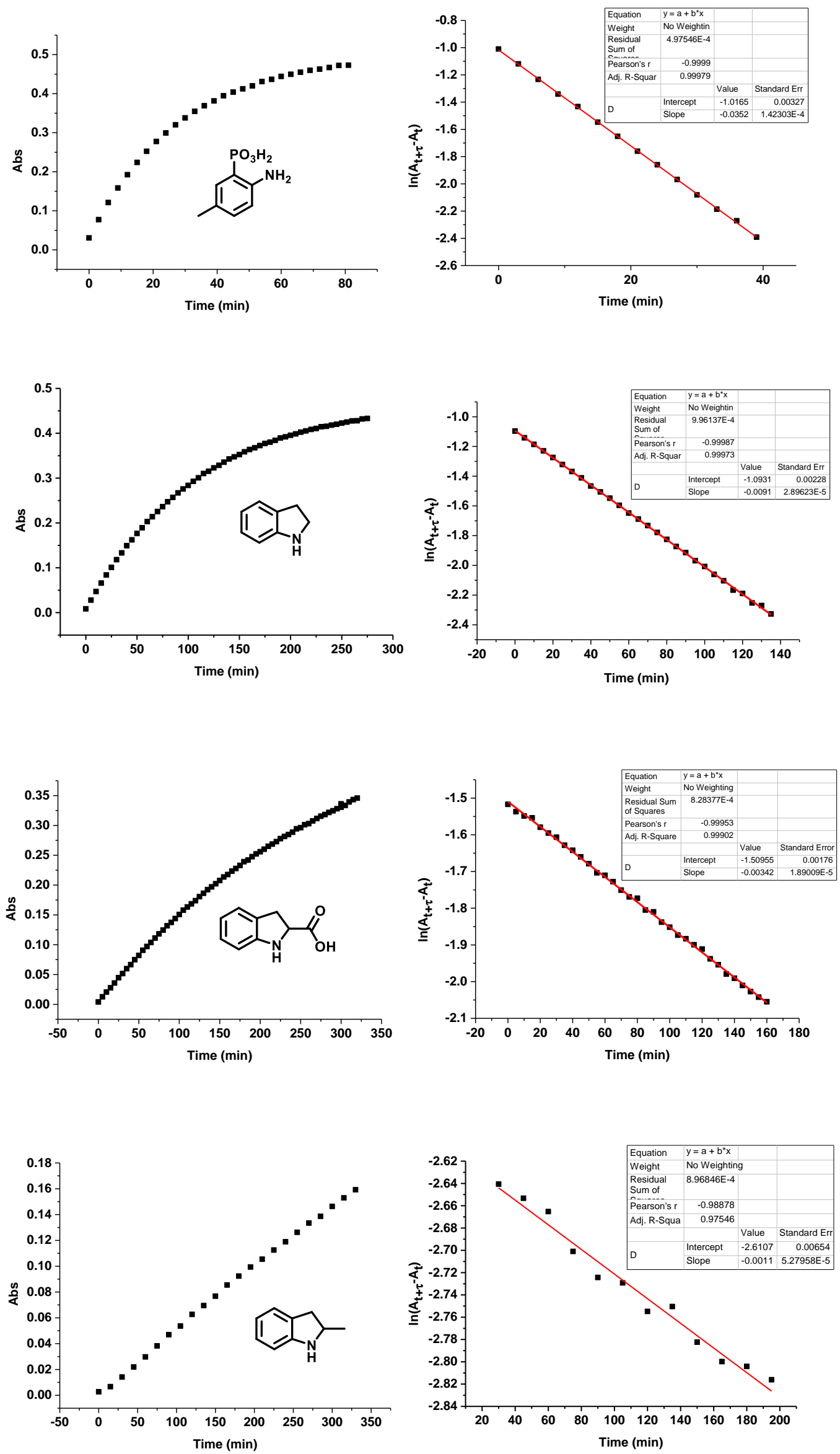

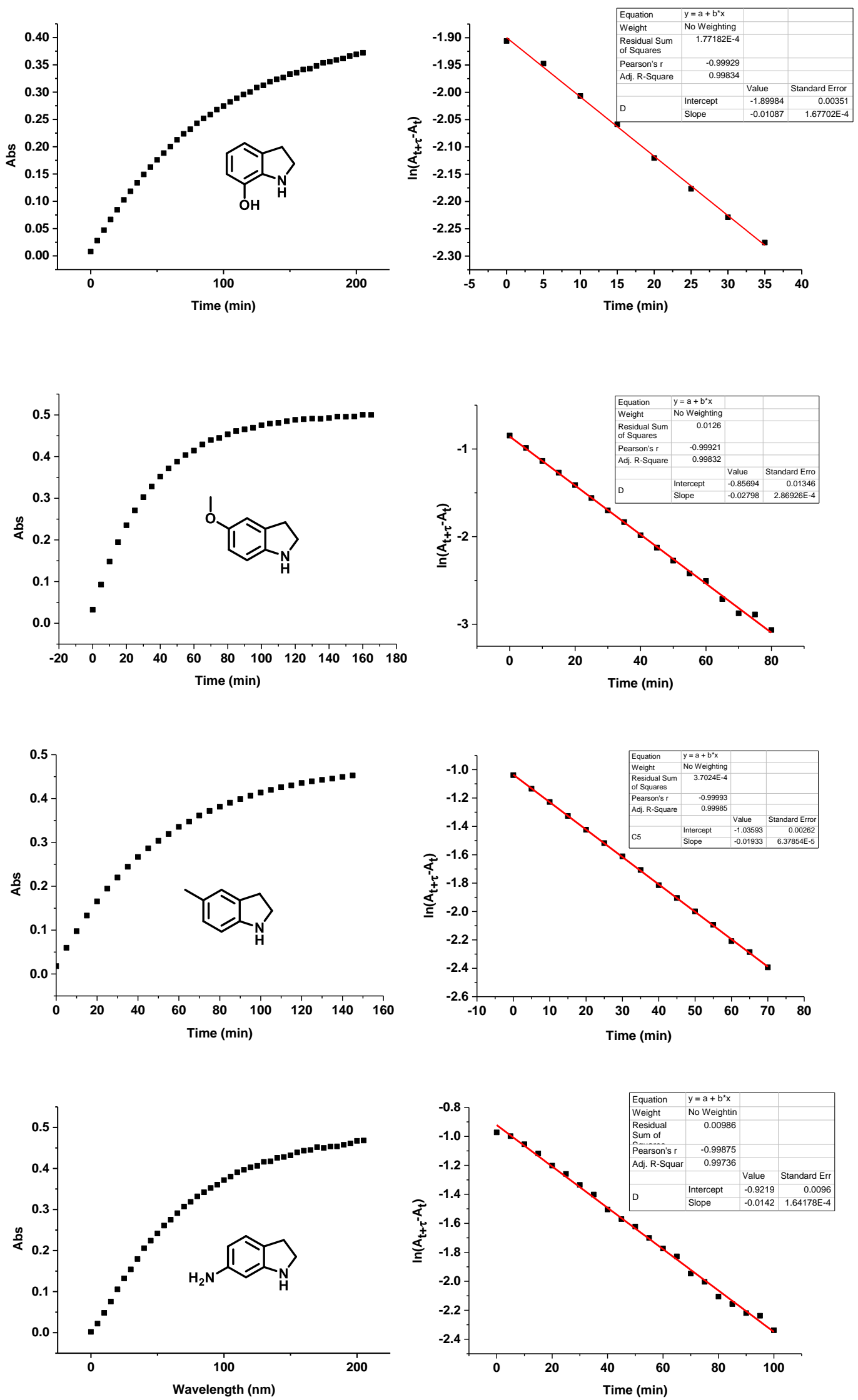

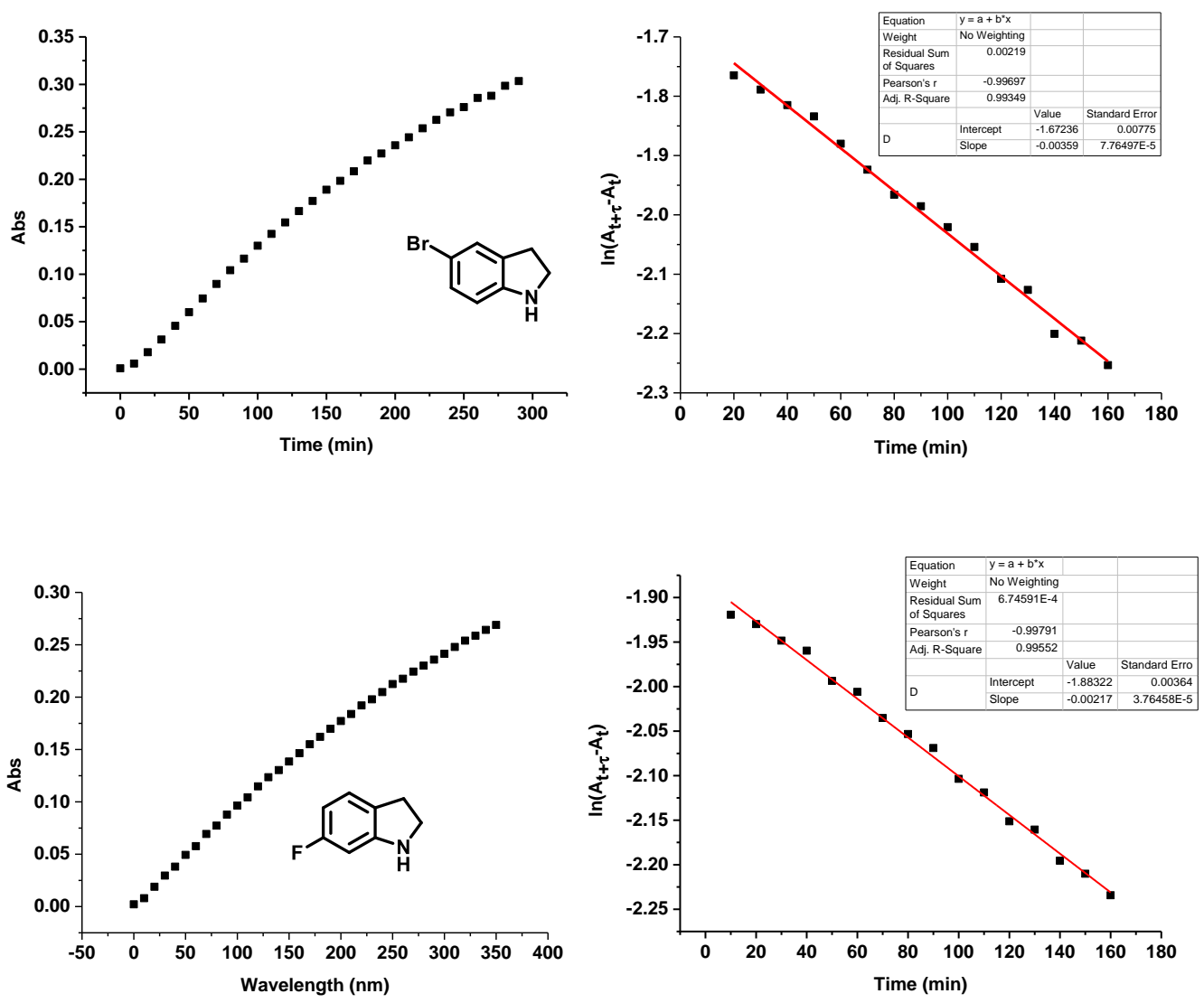
Figure S4. Substrates scopes of nucleophiles. The maximum absorption peak was measured for fast reactions in some cases.
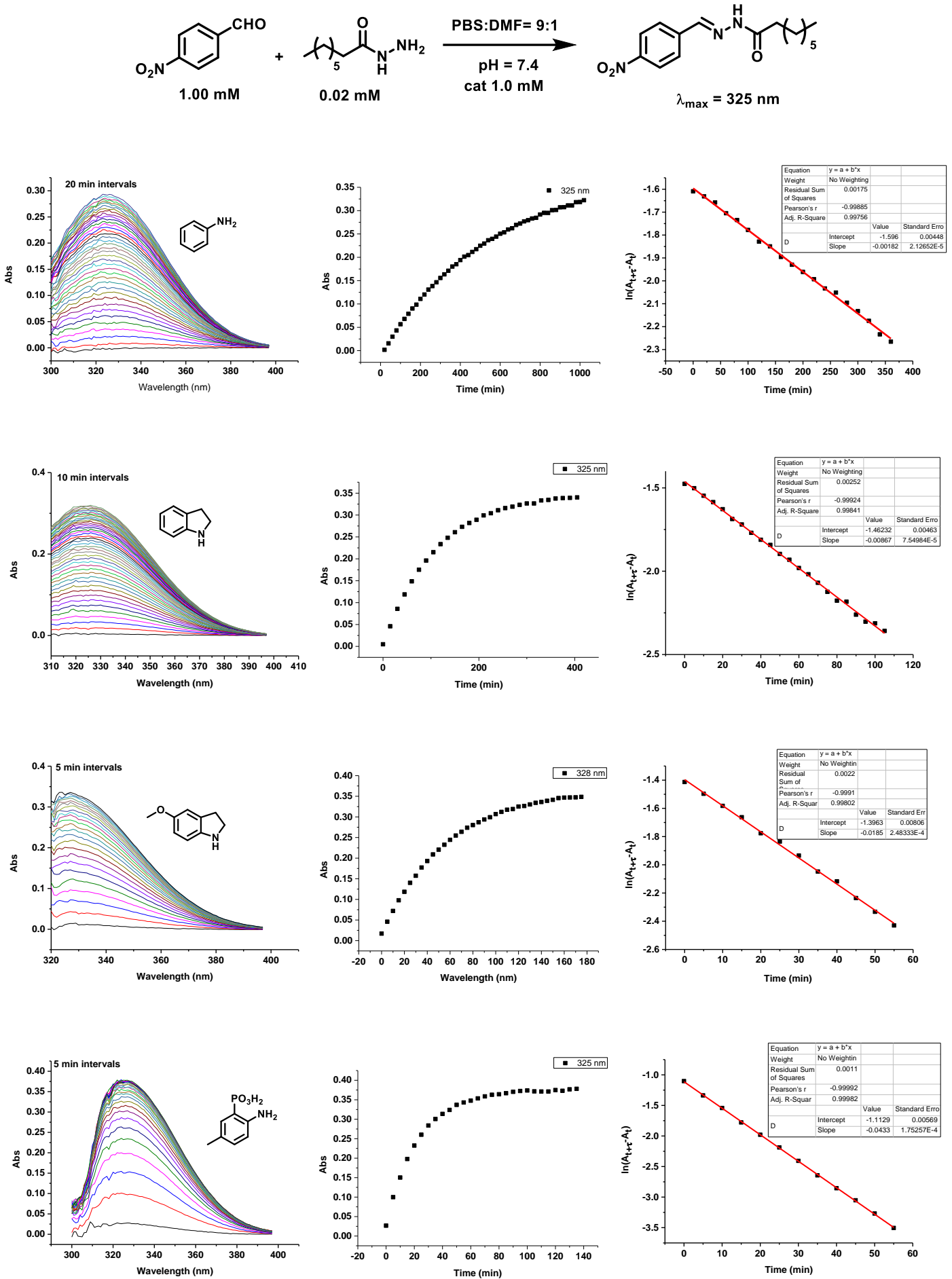

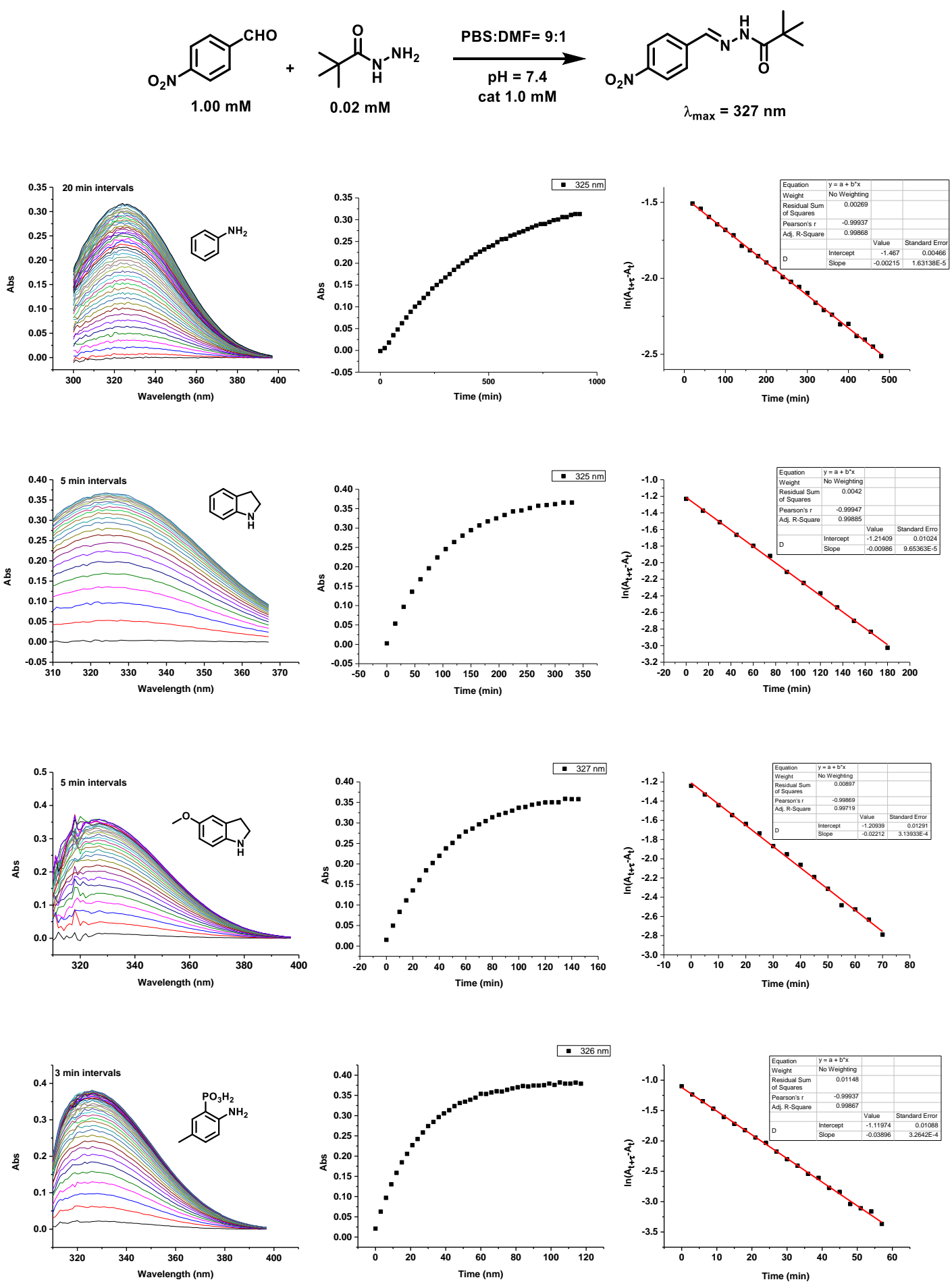

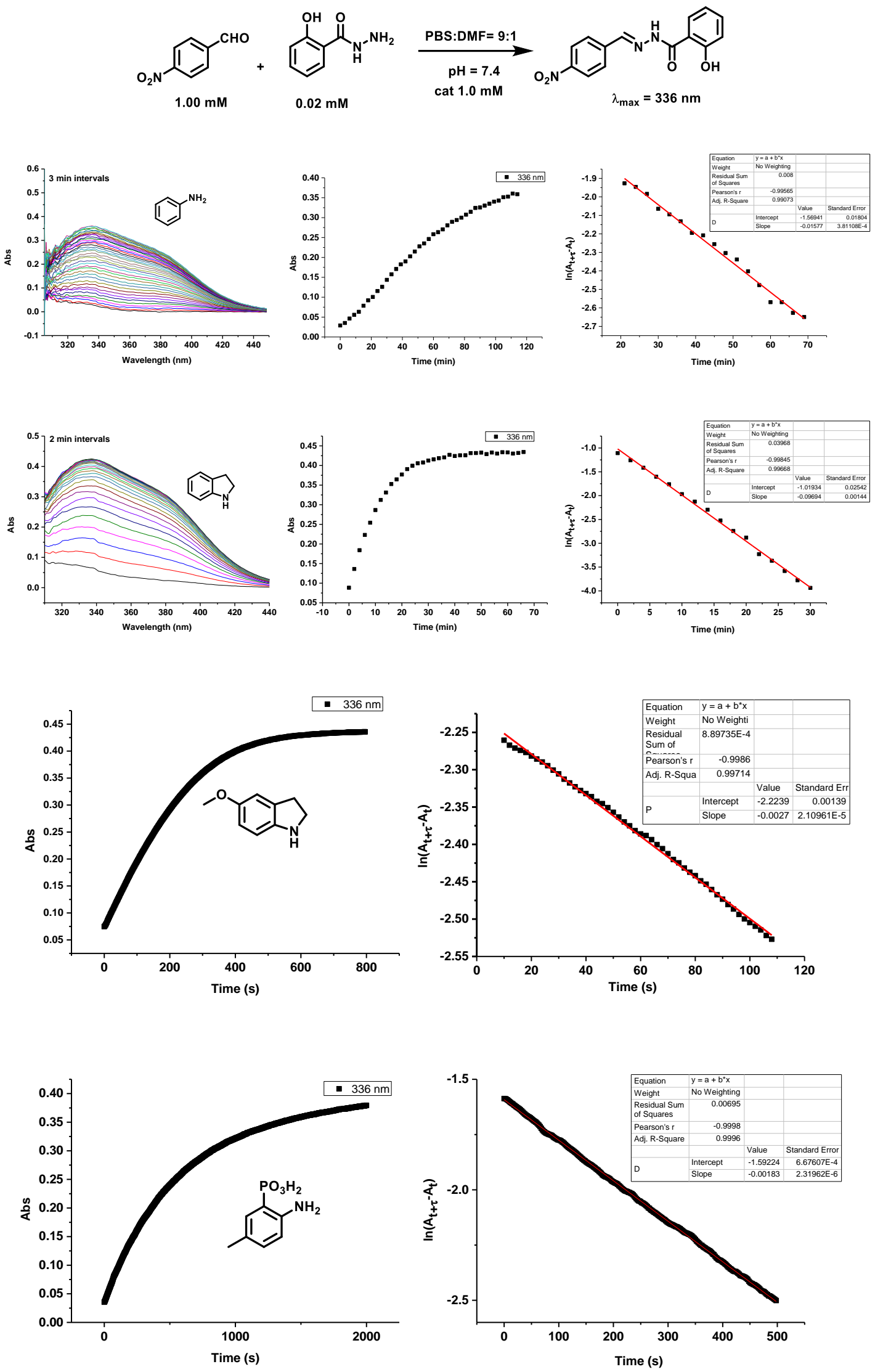

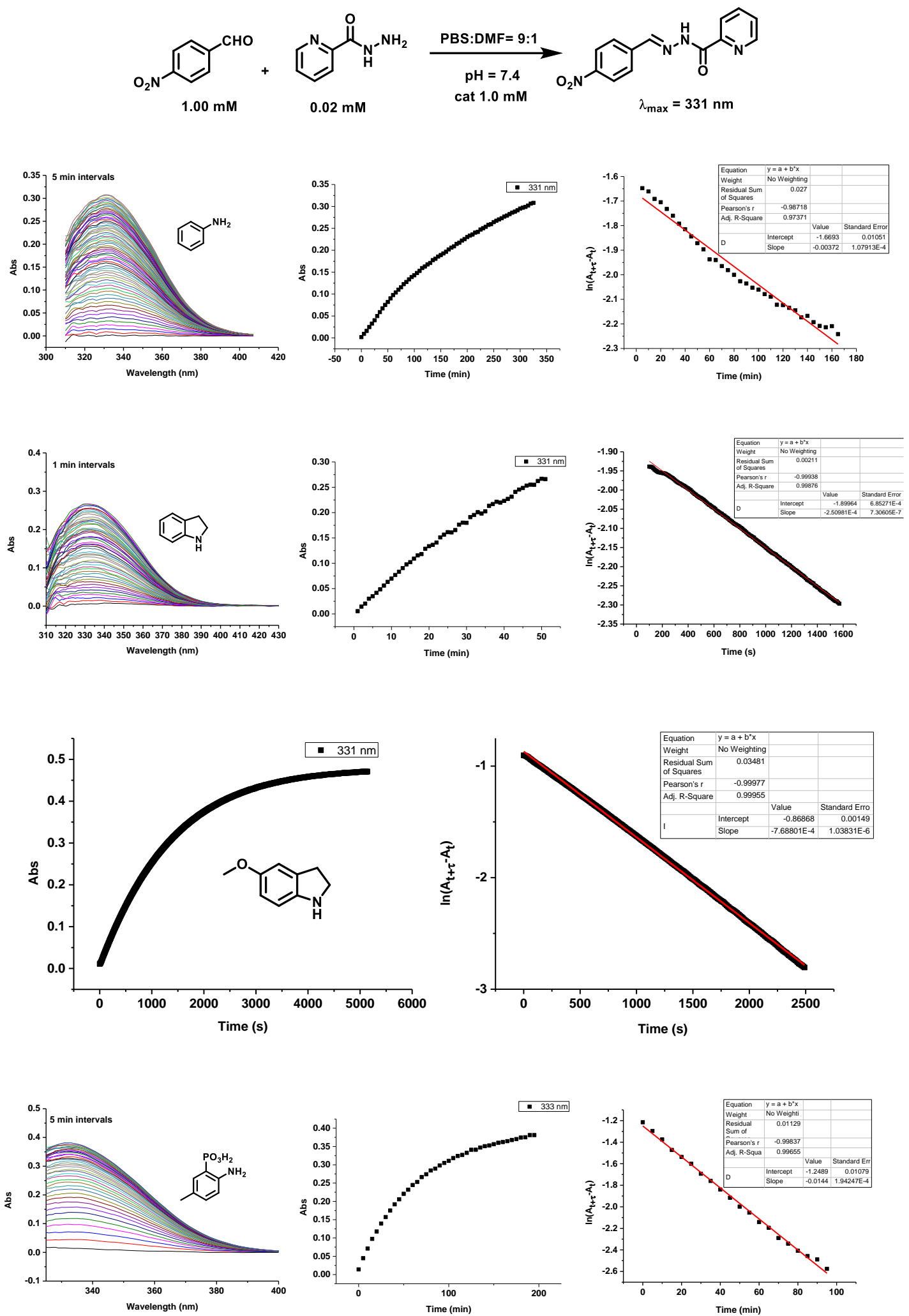

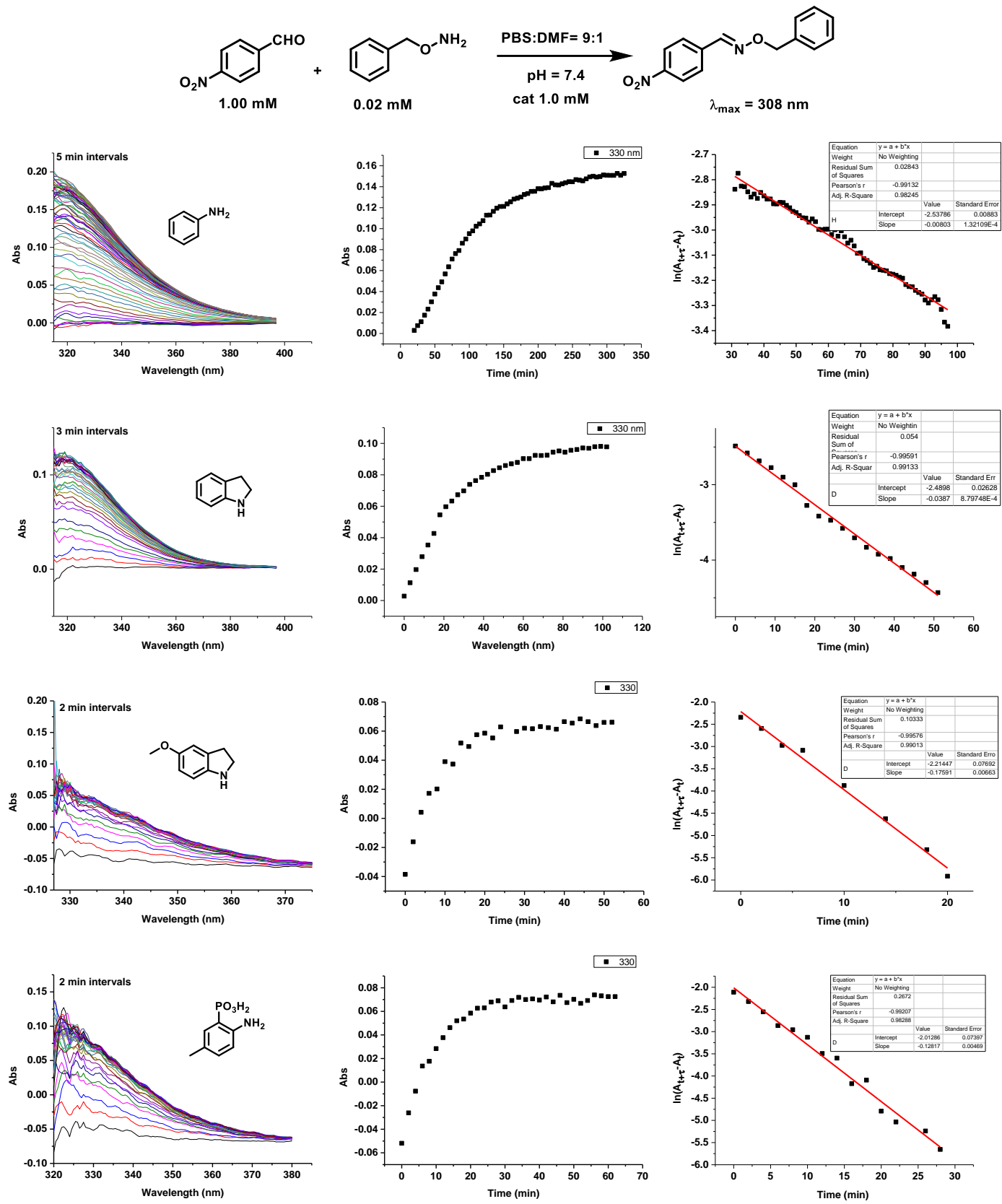


$$
\text { 然 }
$$
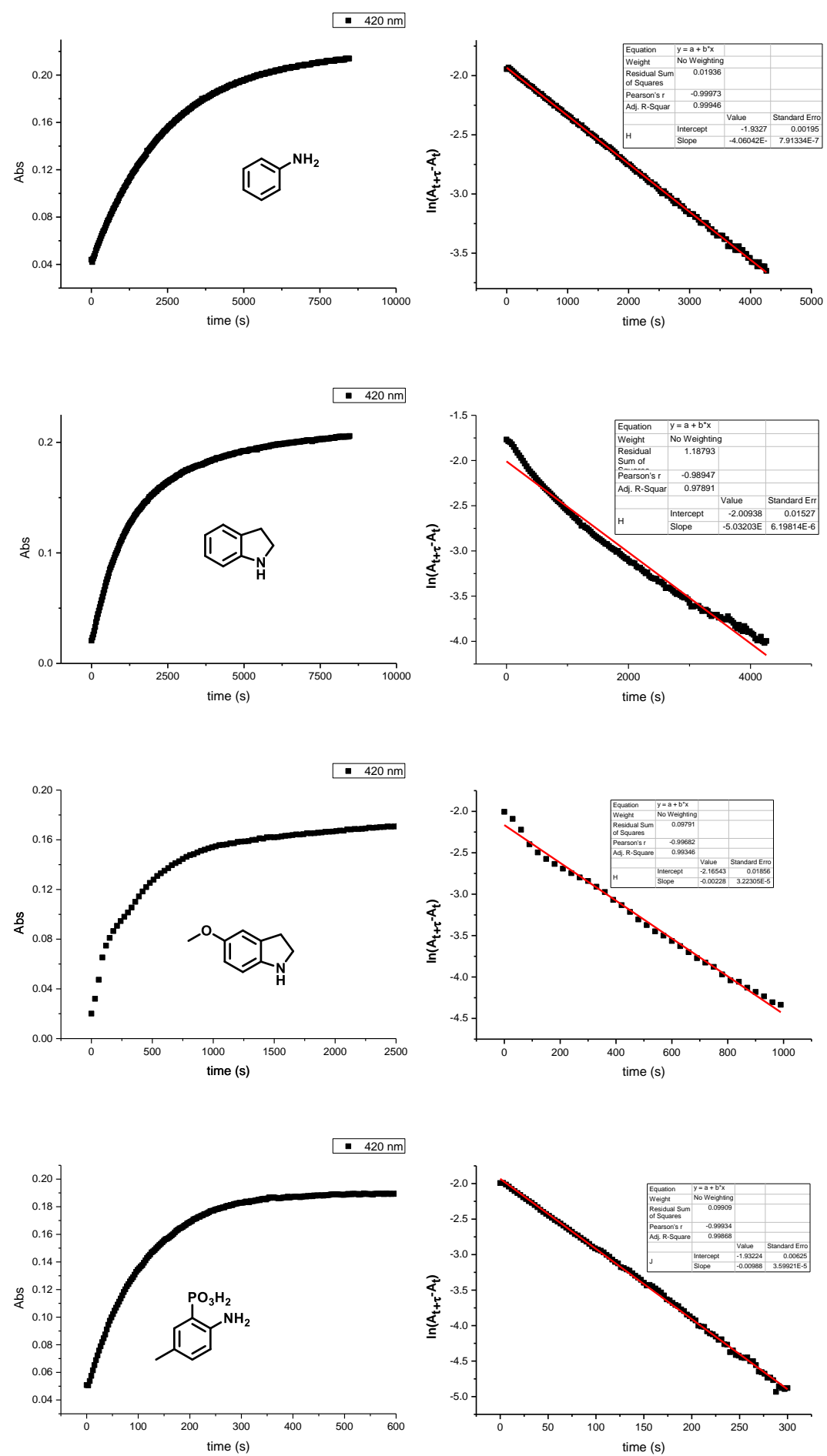
Figure S5. Substrates scopes of aldehyde. The maximum absorption peak was measured for fast reactions in some cases.
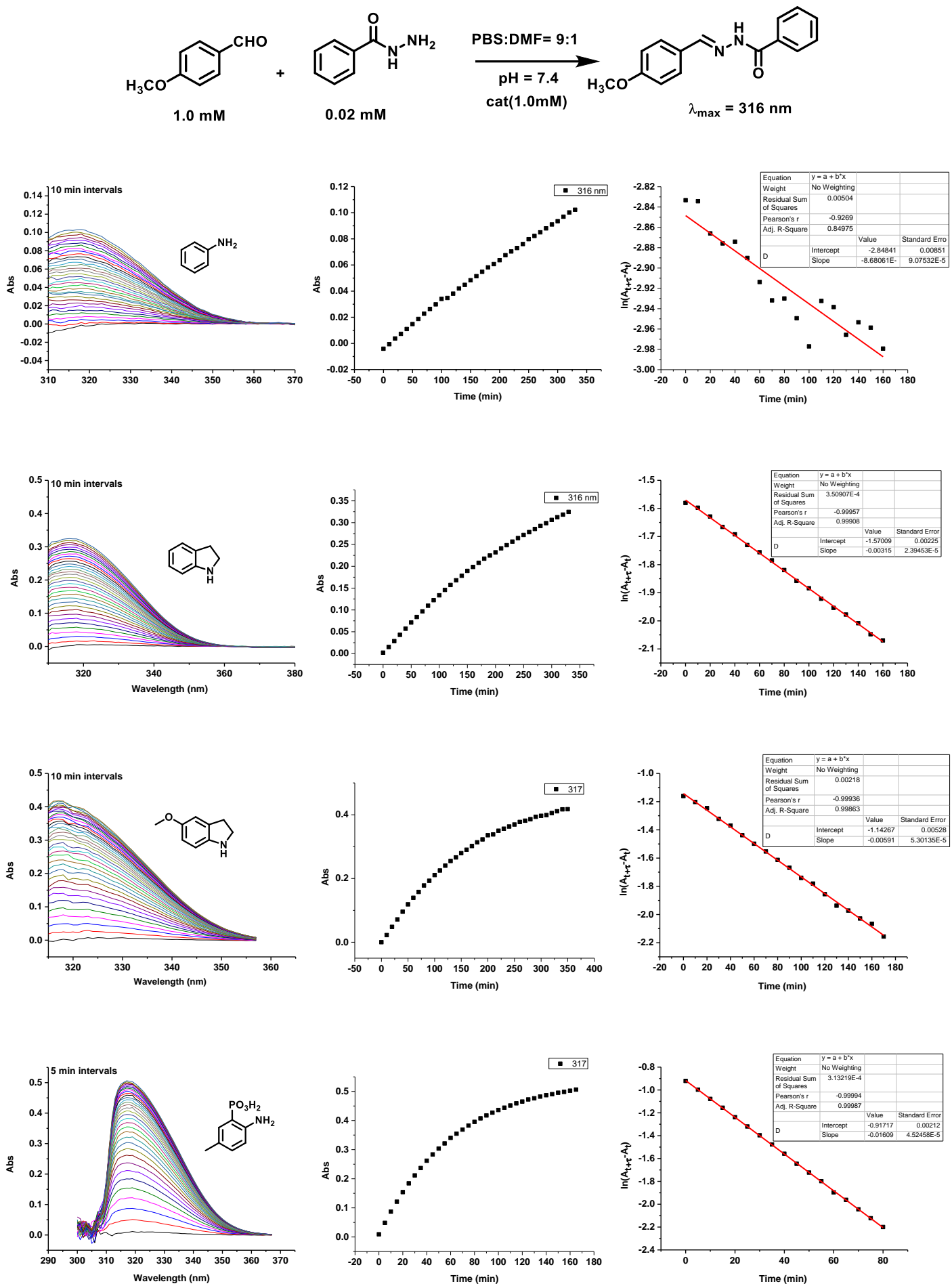



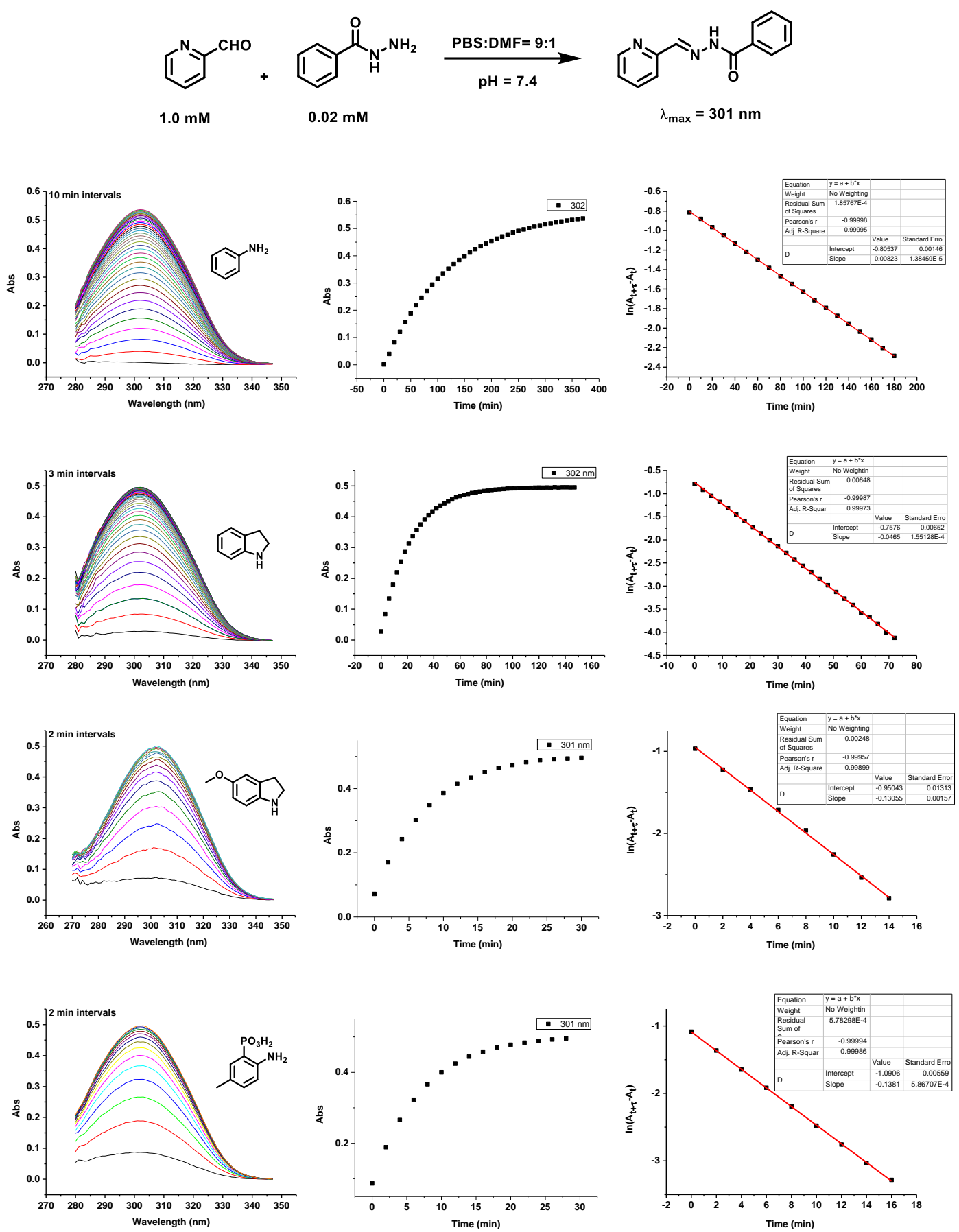

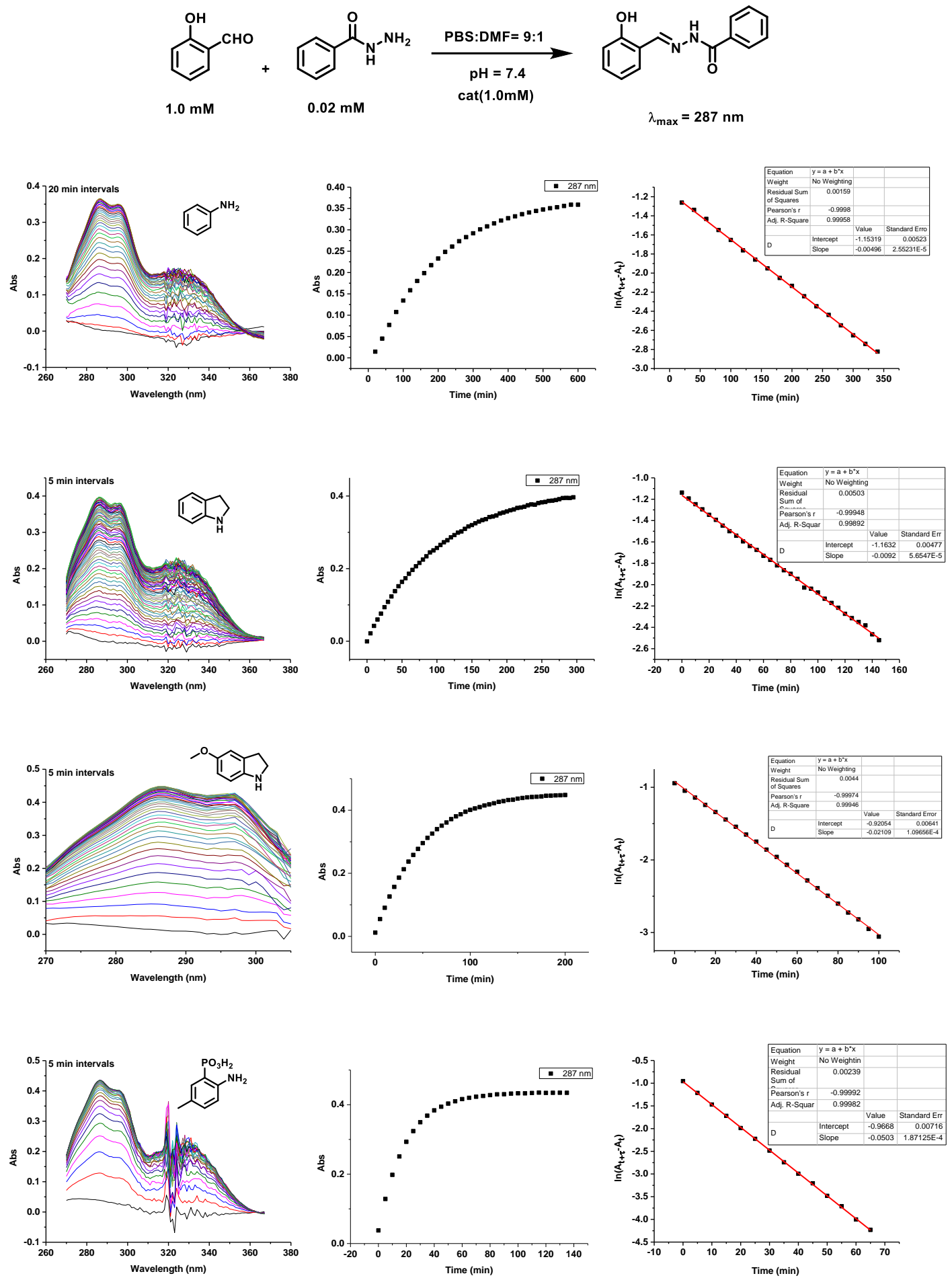
<smiles>O=Cc1cccc2cccnc12</smiles>

$1.0 \mathrm{mM}$<smiles>NNC(=O)c1ccccc1</smiles>

$0.02 \mathrm{mM}$

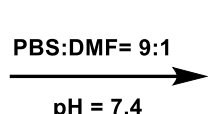

cat(1.0mM)<smiles>O=C(N/N=C/c1cccc2cccnc12)c1ccccc1</smiles>

$\lambda_{\max }=336 \mathrm{~nm}$
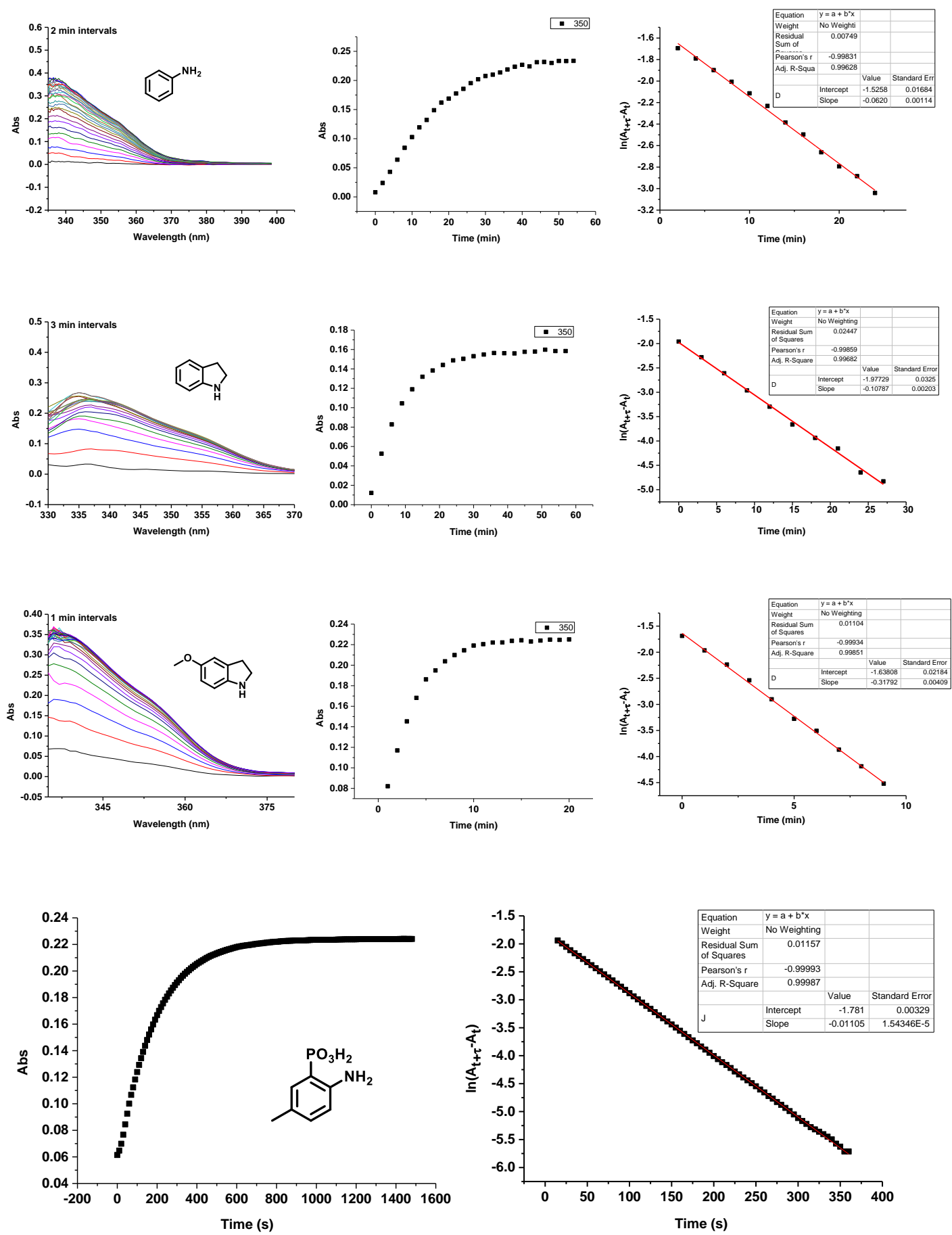

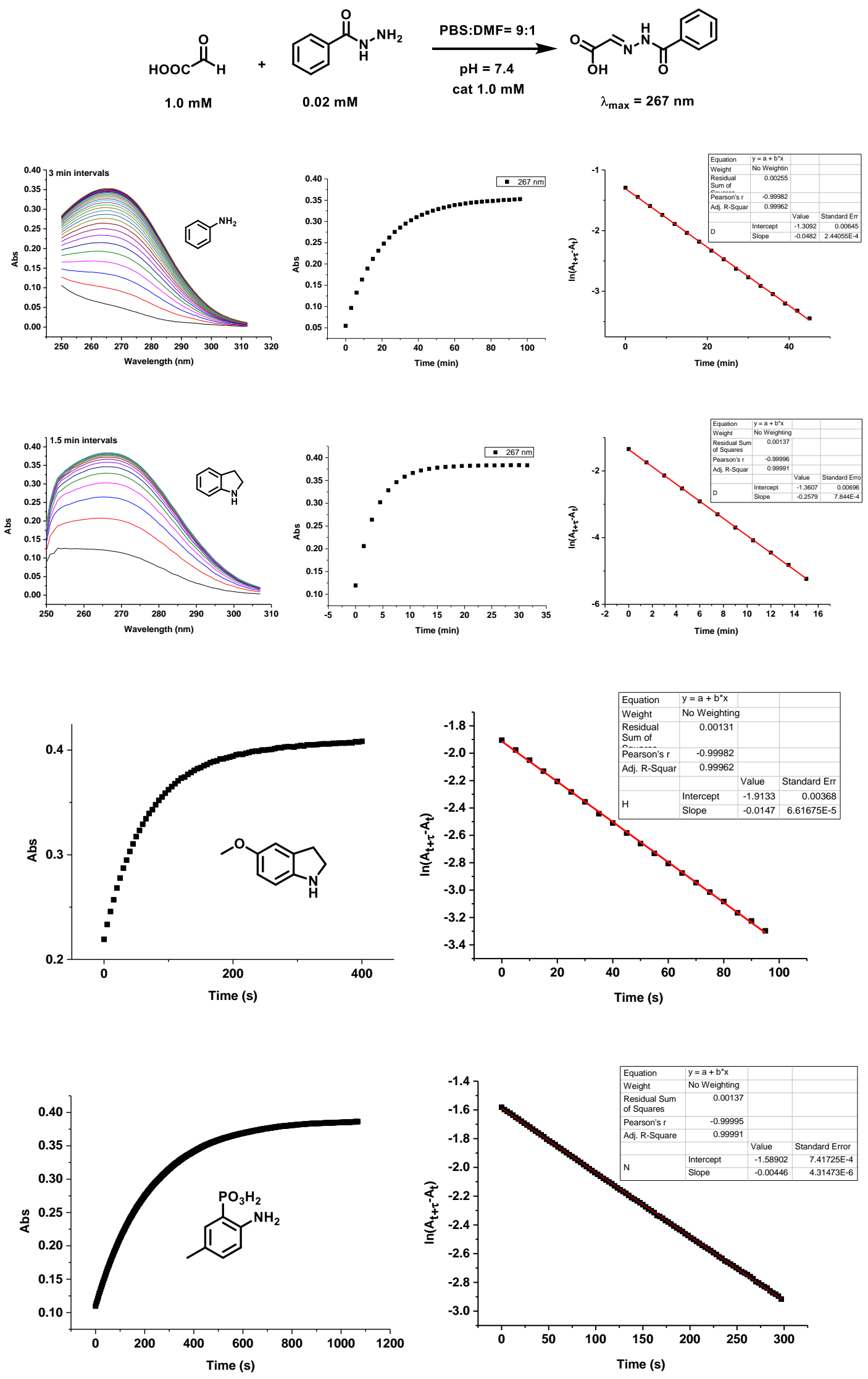
Figure S6. Substituted benzaldehyde reaction rate with benzoylhydrazine for Hammett plot analysis.

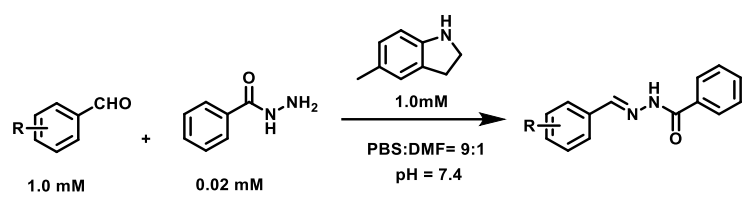
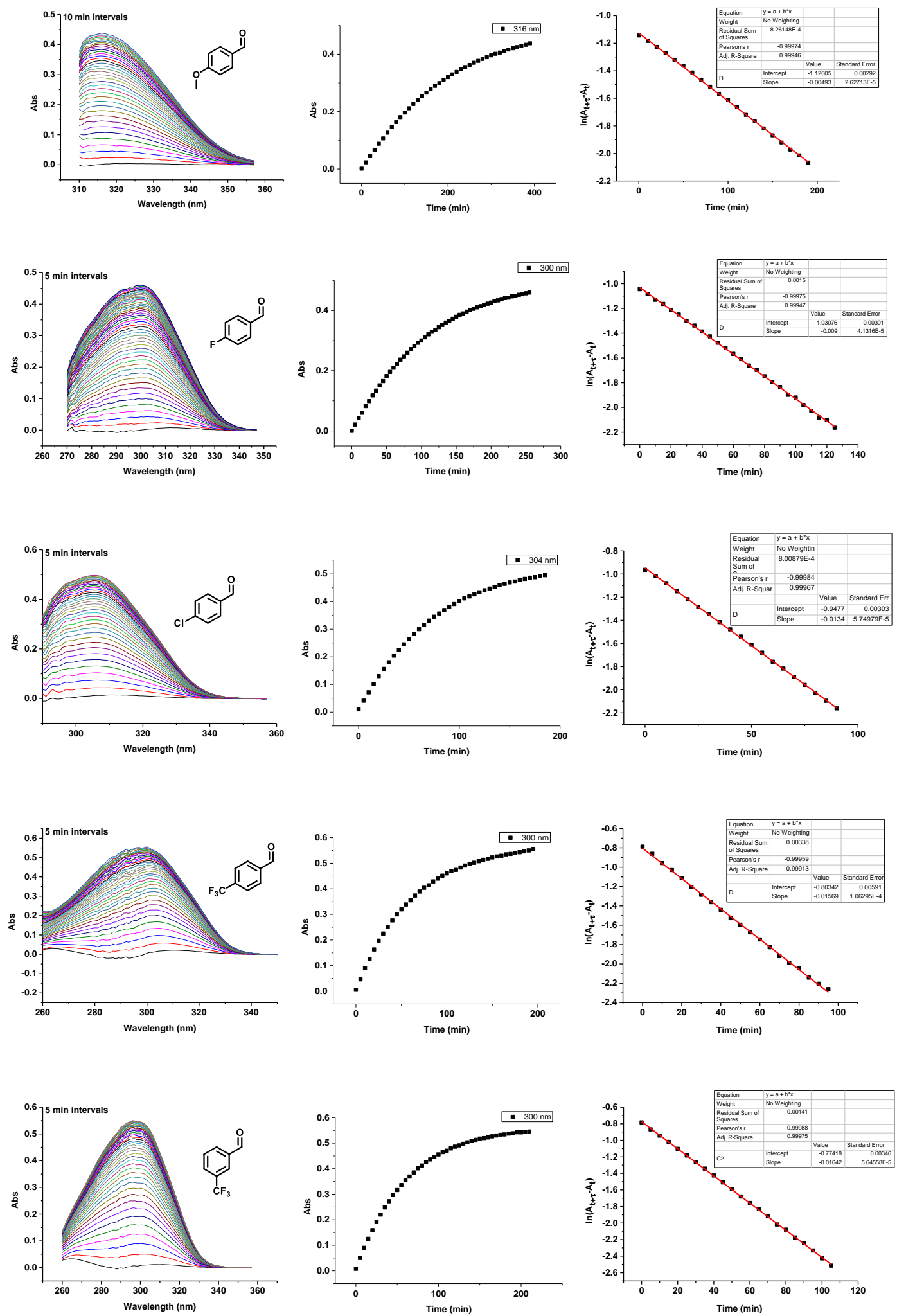


\section{6. pH effects}

\begin{tabular}{|c|c|c|c|c|c|c|c|}
\hline & & & & $\mathrm{pH}$ & $\lambda_{\max }$ & & \\
\hline \multirow[t]{4}{*}{ Cat. } & 7.40 & 7.00 & 6.50 & 6.00 & 5.53 & 5.03 & 4.49 \\
\hline & $\begin{array}{c}0.030 \pm \\
0.002\end{array}$ & $\begin{array}{l}0.056 \pm \\
0.004\end{array}$ & $\begin{array}{l}0.155 \pm \\
0.004\end{array}$ & $\begin{array}{l}0.456 \pm \\
0.011\end{array}$ & $\begin{array}{l}1.087 \pm \\
0.006\end{array}$ & $\begin{array}{l}2.360 \pm \\
0.044\end{array}$ & $\begin{array}{l}3.883 \pm \\
0.032\end{array}$ \\
\hline & $\begin{array}{c}0.151 \pm \\
0.003\end{array}$ & $\begin{array}{l}0.285 \pm \\
0.004\end{array}$ & $\begin{array}{l}0.707 \pm \\
0.001\end{array}$ & $\begin{array}{l}1.816 \pm \\
0.029\end{array}$ & $\begin{array}{l}3.653 \pm \\
0.051\end{array}$ & $\begin{array}{l}5.383 \pm \\
0.080\end{array}$ & $\begin{array}{l}6.600 \pm \\
0.030\end{array}$ \\
\hline & $\begin{array}{c}0.329 \pm \\
0.023\end{array}$ & $\begin{array}{l}0.516 \pm \\
0.013\end{array}$ & $\begin{array}{l}1.194 \pm \\
0.033\end{array}$ & $\begin{array}{l}2.373 \pm \\
0.021\end{array}$ & $\begin{array}{l}3.756 \pm \\
0.021\end{array}$ & $\begin{array}{l}4.656 \pm \\
0.126\end{array}$ & $\begin{array}{l}5.320 \pm \\
0.095\end{array}$ \\
\hline
\end{tabular}

Table S1. Apparent second-order rate constant $\mathrm{k}_{\mathrm{app}}\left(\mathrm{M}^{-1} \mathrm{~s}^{-1}\right)$ measured under different $\mathrm{pH}$.
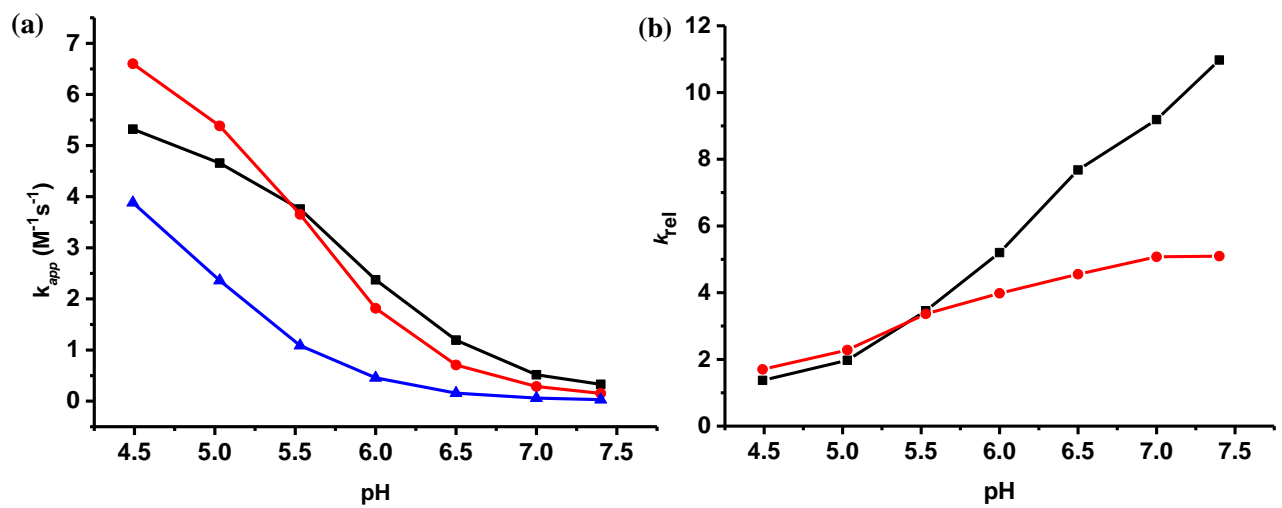

Figure S7. (a) Rate dependence on $\mathrm{pH}$ varying from 4.5 to 7.4 for the model reaction; (b) $\mathrm{k}_{\text {rel }}-\mathrm{pH}$ relationship (relative to aniline). (black: 5-methylindoline; red: indoline; blue: aniline)..

\section{Turbidity measurements of catalytic trishydrazone hydrogelator formation and appearance.}

Turbidity measurements were performed according to reported literature procedures. ${ }^{6}$ To a quartz cuvette $(1 \mathrm{~cm}$ path length) containing $0.3 \mathrm{~mL}$ sodium phosphate buffer $(0.10 \mathrm{M}, \mathrm{pH}=7.0)$ was added $0.6 \mathrm{~mL}$ acylhydrazide $\mathbf{H}$ stock solution $(40 \mathrm{mM})$ and $0.6 \mathrm{~mL}$ aldehyde $\mathbf{A}$ stock solution $(240 \mathrm{mM}), 1.5 \mathrm{~mL}$ catalyst (aniline or 5-methylindoline, stock solution $20 \mathrm{mM}$ ). For uncatalyzed gels $1.5 \mathrm{~mL}$ of phosphate buffer was added instead of the catalyst stock solution. Thus $3 \mathrm{~mL}$ solution containing $8 \mathrm{mM}$ acylhydrazide $\mathbf{H}, 48 \mathrm{mM}$ aldehyde A, $10 \mathrm{mM}$ catalyst was obtained. The solution was measured at $500 \mathrm{~nm}$ wavelength repeatedly for 10 seconds intervals. 
(a)

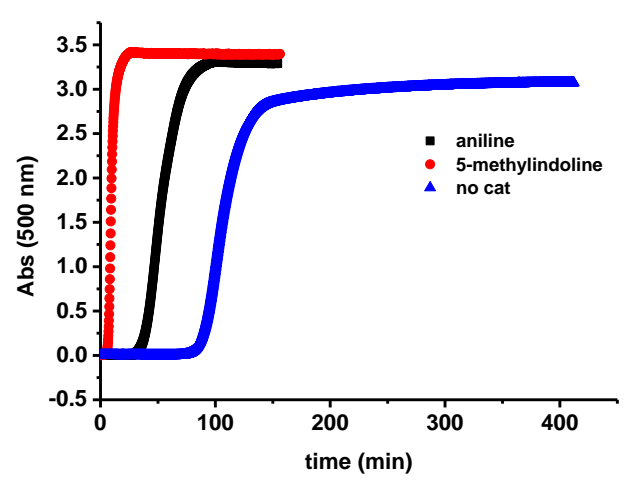

(b)

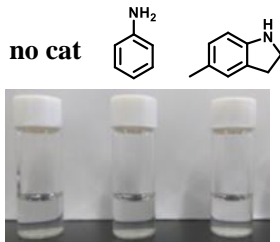

$\mathbf{t}=\mathbf{0}$ min

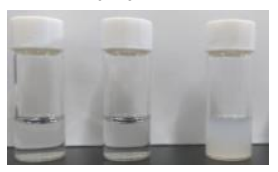

$t=15$ min

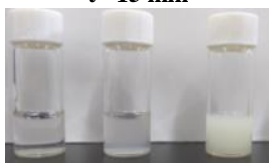

$\mathrm{t}=46 \mathrm{~min}$

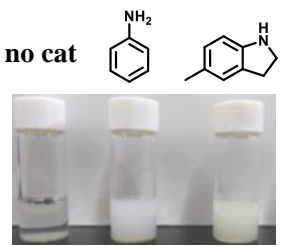

$\mathrm{t}=120 \mathrm{~min}$

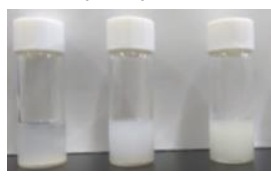

$t=230$ min

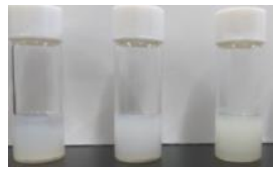

$t=324$ min

Figure S8. (a). Time-dependent turbidity measurements of trishydrazone hydrogelator formation at absorbance of $500 \mathrm{~nm}$ under phosphate buffer $(100 \mathrm{mM}, \mathrm{pH}=7.0)$ and appearance (b). Conditions: 8 $\mathrm{mM}$ acylhydrazide $\mathbf{H}, 48 \mathrm{mM}$ aldehyde $\mathbf{A}$, with or without $10 \mathrm{mM}$ catalyst (aniline or 5-methylindoline)

\section{Rheology of trishydrazone hydrogelator formation}

Oscillatory experiments were performed using a rheometer AR G2 from TA Instruments in a strain-controlled mode. The rheometer was equipped with a steel plate-and plate geometry of diameter $40 \mathrm{~mm}$ and a water trap. The temperature of the plates was controlled at $25 \pm 0.2^{\circ} \mathrm{C}$. All the stock solutions were prepared in phosphate buffer $100 \mathrm{mM} \mathrm{pH}=7.0$. The total volume for each gelation experiment was $0.6 \mathrm{~mL}$, adding $60 \mu \mathrm{L}$ of the phosphate buffer, $120 \mu \mathrm{L}$ of a $240 \mathrm{mM}$ stock solution of the aldehyde $\mathbf{A}, 120 \mu \mathrm{L}$ of a $40 \mathrm{mM}$ stock solution of the acylhydrazide $\mathbf{H}$ and $300 \mu \mathrm{L}$ of a $20 \mathrm{mM}$ stock solution of the catalyst (aniline or 5-methylindoline). Thus each solution contains $8 \mathrm{mM}$ acylhydrazide $\mathbf{H}, 48 \mathrm{mM}$ aldehyde A, $10 \mathrm{mM}$ catalyst. For uncatalyzed gels 300 $\mu \mathrm{L}$ of phosphate buffer was added instead of the catalyst stock solution. After stirring the vial by vortexing for $3 \mathrm{~s}$, the gel was pipetted on the bottom plate of the rheometer and the upper plate was slowly rotated to equally spread the gel. The storage and loss moduli $G$ ' and $G$ " were followed over time with the rheometer during the formation of the gel, setting up the instrument with a frequency of $1 \mathrm{~Hz}$ and under $0.1 \%$ strain. The measurements were stopped when no further increase of $G$ ' was observed. A frequency sweep was measured in the range of $0.01-100 \mathrm{rad} / \mathrm{s}$, confirming that the moduli are constant in the frequency range chosen and the strain sweep revealed that the applied strain percentage is in the linear strain regime. ${ }^{9}$ 


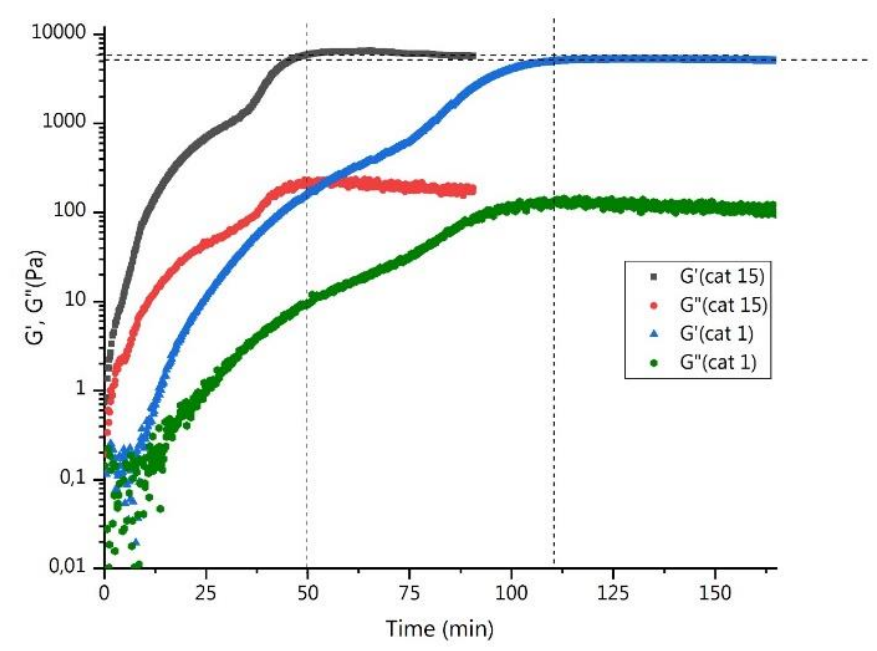

Figure S9. Time-dependent rheology gel formation over time. $G^{\prime}$ and $G^{\prime \prime}$ for aniline-catalyzed gel (blue and green line, respectively) and $G$ ' and $G$ " for 5-methylindoline-catalyzed gel (black and red line, respectively) are plotted. The gelation time (vertical dashed lines) was considered as the moment the $G$ 'value measures $95 \%$ of the plateau value (horizontal dashed lines).

\section{Inverted tube tests of catalytic hydrogelator formation}

9.1 Inverted tube tests of catalytic trishydrazone hydrogelator formation ( $48 \mathrm{mM}$ aldehyde $\mathrm{A}$, $8 \mathrm{mM}$ acylhydrazide $\mathrm{H}, 10 \mathrm{mM}$ catalyst)

All the stock solutions were prepared in sodium phosphate buffer $100 \mathrm{mM} \mathrm{pH}=7.0$. The total volume for each gelation experiment was $0.2 \mathrm{~mL}$ in a $1.5 \mathrm{~mL}$ vial, adding $20 \mu \mathrm{L}$ of the phosphate buffer, $40 \mu \mathrm{L}$ of a $240 \mathrm{mM}$ stock solution of the aldehyde $\mathrm{A}, 40 \mu \mathrm{L}$ of a $40 \mathrm{mM}$ stock solution of the acylhydrazide $\mathbf{H}$ and $100 \mu \mathrm{L}$ of a $20 \mathrm{mM}$ stock solution of the catalyst. Thus each solution contains $8 \mathrm{mM}$ acylhydrazide $\mathbf{H}, 48 \mathrm{mM}$ aldehyde $\mathbf{A}$ and $10 \mathrm{mM}$ catalyst. For uncatalyzed gels $100 \mu \mathrm{L}$ of phosphate buffer was added instead of the catalyst stock solution. Each vial was stirred by vortexing for $3 \mathrm{~s}$, capped, placed on a stable surface and left undisturbed for the selected time. The gelation of the uncatalyzed, aniline-catalyzed and 5-methylindoline-catalyzed sample were run in parallel, and the three vials were turned upside-down simultaneously to evaluate the formation of the gel.

\subsection{Inverted tube tests of catalytic trishydrazone hydrogelator formation (120 $\mathrm{mM}$ aldehyde}

\section{A, $20 \mathrm{mM}$ acylhydrazide $\mathrm{H}, 10 \mathrm{mM}$ catalyst)}

The 5-methylindoline catalyzed and the uncatalyzed gelation were carried in parallel in $1.5 \mathrm{~mL}$ vials. All the stock solutions were prepared in sodium phosphate buffer $100 \mathrm{mM} \mathrm{pH}=7.0$. To each vial $125 \mu \mathrm{L}$ of a $480 \mathrm{mM}$ stock solution of aldehyde $\mathrm{A}, 167 \mu \mathrm{L}$ of a $60 \mathrm{mM}$ stock solution of the acylhydrazide $\mathbf{H}, 208 \mu \mathrm{L}$ of a $24 \mathrm{mM}$ stock solution of 5-methylindoline were added. Thus, 0.5 $\mathrm{mL}$ solution containing $20 \mathrm{mM}$ acylhydrazide $\mathbf{H}, 120 \mathrm{mM}$ aldehyde A, $10 \mathrm{mM}$ catalyst was obtained. For uncatalyzed gels $208 \mu \mathrm{L}$ of sodium phosphate buffer $(100 \mathrm{mM} \mathrm{pH}=7.0)$ was added instead of the catalyst stock solution. The vials were capped, shacked by vortexing for $3 \mathrm{~s}$, placed on a stable surface and left undisturbed for the selected time. 


\subsection{Inverted tube tests of catalytic trishydrazone hydrogelator formation with sulfonate}

aldehyde $\mathrm{AS}$ in phosphate buffer $(120 \mathrm{mM}$ aldehyde $\mathrm{A}, 20 \mathrm{mM}$ acylhydrazide $\mathrm{H}, 10 \mathrm{mM}$ catalyst)

The 5-methylindoline catalyzed and the uncatalyzed gelation were carried in parallel in $1.5 \mathrm{~mL}$ vials. All stock solutions were prepared in sodium phosphate buffer $100 \mathrm{mM} \mathrm{pH}=7.0$. To each vial $125 \mu \mathrm{L}$ of a $480 \mathrm{mM}$ stock solution of aldehyde (aldehyde A with $30 \mathrm{~mol} \%$ sulfonate-aldehyde AS), $167 \mu \mathrm{L}$ of a $60 \mathrm{mM}$ stock solution of the acylhydrazide $\mathbf{H}, 208 \mu \mathrm{L}$ of 24 $\mathrm{mM}$ stock solution of 5-methylindoline were added. Thus, $0.5 \mathrm{~mL}$ solution containing $20 \mathrm{mM}$ acylhydrazide H, $120 \mathrm{mM}$ aldehyde (aldehyde A, $30 \mathrm{~mol} \%$ sulfonate-aldehyde AS), $10 \mathrm{mM}$ catalyst was obtained. For uncatalyzed gels $208 \mu \mathrm{L}$ of sodium phosphate buffer $(100 \mathrm{mM} \mathrm{pH}=7.0)$ was added instead of the catalyst stock solution. The vials were capped, shacked by vortexing for $3 \mathrm{~s}$, placed on a stable surface and left undisturbed for the selected time.

Time for

5-methylindoline-catalyzed gelation (h)
Time for aniline-catalyzed gelation (h)

Time for uncatalyzed gelation (h)

\begin{tabular}{l|ccc} 
Gelation (9.1) & 2.0 & 4.0 & $>8.0$ \\
Gelation (9.2) & 2.0 & 3.0 & 8.0 \\
Gelation (9.3) & 1.5 & - & 6.0
\end{tabular}

Table S2. Overview of the times for the trishydrazone hydrogelator formation with different compositions, concentrations and catalysts.

(a)

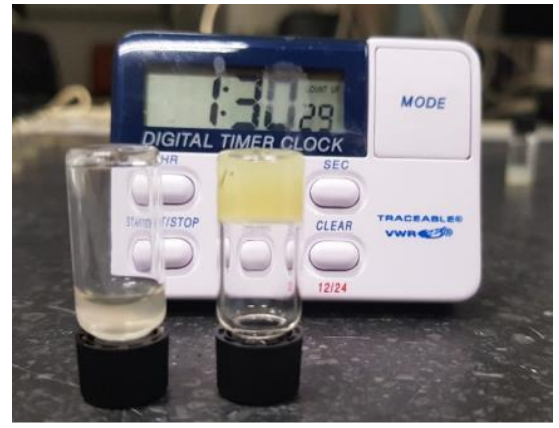

(b)

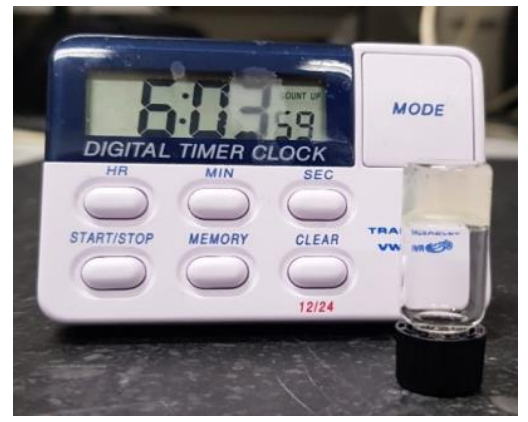

Figure S10. (a) Inverted vials after $1.5 \mathrm{~h}$ of uncatalyzed gelation (on the left) and 5-methylindoline catalyzed gelation (on the right); (b) Inverted vial after $6.0 \mathrm{~h}$ of uncatalyzed gelation. Conditions: 20 $\mathrm{mM}$ acylhydrazide $\mathbf{H}, 120 \mathrm{mM}$ aldehyde A, sulfonate aldehyde AS (30 mol \%), $10 \mathrm{mM}$ 5 -methylindoline catalyst (for the catalyzed reaction) in phosphate buffer $100 \mathrm{mM} \mathrm{pH=7.0.}$

\section{Reference}

1. Larsen, D.; Pittelkow, M.; Karmakar, S.; Kool, E. T., New Organocatalyst Scaffolds with High Activity in Promoting Hydrazone and Oxime Formation at Neutral pH. Org. Lett. 2015, 17, 274.

2. (a) Kool, E. T.; Park, D.-H.; Crisalli, P., Fast Hydrazone Reactants: Electronic and Acid/Base Effects Strongly Influence Rate at Biological pH. J. Am. Chem. Soc. 2013, 135, 17663. (b) Hemalatha, M. R. K.; Noorbatcha, I. An Undergraduate Physical Chemistry Experiment on the Analysis of First-Order Kinetic Data. J. Chem. Educ. 1997, 74, 972-974. 
3. Aubry, C.; Wilson, A. J.; Emmerson, D.; Murphy, E.; Chan, Y. Y.; Dickens, M. P.; García, M. D.; Jenkins, P. R.; Mahale, S.; Chaudhuri, B. Fascaplysin-inspired diindolyls as selective inhibitors of CDK4/cyclin D1. Bioorg. Med. Chem. 2009, 17, 6073.

4. Crisalli, P.; Kool, E. T., Importance of ortho Proton Donors in Catalysis of Hydrazone Formation. Org. Lett. 2013, 15, 1646.

5. van Dijken, D. J.; Kovaříček, P.; Ihrig, S. P.; Hecht, S., Acylhydrazones as Widely Tunable Photoswitches. J. Am. Chem. Soc. 2015, 137, 14982.

6. Boekhoven, J.; Poolman, J. M.; Maity, C.; Li, F.; van der Mee, L.; Minkenberg, C. B.; Mendes, E.; van Esch, J. H.; Eelkema, R., Catalytic control over supramolecular gel formation. Nat. Chem. 2013, 5, 433.

7. Leigh, D. A.; Thomson, A. R. An ammonium/bis-ammonium switchable molecular shuttle. Tetrahedron 2008 $64,8411$.

8. Uzun, O.; Hu, Y.; Verma, A.; Chen, S.; Centrone, A.; Stellacci, F. Water-soluble amphiphilic gold nanoparticles with structured ligand shells. Chem. Commun. 2008, 196.

9. Poolman, J. M.; Boekhoven, J.; Besselink, A.; Olive, A. G.; van Esch, J. H.; Eelkema, R. Variable gelation time and stiffness of low-molecular-weight hydrogels through catalytic control over self-assembly. Nat Protoc. 2014, 9, 977. 


\section{1. ${ }^{1} \mathrm{H}-\mathrm{NMR}$ and ${ }^{13} \mathrm{C}$-NMR spectra for synthesized compounds.}

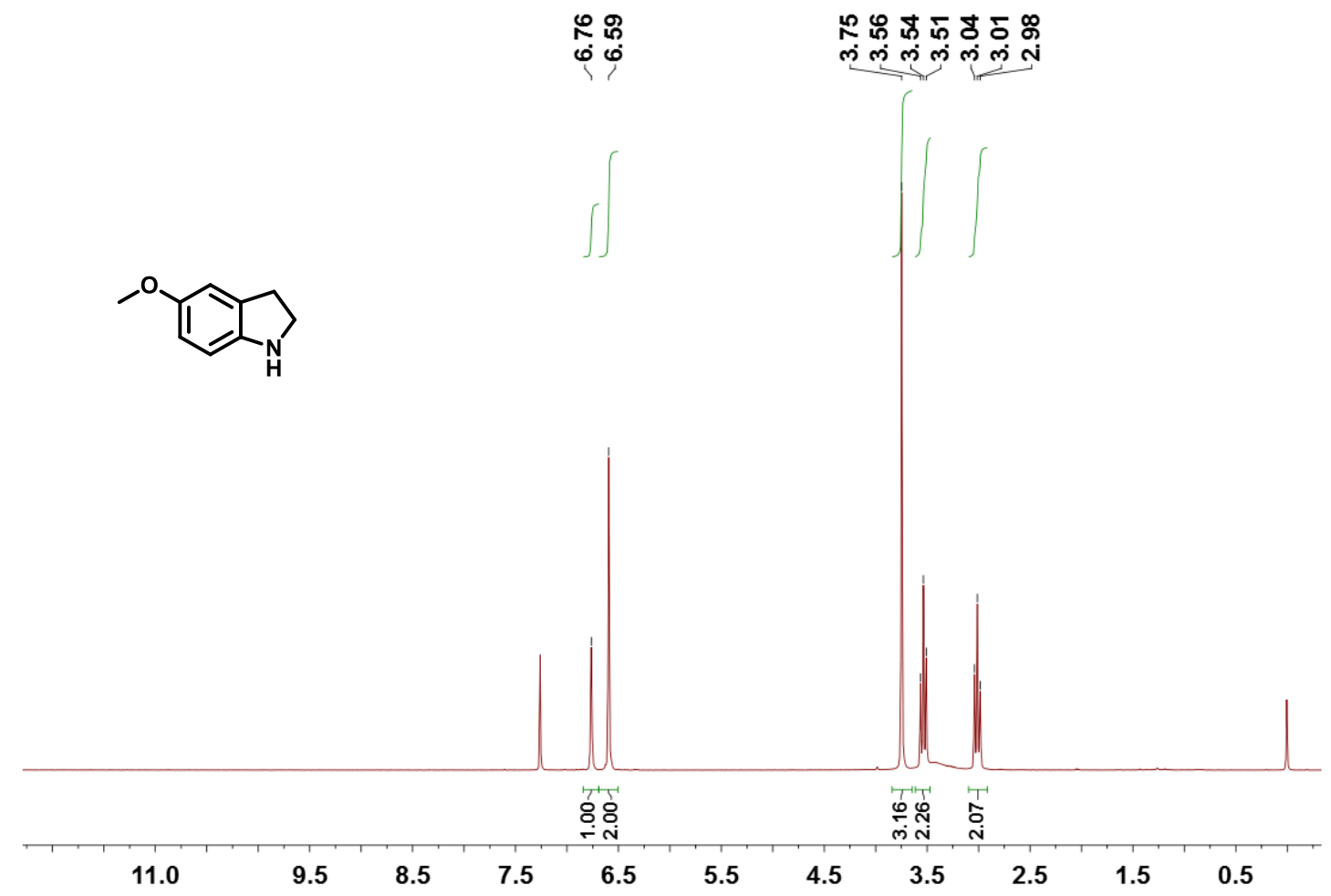

${ }^{1} \mathrm{H}$ NMR spectra $(300 \mathrm{MHz})$ of 5-methoxylindoline in $\mathrm{CDCl}_{3}$.

\begin{tabular}{|c|c|c|c|c|c|}
\hline 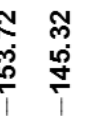 & $\frac{\text { m}}{\stackrel{m}{m}}$ & 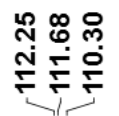 & 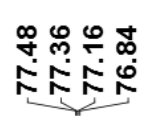 & 웅 & \\
\hline
\end{tabular}

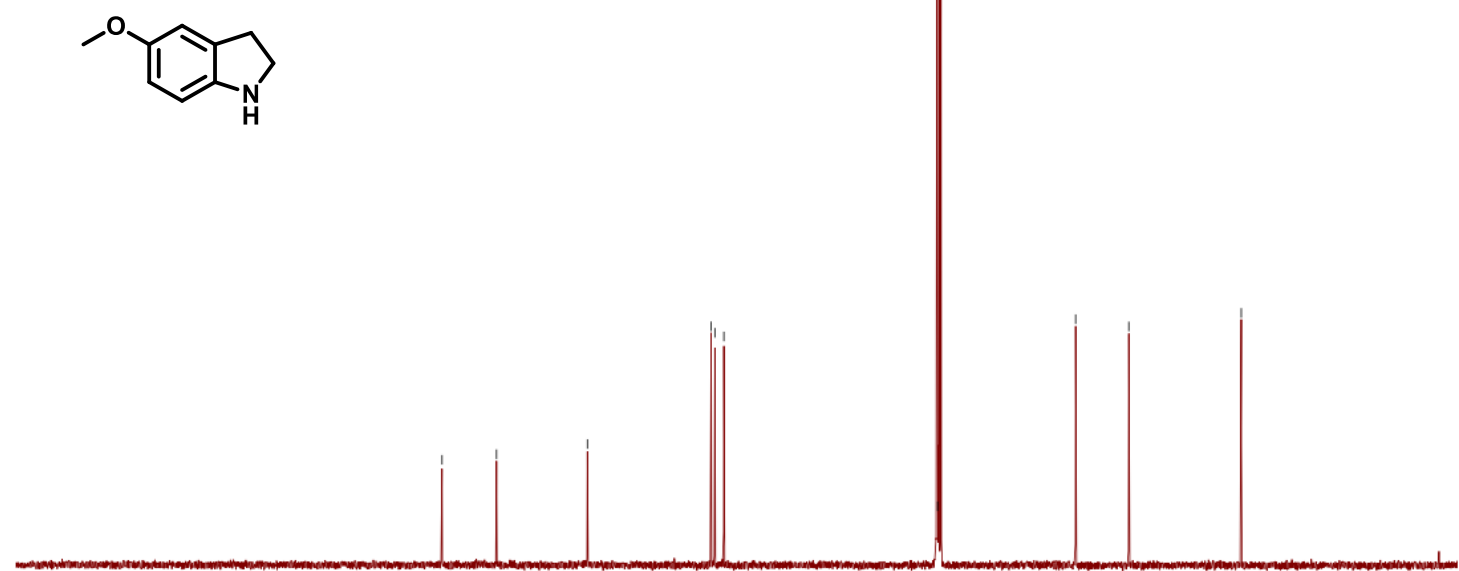

$\begin{array}{lllllllllllllllllllll}210 & 190 & 170 & 150 & 130 & 110 & 90 & 80 & 70 & 60 & 50 & 40 & 30 & 20 & 10 & 0\end{array}$

${ }^{13} \mathrm{C}$ NMR spectra $(75 \mathrm{MHz})$ of 5-methoxylindoline in $\mathrm{CDCl}_{3}$. 


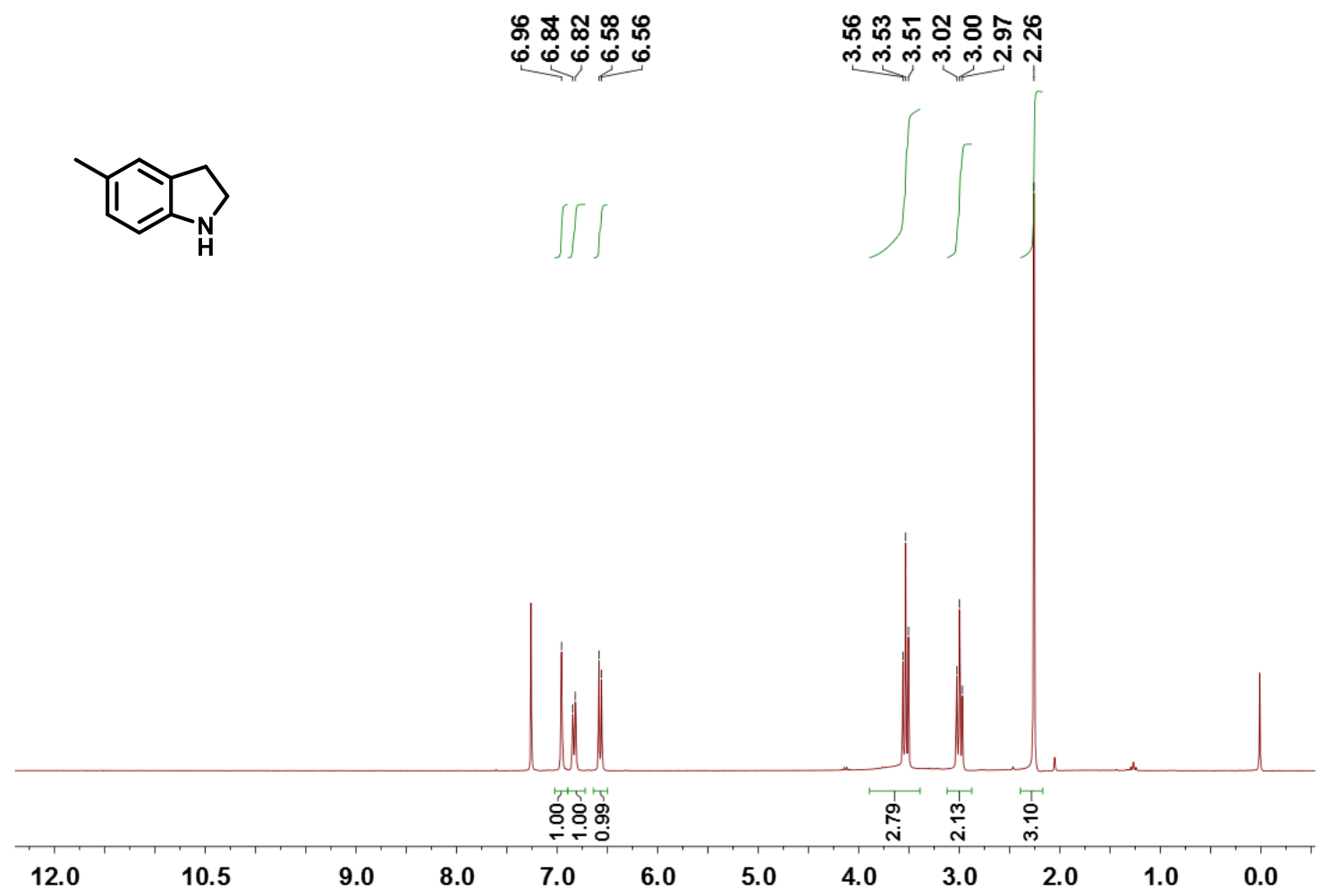

${ }^{1} \mathrm{H}$ NMR spectra $(300 \mathrm{MHz})$ of 5-methylindoline in $\mathrm{CDCl}_{3}$.

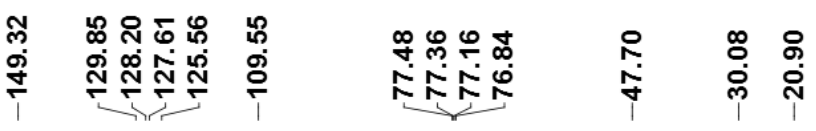<smiles>Cc1ccc2c(c1)CCN2</smiles>

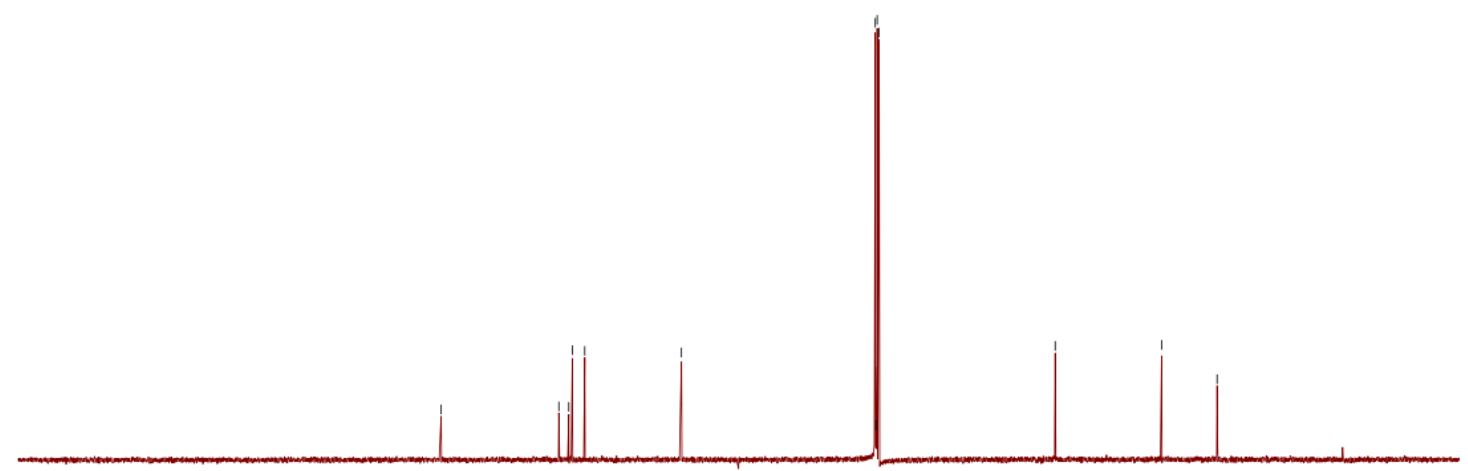

$160 \quad 140$ 120
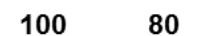

60

40

20

${ }^{13} \mathrm{C}$ NMR spectra $(75 \mathrm{MHz})$ of 5-methylindoline in $\mathrm{CDCl}_{3}$. 


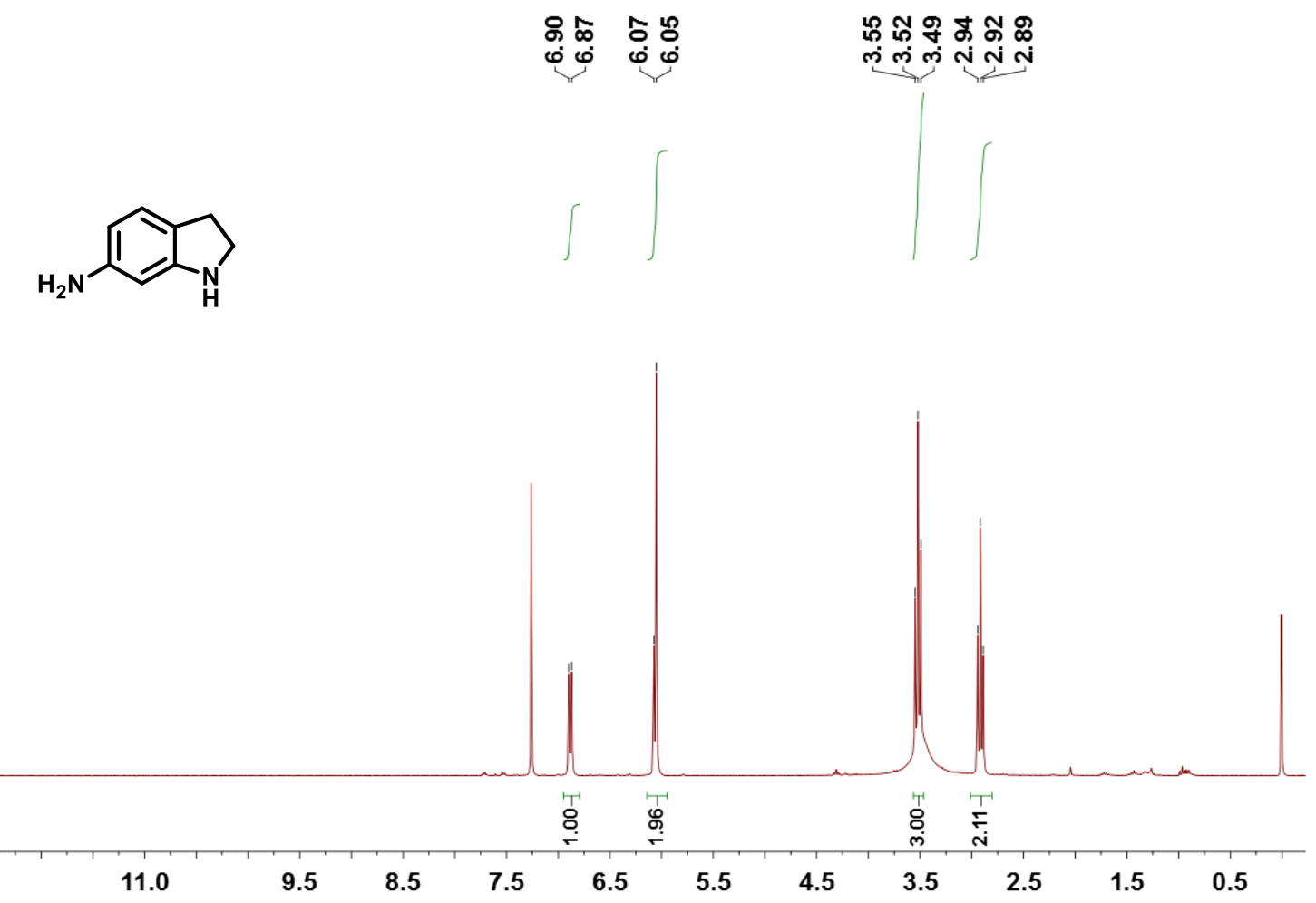

${ }^{1} \mathrm{H}$ NMR spectra $(300 \mathrm{MHz})$ of indolin-6-amine in $\mathrm{CDCl}_{3}$.

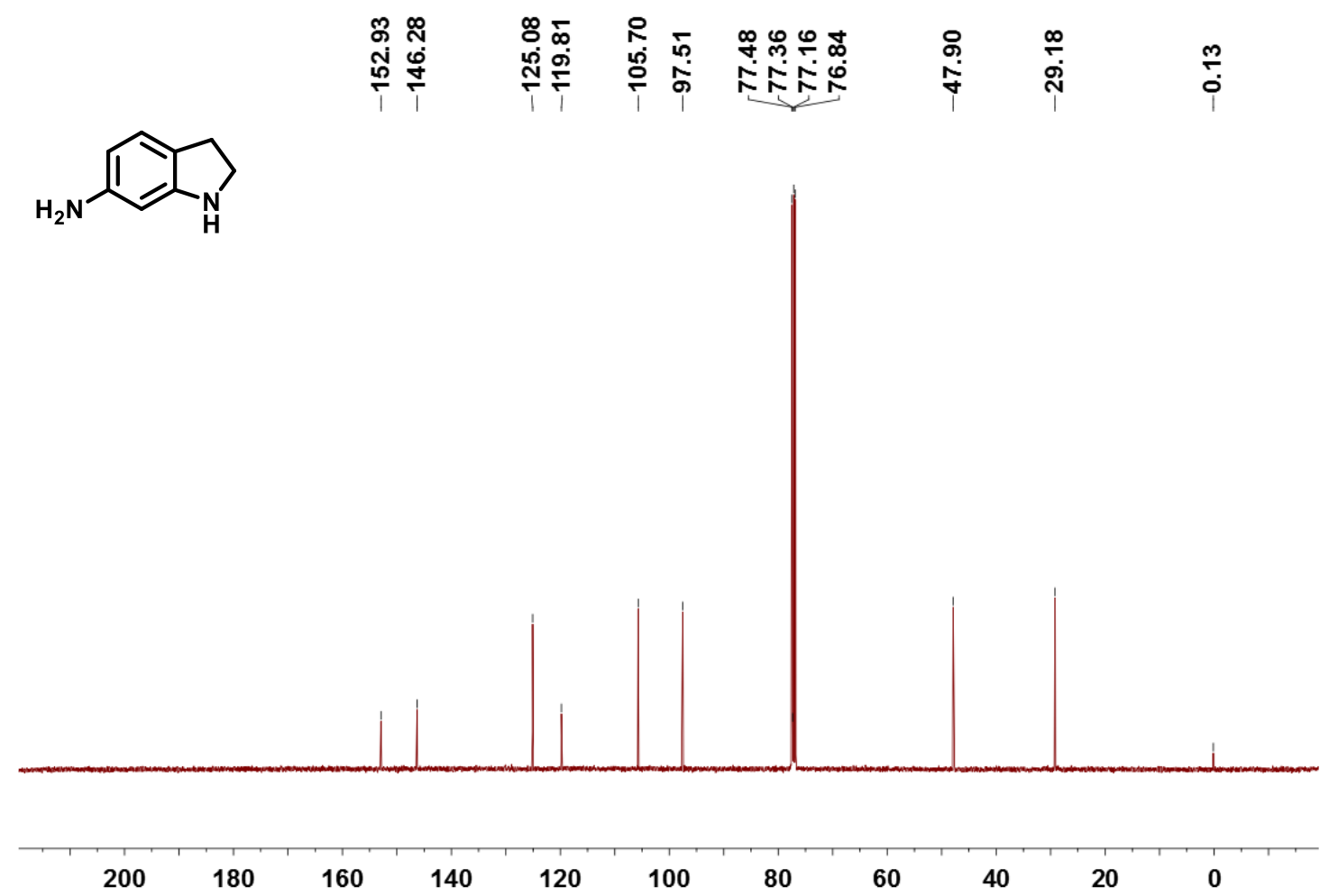

${ }^{13} \mathrm{C}$ NMR spectra $\left(75 \mathrm{MHz}\right.$ ) of indolin-6-amine in $\mathrm{CDCl}_{3}$. 

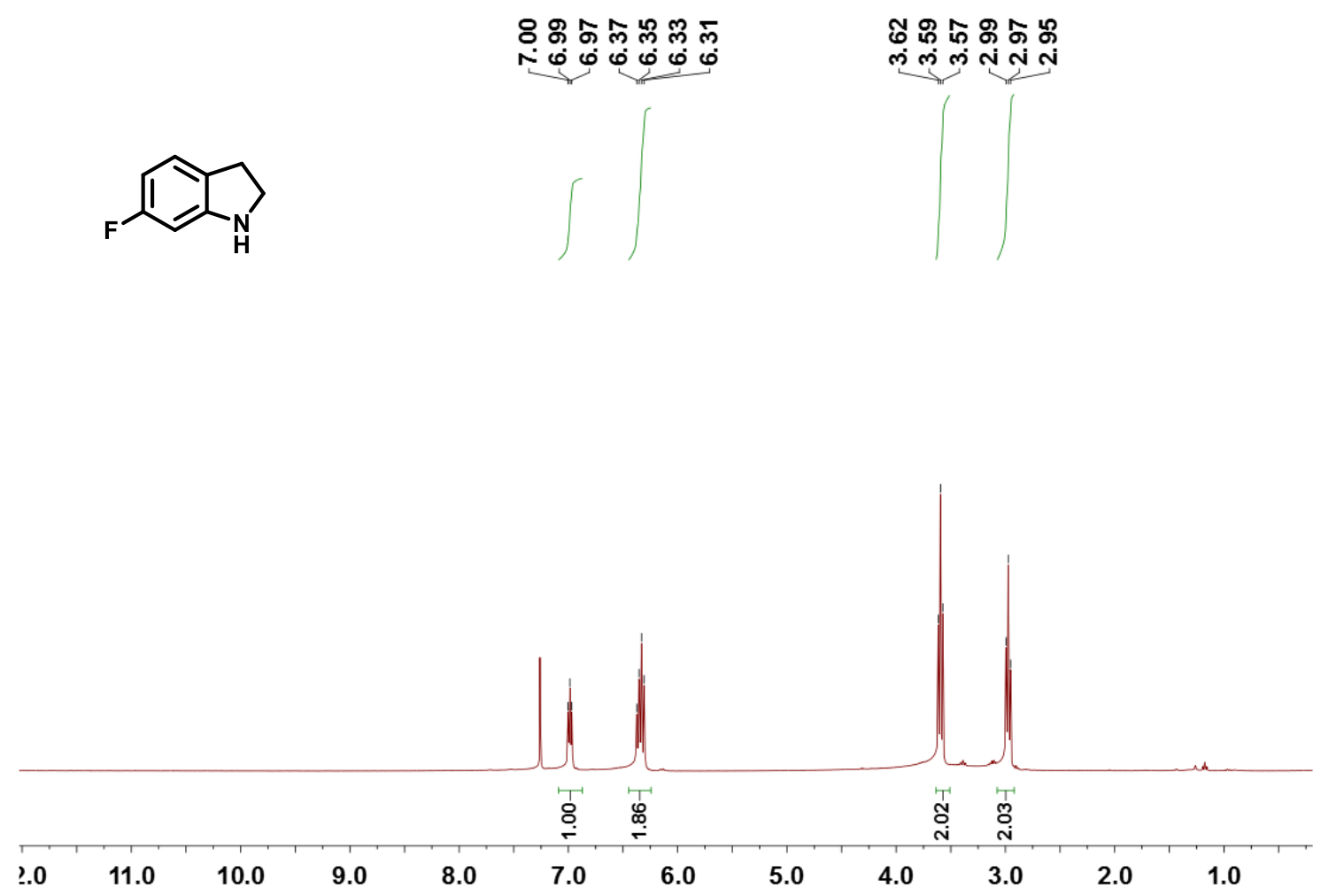

${ }^{1} \mathrm{H}$ NMR spectra (400 MHz) of 6-fluoroindoline in $\mathrm{CDCl}_{3}$.

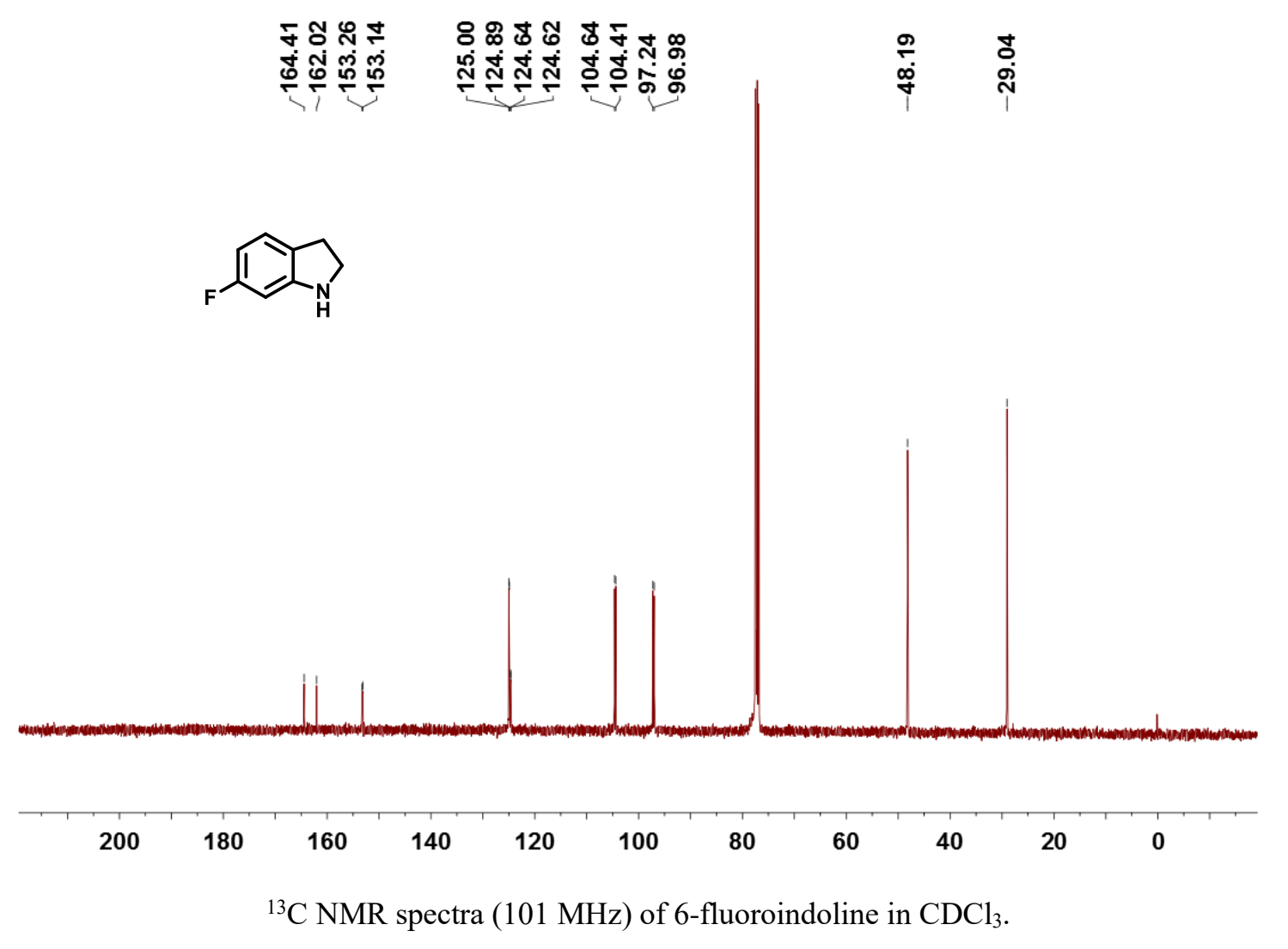


$\underbrace{}_{\mathrm{H}}$
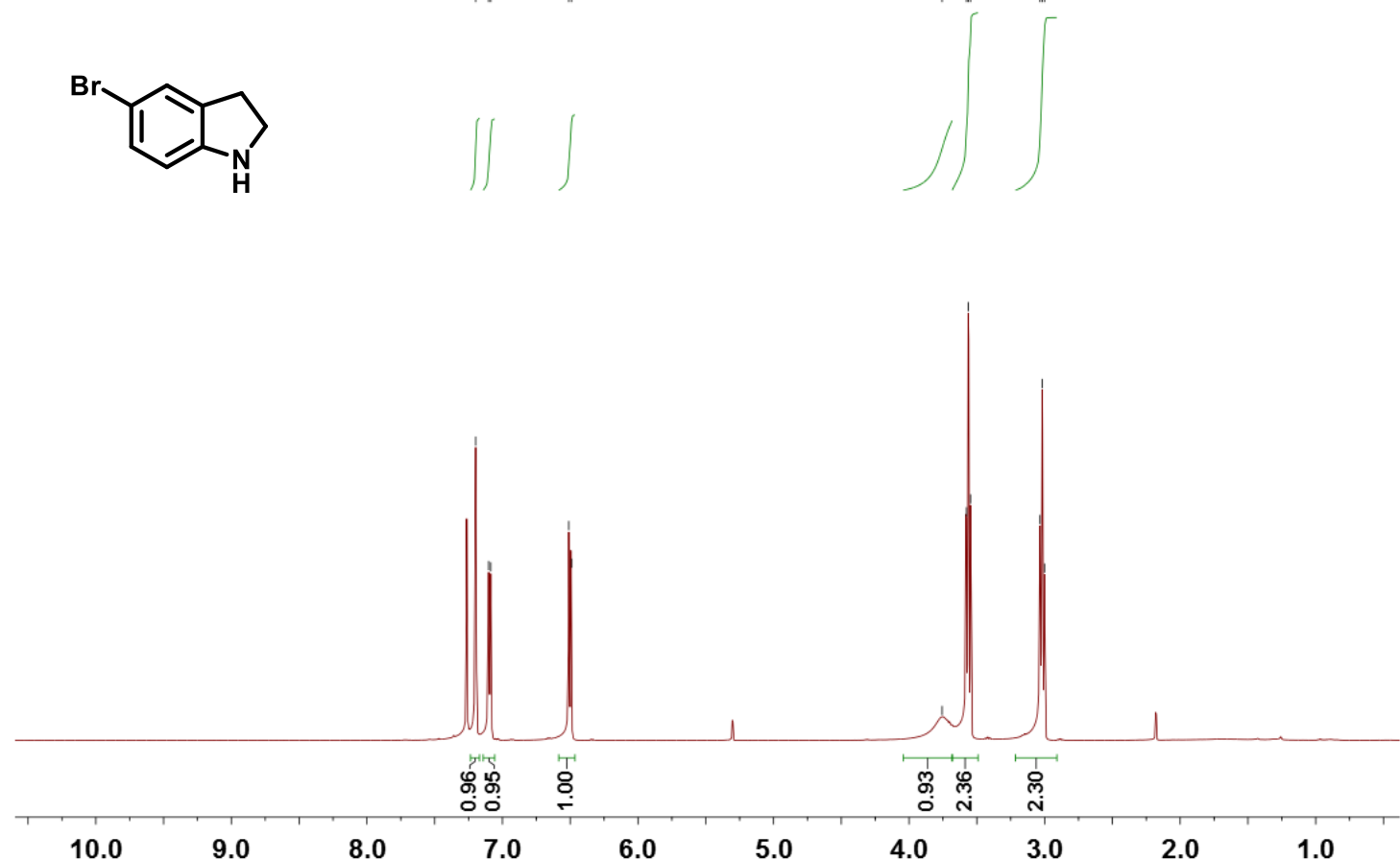

${ }^{1} \mathrm{H}$ NMR spectra $(500 \mathrm{MHz})$ of 5-bromoindoline in $\mathrm{CDCl}_{3}$.

\begin{tabular}{|c|c|c|c|c|}
\hline 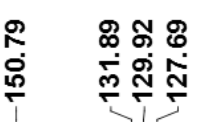 & 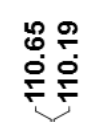 & 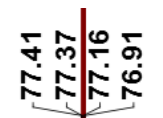 & $\stackrel{+}{\frac{j}{5}}$ & 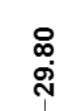 \\
\hline
\end{tabular}<smiles>Brc1ccc2c(c1)CCN2</smiles>

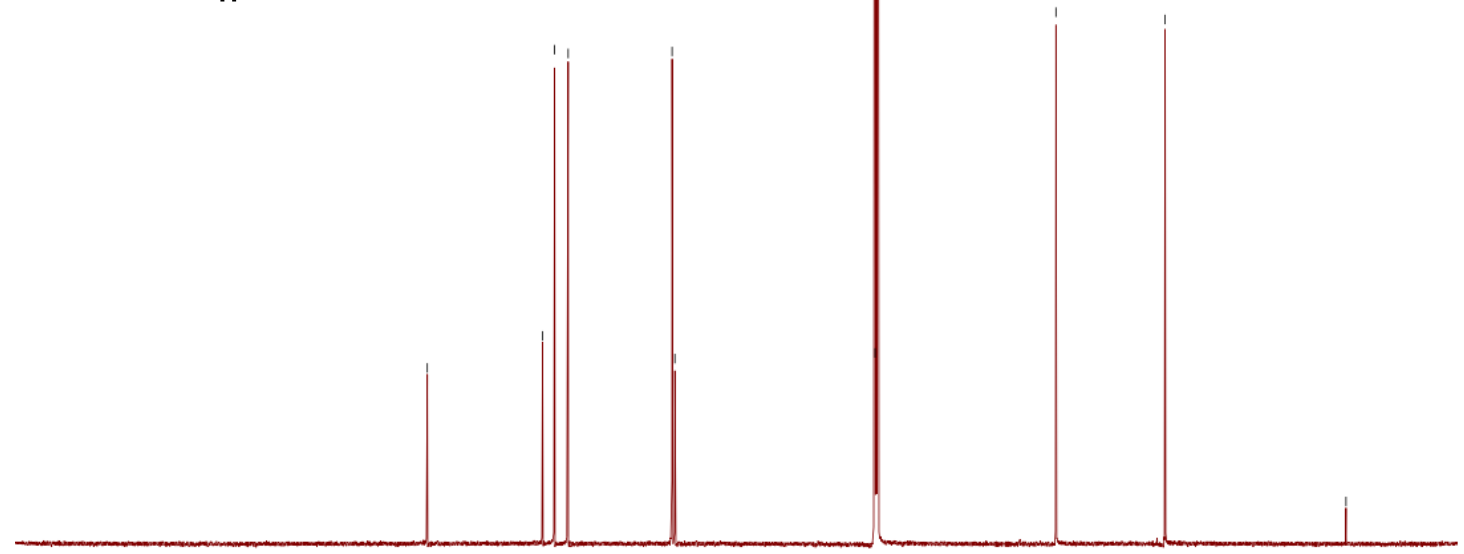

200

180

$160 \quad 140 \quad 120$

100

60

40

20

${ }^{13} \mathrm{C} \mathrm{NMR}$ spectra $(126 \mathrm{MHz})$ of 5-bromoindoline in $\mathrm{CDCl}_{3}$. 


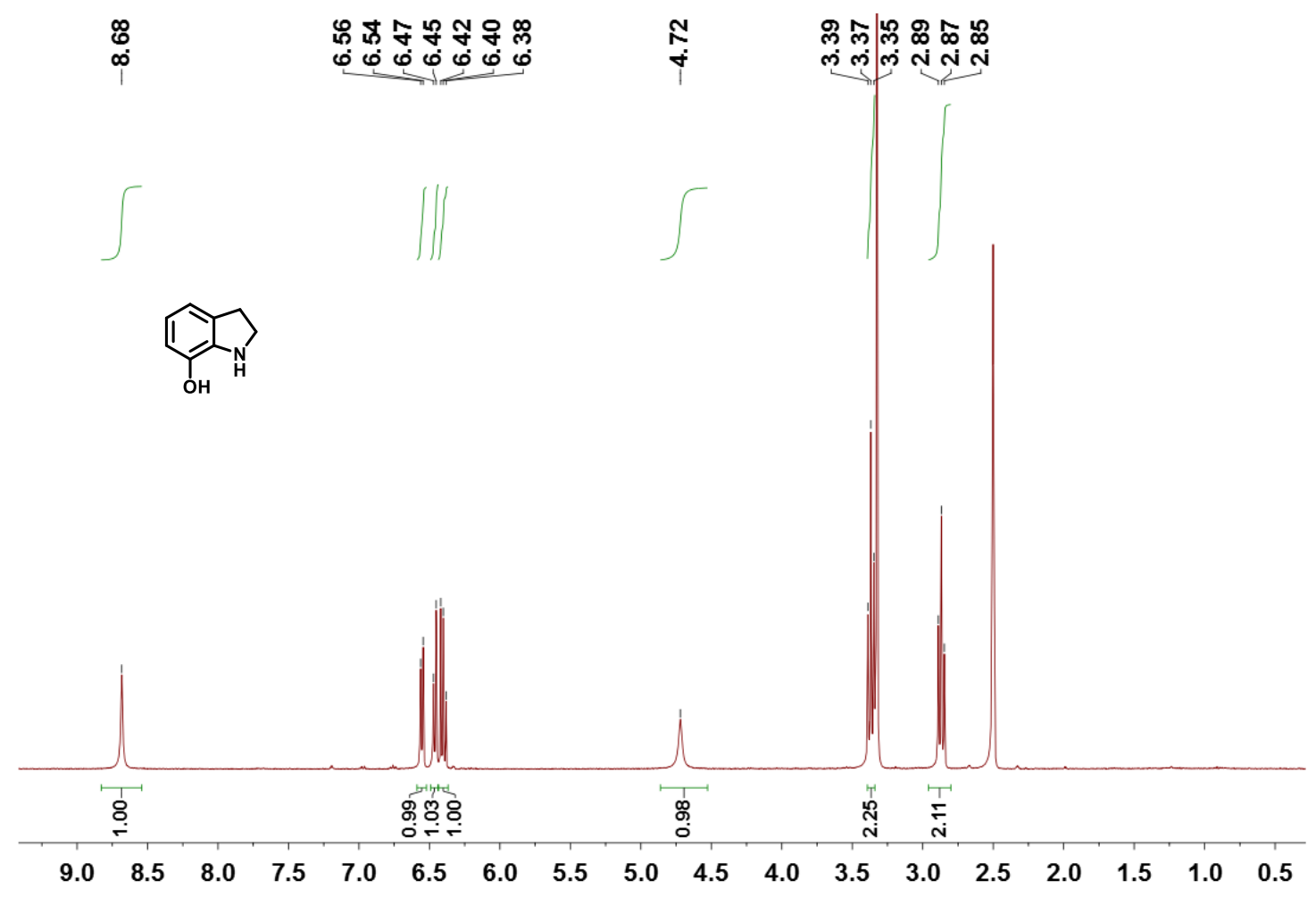

${ }^{1} \mathrm{H}$ NMR spectra $(400 \mathrm{MHz})$ of indolin-7-ol in DMSO- $d_{6}$.
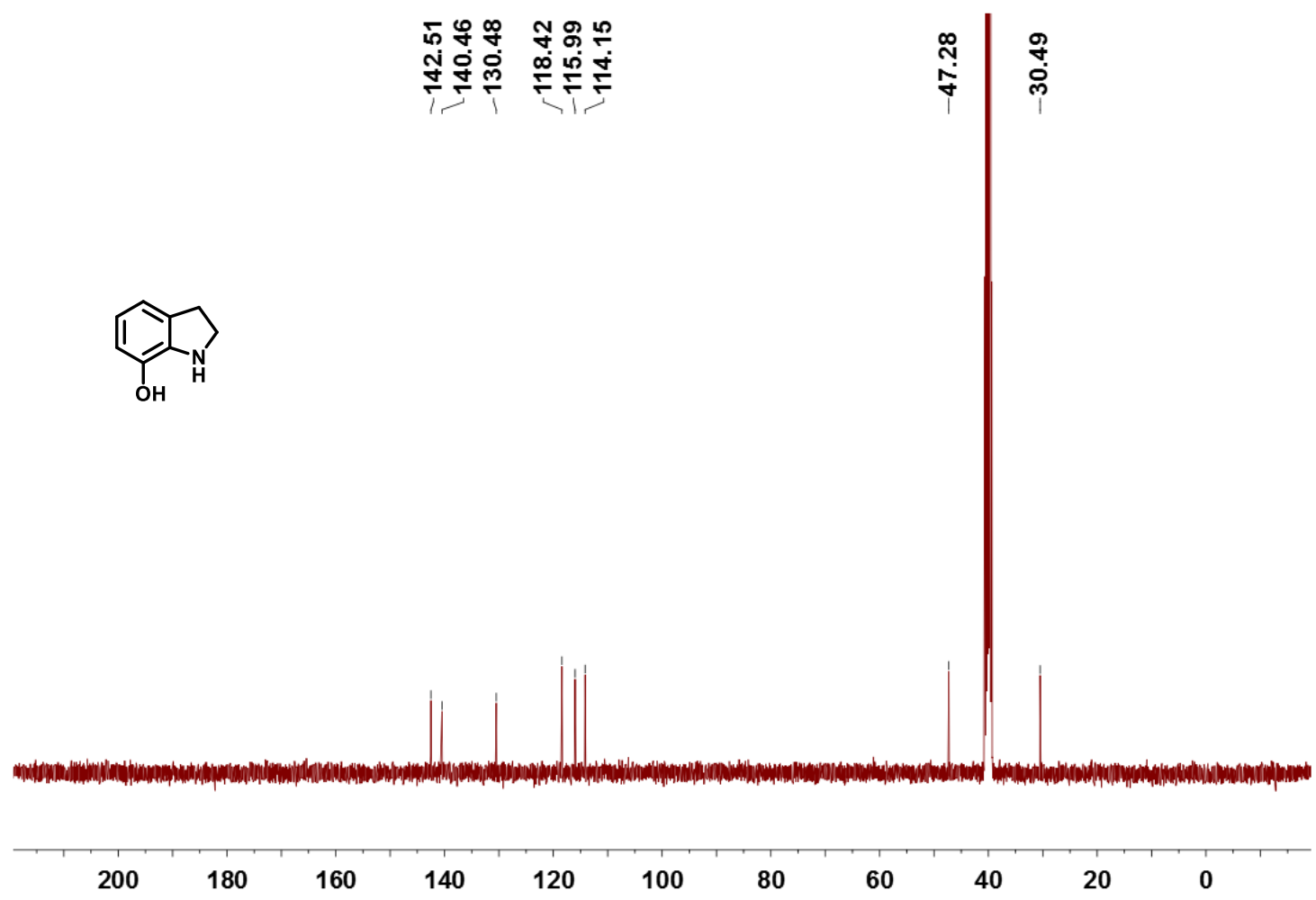

${ }^{13} \mathrm{C}$ NMR spectra (101 MHz) of indolin-7-ol in DMSO- $d_{6}$. 

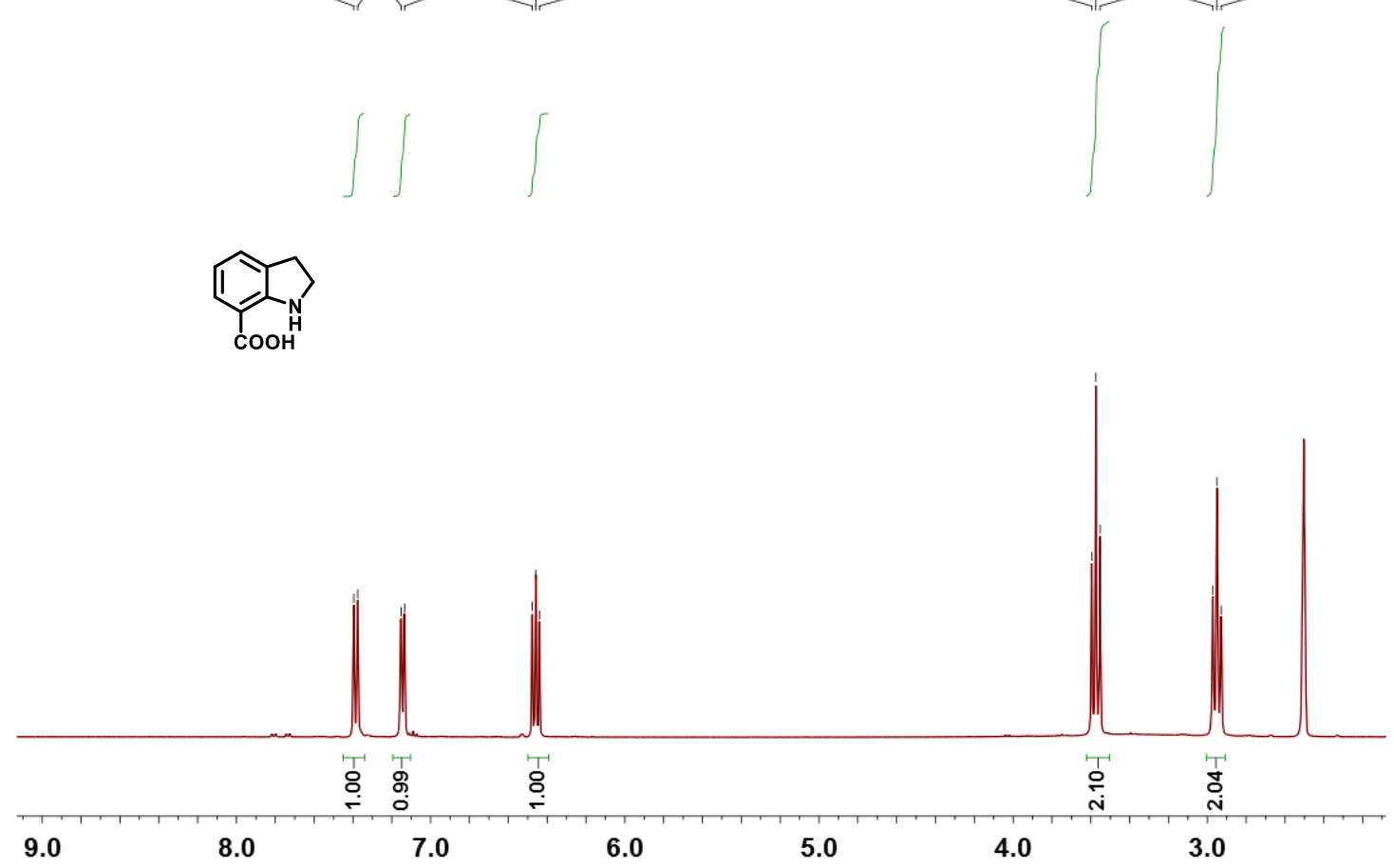

${ }^{1} \mathrm{H}$ NMR spectra $(400 \mathrm{MHz})$ of indoline-7-carboxylic acid in DMSO- $d_{6}$.
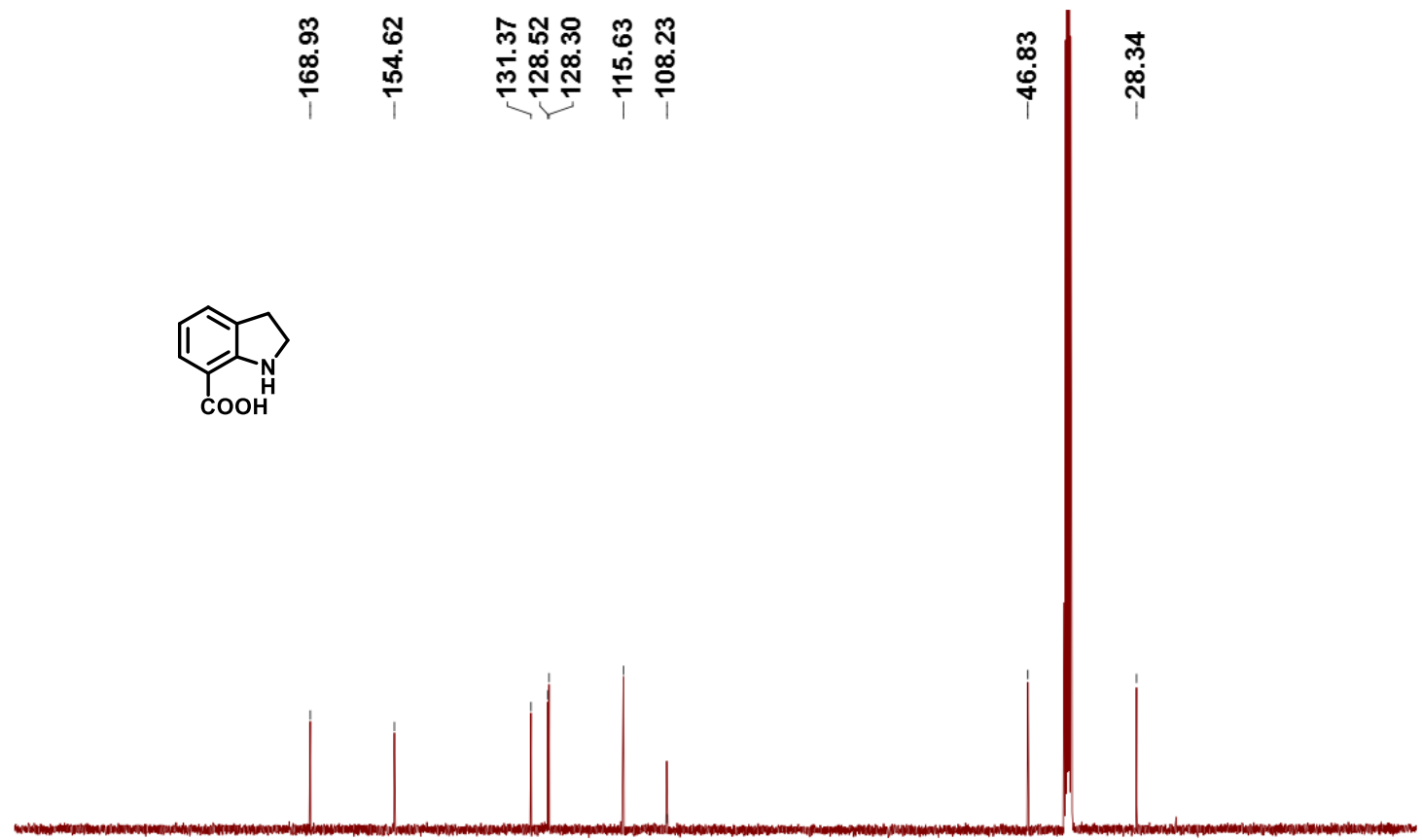

${ }^{13} \mathrm{C}$ NMR spectra $(101 \mathrm{MHz})$ of indoline-7-carboxylic acid in DMSO- $d_{6}$. 


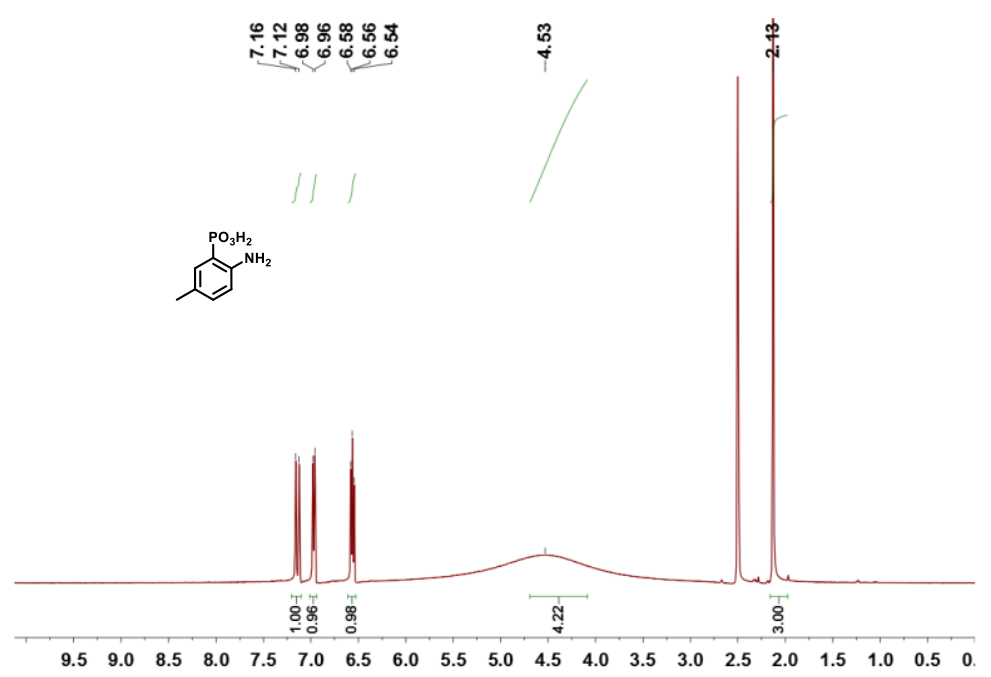

${ }^{1} \mathrm{H}$ NMR spectra (400 MHz) of 5-methyl-2-aminobenzene phosphonic acid in DMSO- $d_{6}$. $\stackrel{8}{\circ}$

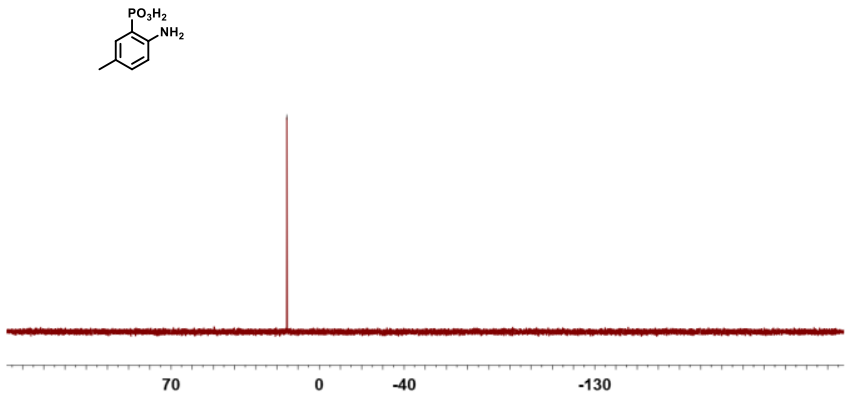

${ }^{31} \mathrm{P}$ NMR spectra (162 MHz) of 5-methyl-2-aminobenzene phosphonic acid in DMSO- $d_{6}$.

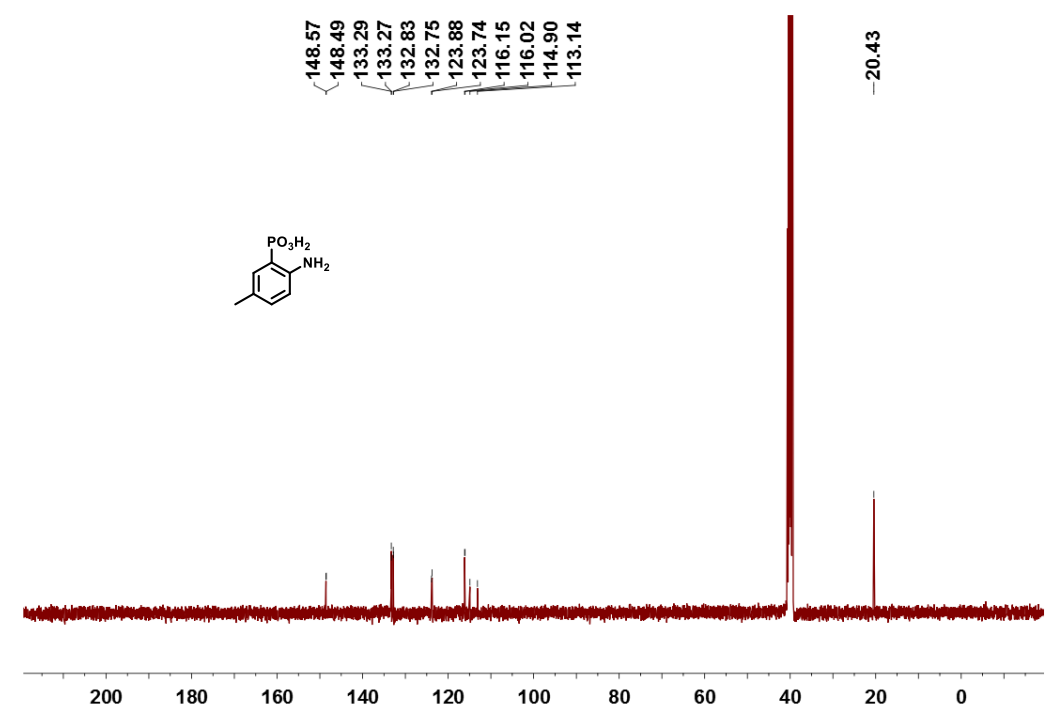

${ }^{13} \mathrm{C}$ NMR spectra (101 MHz) of 5-methyl-2-aminobenzene phosphonic acid in DMSO- $d_{6}$. 


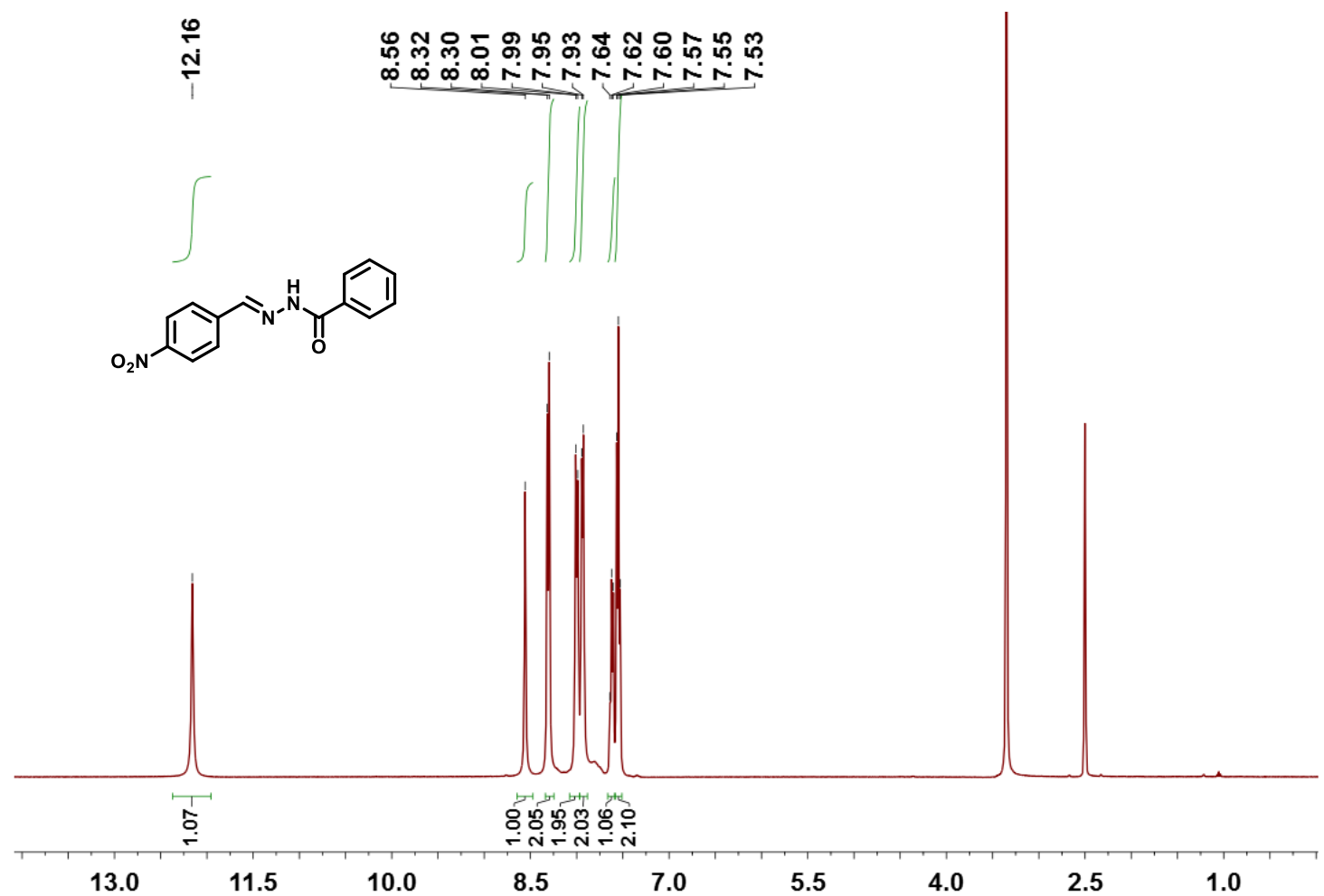

${ }^{1} \mathrm{H}$ NMR spectra (400 MHz) of (4-nitrobenzylidene)benzohydrazide 1 in DMSO- $d_{6}$.

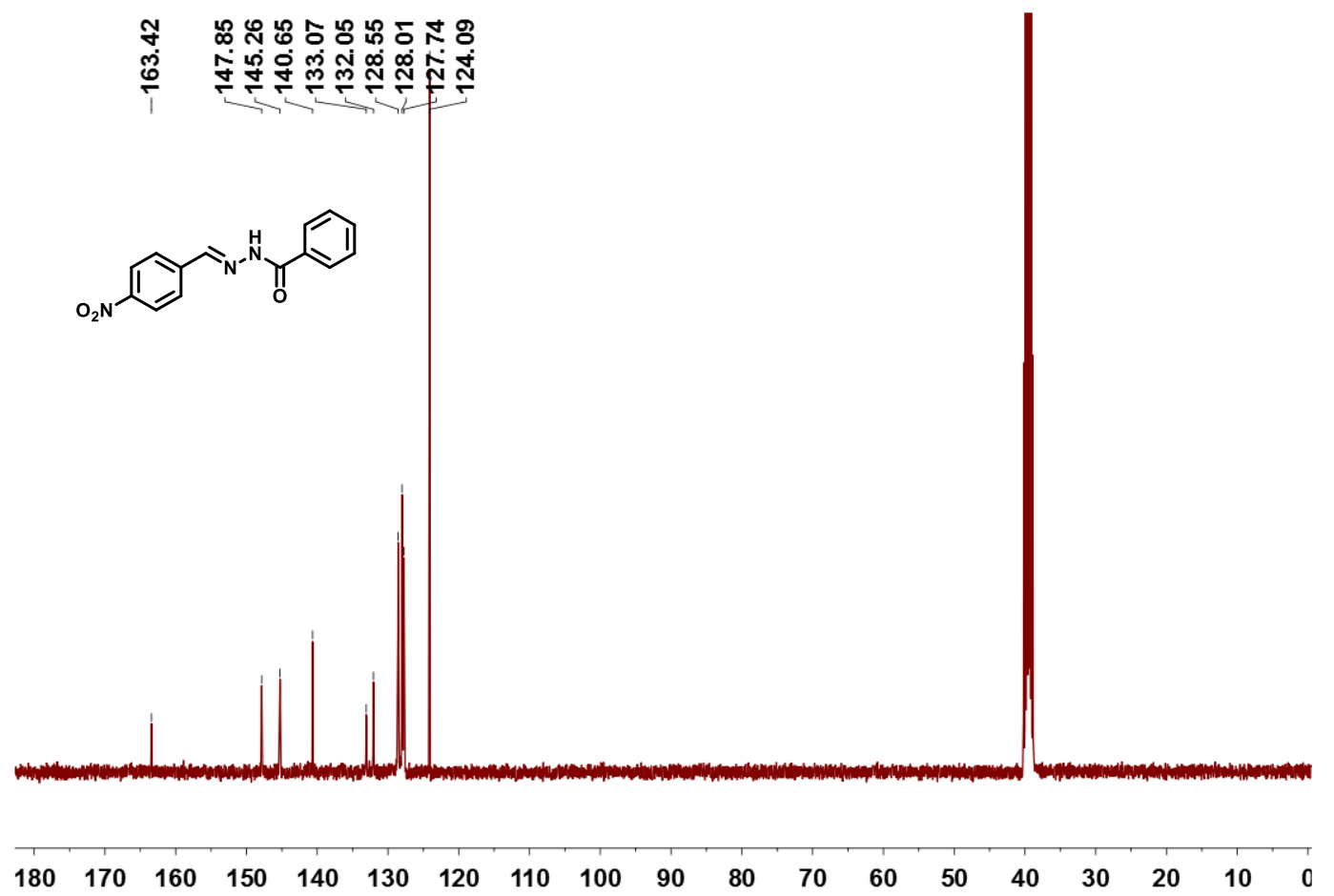

${ }^{13} \mathrm{C}$ NMR spectra $(101 \mathrm{MHz})$ of (4-nitrobenzylidene)benzohydrazide 1 in DMSO- $d_{6}$. 


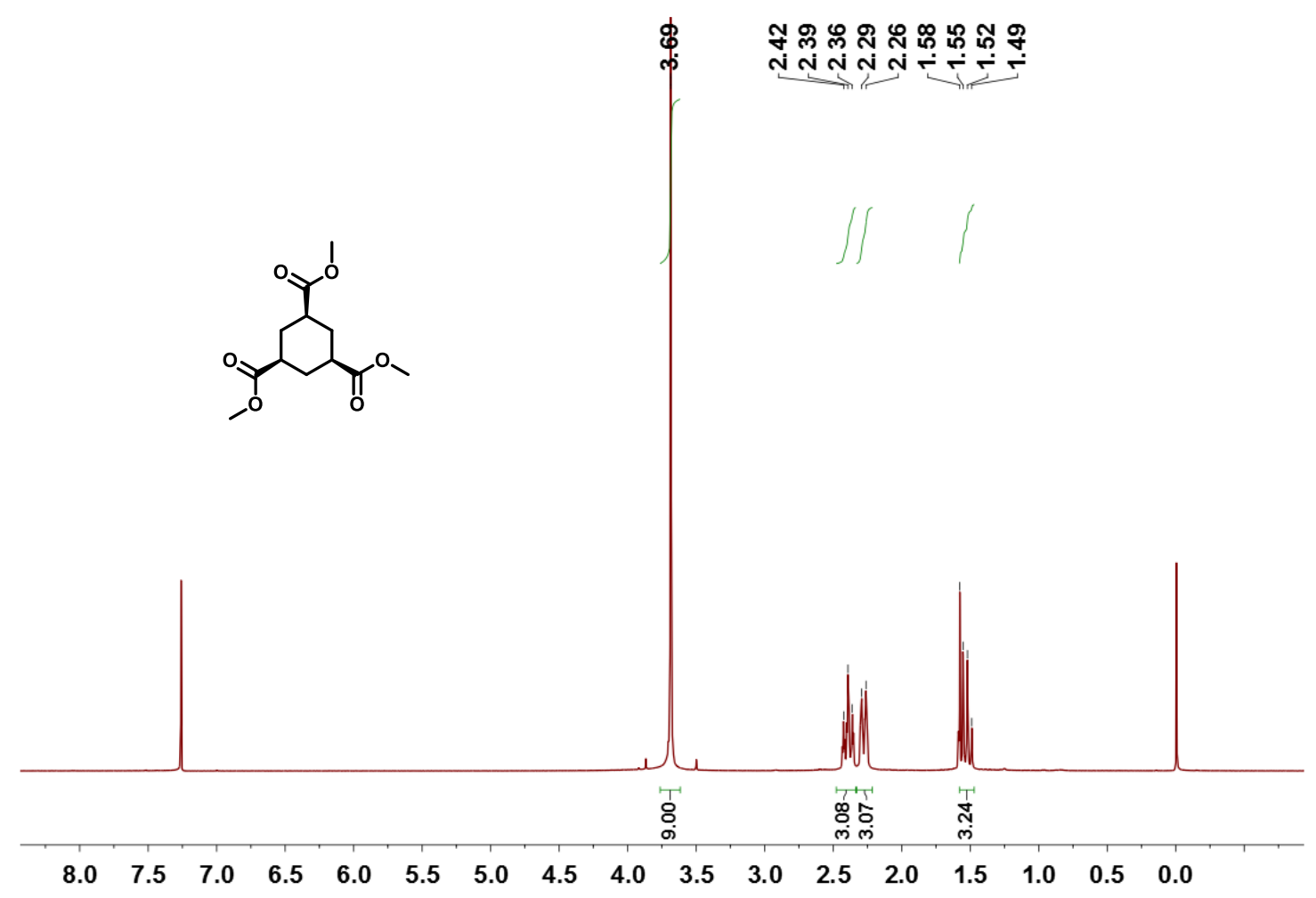

${ }^{1} \mathrm{H}$ NMR spectra (400 MHz) of trimethyl-cyclohexane-1,3,5-tricarboxylate in $\mathrm{CDCl}_{3}$.

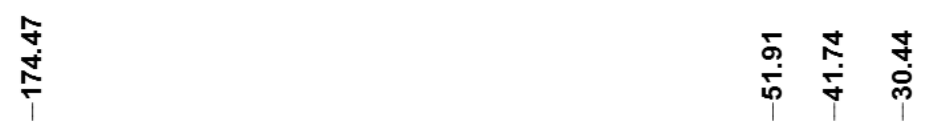<smiles>COC(=O)C1CC(C(=O)OC)CC(C(=O)OC)C1</smiles>

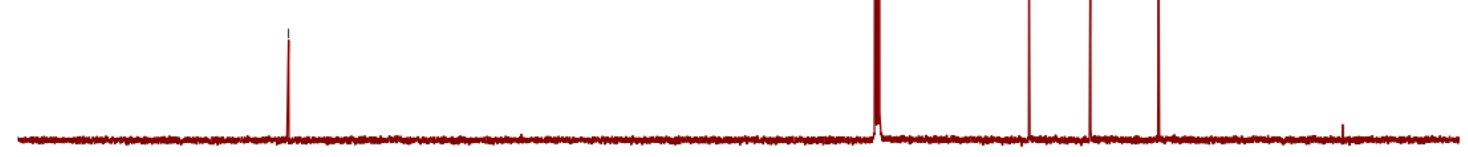

${ }^{13} \mathrm{C}$ NMR spectra (101 MHz) of trimethyl-cyclohexane-1,3,5-tricarboxylate in $\mathrm{CDCl}_{3}$. 


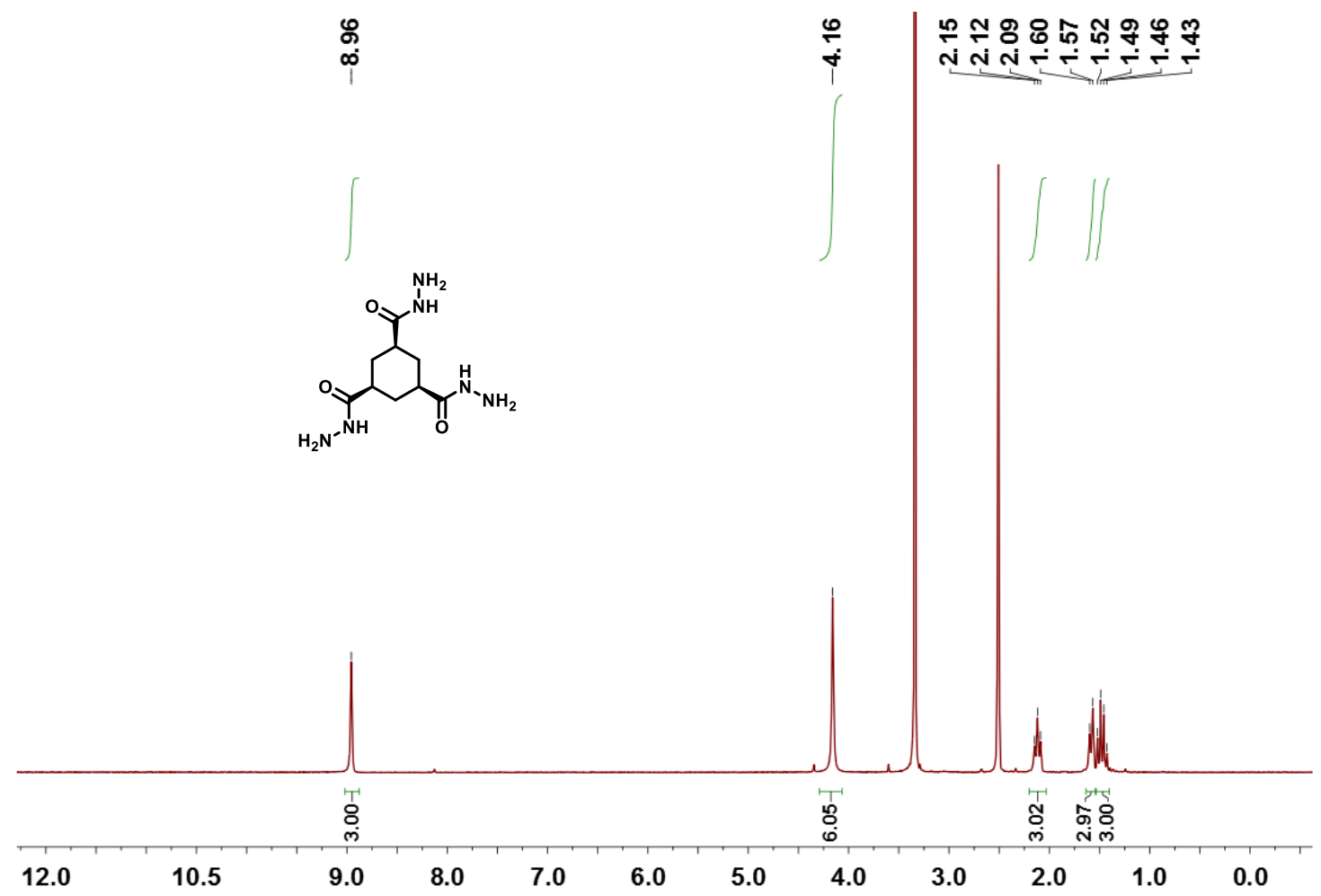

${ }^{1} \mathrm{H}$ NMR spectra $(400 \mathrm{MHz})$ of trishydrazide $\mathbf{H}$ in DMSO- $d_{6}$.

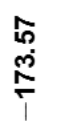

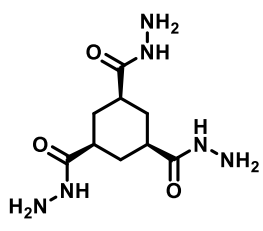

${ }^{13} \mathrm{C}$ NMR spectra $(101 \mathrm{MHz})$ of trishydrazide $\mathbf{H}$ in DMSO- $d_{6}$. 


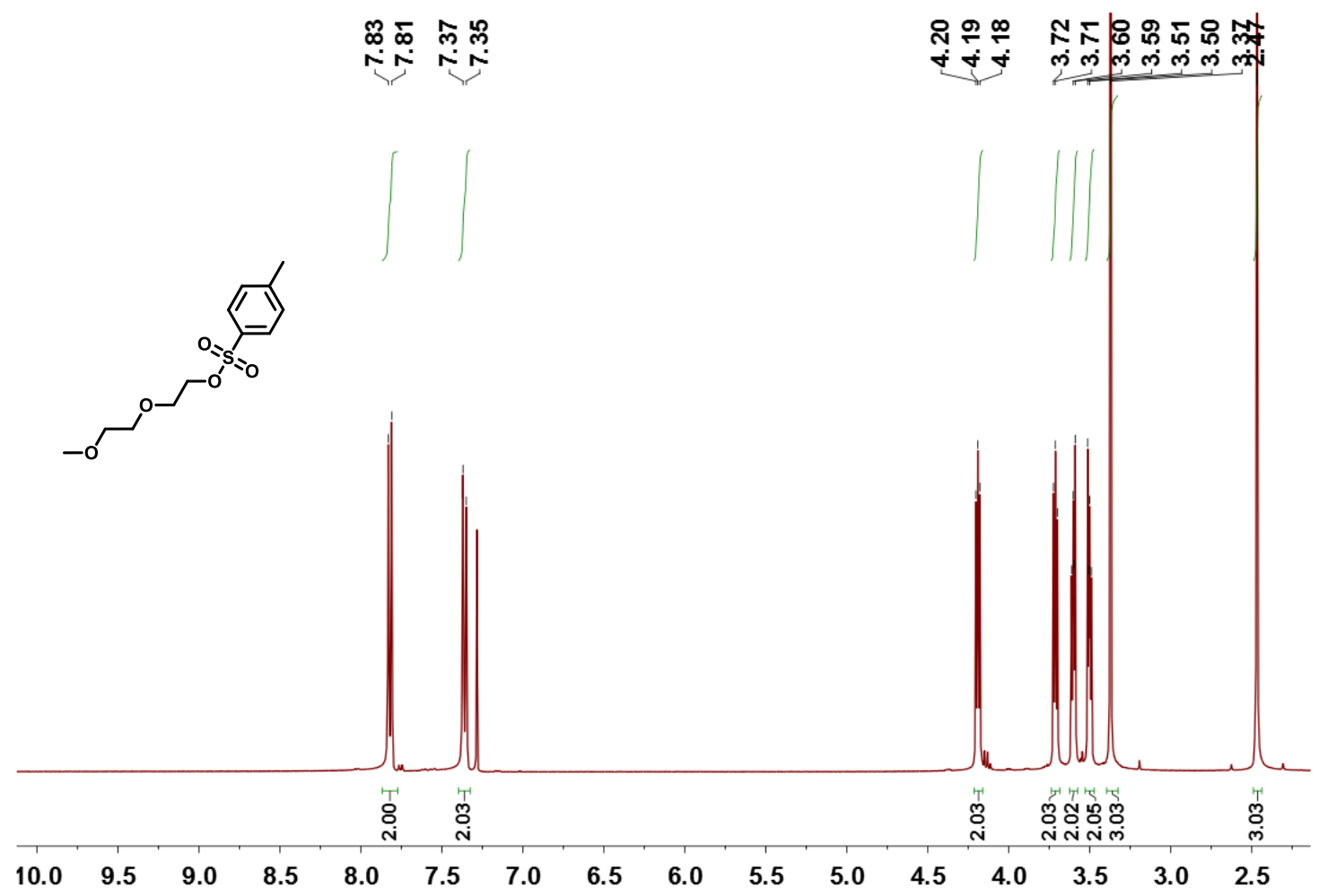

${ }^{1} \mathrm{H}$ NMR spectra (400 MHz) of 2-(2-methoxyethoxy)ethyl 4-methylbenzenesulfonate in $\mathrm{CDCl}_{3}$.

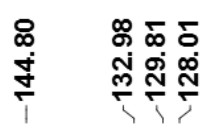

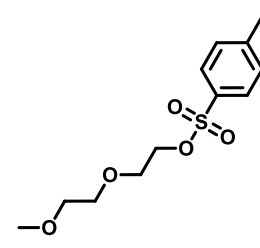

$150 \quad 140 \quad 130$

${ }^{13} \mathrm{C}$ NMR spectra (400 MHz) of 2-(2-methoxyethoxy)ethyl 4-methylbenzenesulfonate in $\mathrm{CDCl}_{3}$.

\section{ํำ

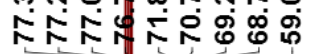

$\stackrel{\leftrightarrow}{\oplus}$

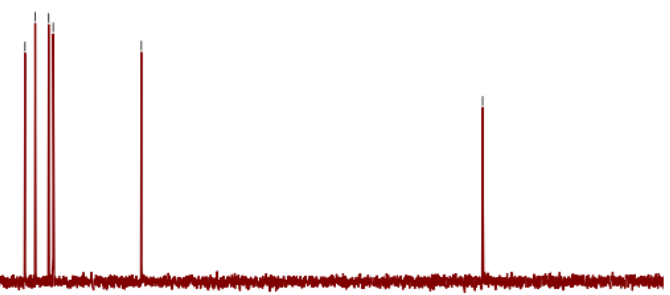




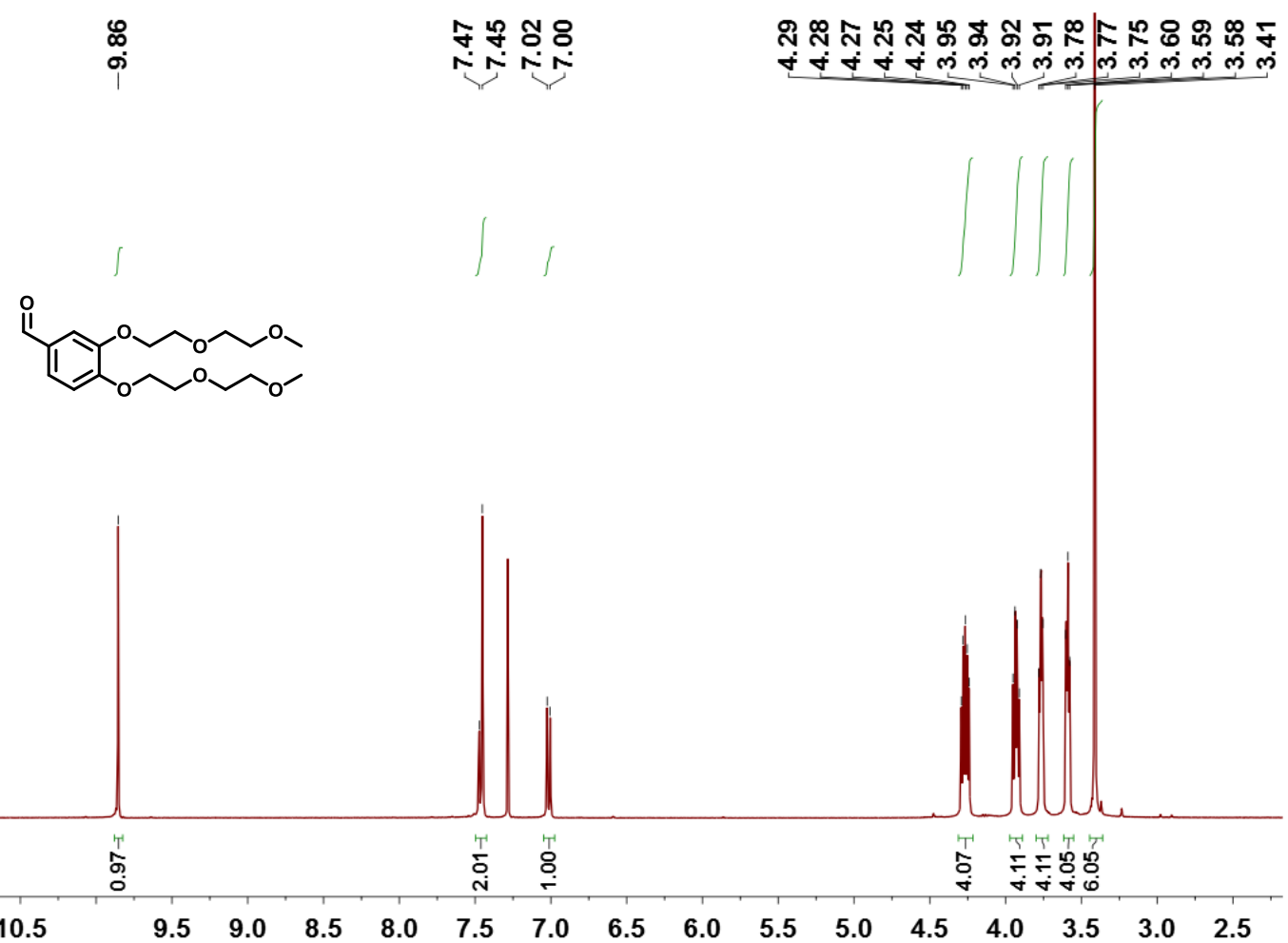

${ }^{1} \mathrm{H}$ NMR spectra $(400 \mathrm{MHz})$ of aldehyde $\mathbf{A}$ in $\mathrm{CDCl}_{3}$.

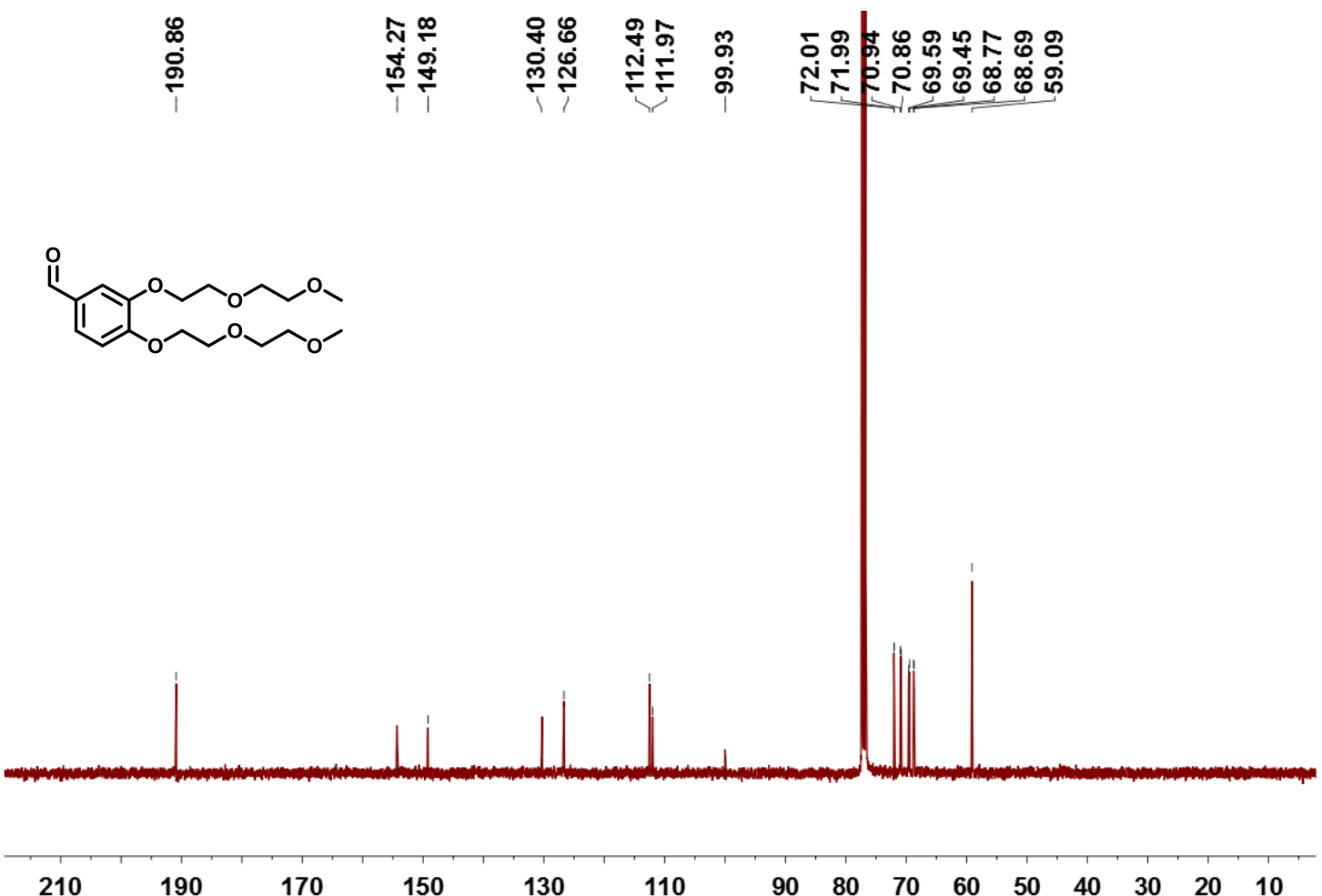

${ }^{13} \mathrm{C}$ NMR spectra (400 $\mathrm{MHz}$ ) of aldehyde $\mathbf{A}$ in $\mathrm{CDCl}_{3}$. 


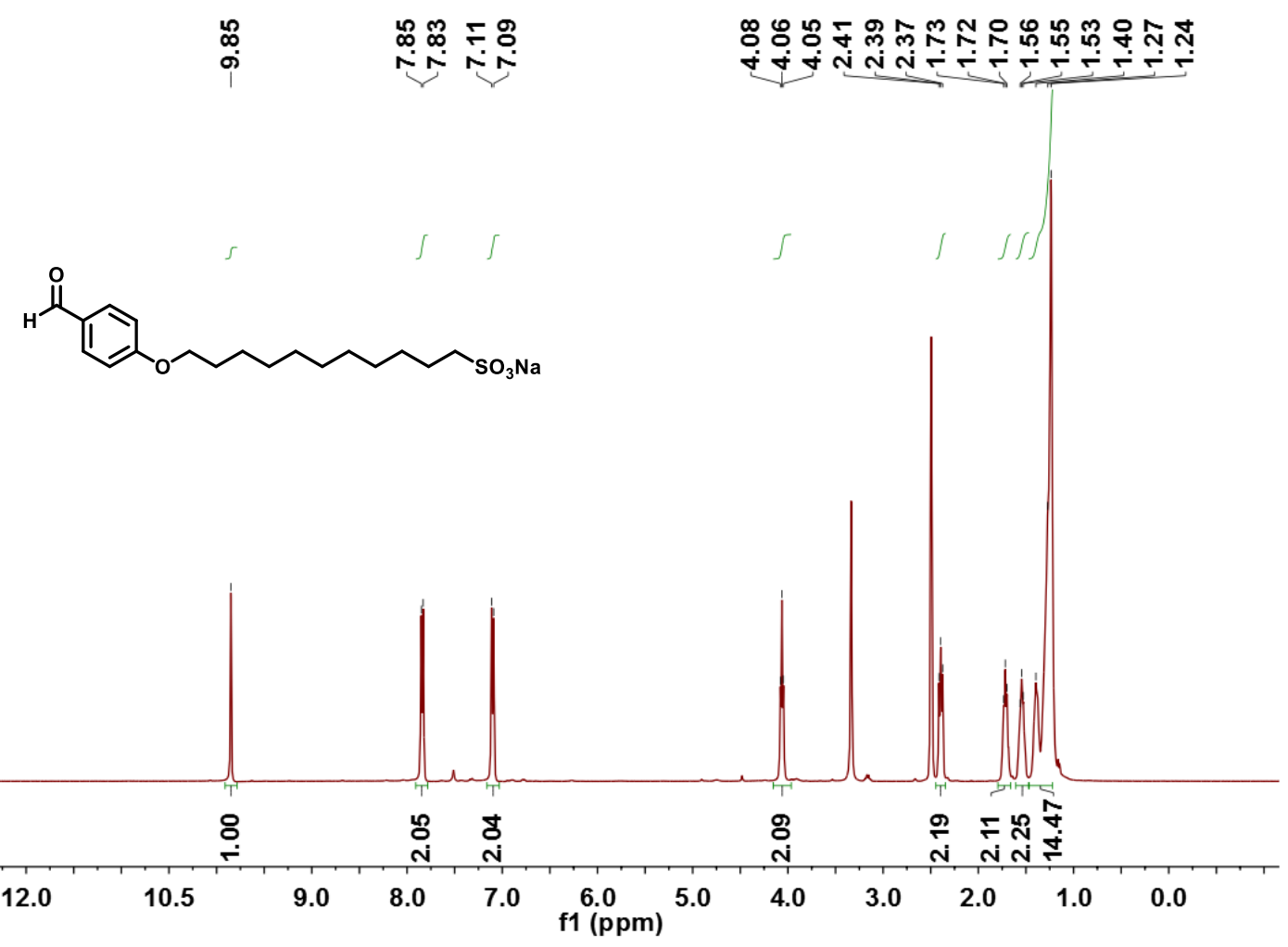

${ }^{1} \mathrm{H}$ NMR spectra (400 MHz) of compound alkylsulfonate benzaldehyde AS in DMSO- $d_{6}$.
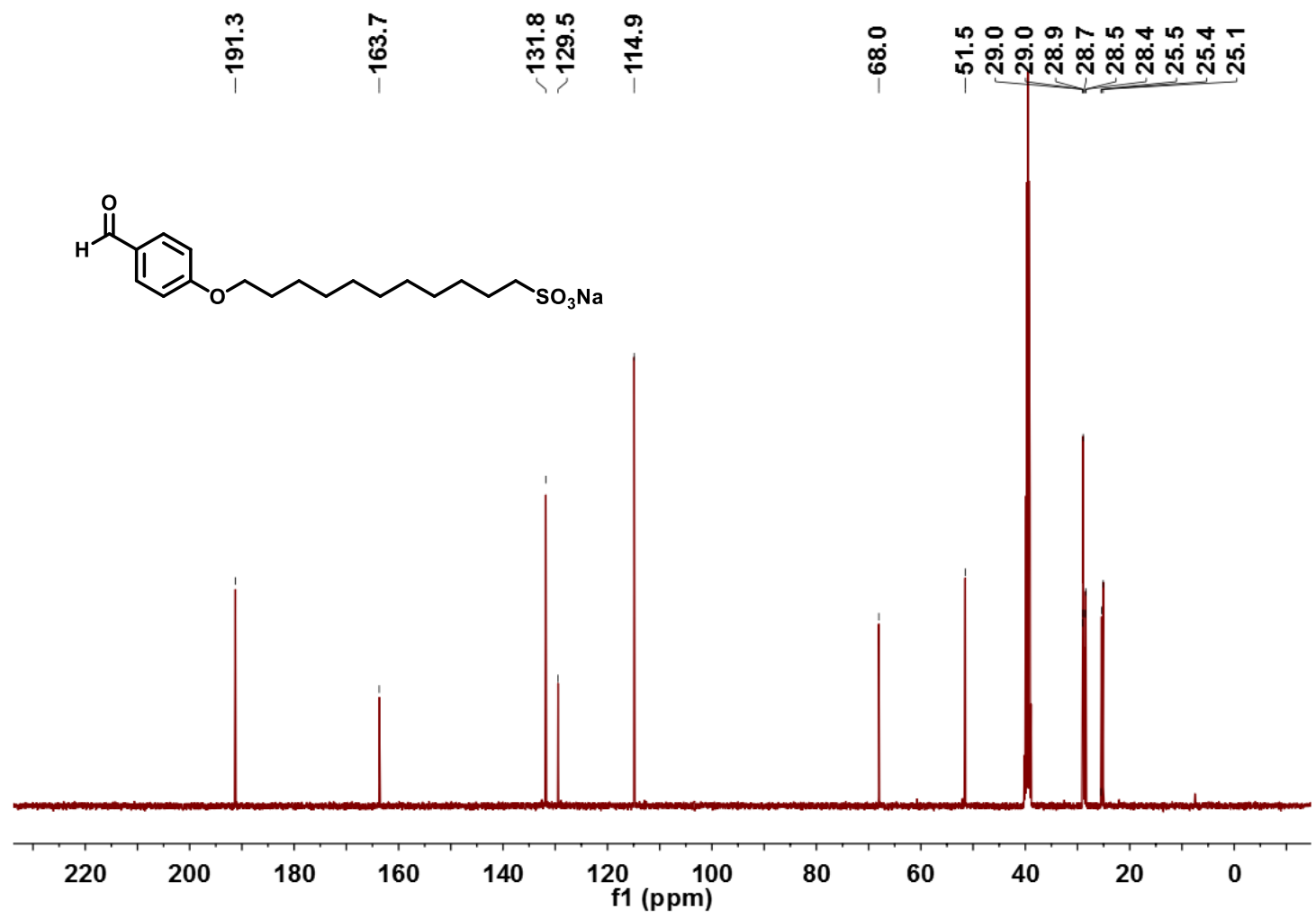

${ }^{13} \mathrm{C}$ NMR spectra (101 MHz) of compound alkylsulfonate benzaldehyde $\mathbf{A S}$ in DMSO- $d_{6}$. 